\title{
Al oeste del Sella. Geoarqueología y cronoestratigrafía del registro del Pleistoceno superior de la cueva de El Cierro (Fresnu, Ribadesella, Asturias, España)
}

\author{
J. F. Jordá Pardo ${ }^{(1,2)}$, P. Carral González ${ }^{(3)}$, D. Álvarez-Alonso ${ }^{(4,2)}$, P. Arias ${ }^{(5)}$, J. Bécares ${ }^{(6,2)}$, M. Cubas ${ }^{(7,2)}$, \\ S. Martín-Jarque ${ }^{(6,2)}$, R. Portero ${ }^{(6,2)}$, L. C. Teira ${ }^{(5)}$ y E. Álvarez-Fernández ${ }^{(6,2)}$
}

(1) Laboratorio de Estudios Paleolíticos. Departamento de Prehistoria y Arqueología. UNED. Senda del Rey, 7. Ciudad Universitaria. E-28040 Madrid, España. jjorda@geo.uned.es

(2) Grupo de Investigación Reconocido PREHUSAL, Universidad de Salamanca.

(3) Departamento de Geología y Geoquímica. UAM. Campus de Cantoblanco. E-28049 Madrid, España pilar.carral@uam.es

(4) Departamento de Prehistoria y Arqueología, UNED Centro Asociado de Asturias, Avenida Jardín Botánico 1345 (Calle inferior), E-33203 Gijón, España. dalvarez@gijon.uned.es

(5) Instituto Internacional de Investigaciones Prehistóricas de Cantabria. Edificio Interfacultativo. Universidad de Cantabria. Avenida de los Castros, 52. E-39005 Santander, España. ariasp@unican.es, luis.teira@gestion.unican.es

(6) Departamento de Prehistoria, Historia Antigua y Arqueología. Universidad de Salamanca. Calle Cervantes, s/n. E-37001 Salamanca, España.

jbecares@usal.es, s.jarque@hotmail.es, rodrigoportero@hotmail.com,epanik@usal.es

(7) Sociedad de Ciencias Aranzadi. Zorroagagaina, 11. E-20014 Donostia-San Sebastian, España. mcubas.morera@gmail.com

\section{RESUMEN}

La cueva de El Cierro (Fresno, Ribadesella, Asturias) es una cavidad kárstica situada en la margen oeste del río Sella y desarrollada en las calizas carboníferas del Macizo Asturiano de la Cordillera Cantábrica (norte de la Península lbérica), que contiene un importante registro sedimentario, arqueológico y paleontológico del Pleistoceno superior y Holoceno inferior, con abundantes evidencias tecnológicas y restos faunísticos. EI registro arqueológico arranca con un nivel que podría corresponder al Paleolítico medio final, sigue con una completa secuencia del Paleolítico superior de la que se cuenta con un nivel del Magdaleniense inferior claramente identificado y datado, y termina con unos niveles datados a finales del Paleolítico superior/Aziliense y en el Mesolítico que configuran un conchero. La secuencia estratigráfica se compone de catorce niveles agrupados en dos unidades litoestratigráficas con características sedimentarias muy distintas, una inferior, siliciclástica y otra superior biogénica formada por la acumulación de conchas y huesos de aporte antrópico, que se estudian con metodología geoarqueológica. En este trabajo se analiza la secuencia litoestratigráfica y se presentan los datos de los análisis granulométricos, mineralógicos, edafológicos y radiométricos. El resultado de estos análisis permite interpretar con precisión tanto la litoestratigrafía del depósito como los procesos sedimentarios y diagenéticos responsables de su formación y posterior evolución. Las dataciones radiocarbónicas disponibles permiten situar los niveles superiores de la secuencia siliciclástica en el GS $2 \mathrm{~b}$ y el conchero inferior en el GI 1 y el GS 1 (Dryas reciente), al final del Pleistoceno superior, mientras que el conchero superior estaría situado en la cronozona Boreal en los inicios del Holoceno.

Palabras clave: karst, norte de Iberia, Pleistoceno superior, procesos sedimentarios, radiocarbono.

\section{Geoarchaeological and Chronostratigraphic study of the Upper Pleistocene record of the Cierro cave (Fresno, Ribadesella, Asturias, Spain)}

\section{ABSTRACT}

The Cierro Cave (Fresno, Ribadesella, Asturias) is a karst cavity located in the west bank of the Sella river and developed in the Carboniferous limestone of the Asturian Massif of the Cantabrian Range (northern Iberian 
Jordá Pardo, J.F., et al., 2018. Al oeste del Sella. Geoarqueología y cronoestratigrafía... Boletín Geológico y Minero, 129 (1/2): $207-250$

Peninsula). This cave contains an important sedimentary, archaeological and palaeontological record of the Upper Pleistocene and Early Holocene with abundant technological remains (lithic and bone industries) and bone remains of mammals and others vertebrates. The archaeological record starts with a probably Middle Palaeolithic level, followed by a complete sequence of the Upper Paleolithic, with a Lower Magdalenian level clearly identified and dated, and ends with levels of the Late Upper Magdalenian/Azilian and the Mesolithic forming three shell middens. The stratigraphic sequence consists of fourteen levels grouped in two litostratigraphic units with very different sedimentary characteristics studied by geoarchaeological methods. The lower unit is characterized by the significant presence of siliceous sands and silts while the upper unit is formed by three anthropic shell middens cemented by carbonates. This paper analyzes the lithostratigraphic sequence and shows the results of the granulometric, mineralogical, edaphic and radiometric analysis. These results allows us to interpret precisely the lithostratigraphy of the deposits and the sedimentary and diagenetic processes responsible for their formation and evolution. In addition, the radiocarbon dates obtained allow us to place the upper levels of the clastic sequence in the GS $2 b$ and the lower shell midden in GI 1 and GS 1 at the end of the Upper Pleistocene, while the upper shell midden would be located in the Boreal cronozona in the Early Holocene.

Key words: karst, northern Iberia, radiocarbon, sedimentary processes, Upper Pleistocene.

\section{ABRIDGED ENGLISH VERSION}

\section{Introduction, regional background, and history of the research in the Cierro cave}

The Cierro cave (Fresno, Ribadesella, Asturias, Spain) (Fig. 1) contains an important archaeological site from the Late Upper Pleistocene and the beginnings of the Holocene known from the mid $20^{\text {h }}$ Century, which has provided materials from the Upper Paleolithic. In this paper we show the results of the geoarchaeological and chronostratigraphic study undertaken within the framework of the research project "La explotación de los recursos marinos en la Europa Atlántica durante el Pleistoceno tardío y el Holoceno" (HAR2011-29907-C03-03/HIST).

In Asturias there are numerous cavities with palaeontological and archaeological remains from the cited chronology. These sites have been studied by geologists, palaeontologists, and prehistorians from the early $20^{\text {th }}$ Century to the present day. The first studies were undertaken by the geologist Hernández-Pacheco and the prehistorians and palaeontologists Conde de la Vega del Sella, Hugo Obermaier, and Paul Wernert, who during the first years of the 20th Century made archaeological interventions in caves and rock shelters from the east to the west of Asturias (Hernández-Pacheco, 1959; Obermaier, 1925; Rasilla Vives, 1991; Díaz García and Polledo González, 2014). After a period of inactivity, during the 1950s, these studies were resumed through the collaboration between the prehistorian Francisco Jordá Cerdá (from now on FJC) and the geologist Noel Llopis Lladó, with results such as the Mapa del Cuaternario de Asturias (Llopis Lladó and Jordá, 1957) and an interpretation concerning the stratigraphic location of the Asturian shell midden (Jordá Cerdá, 1958, 1959; Llopis Lladó, 1953a, 1953b). During the 1970s the geologist Manuel Hoyos Gómez resumed the geological study of the karstic sites from the Pleistocene in Asturias (Hoyos Gómez, 1979) and participated as a geologist in the excavations at the Cierro cave.

In 1958 FJC discovered for science the cave of El Cierro (Jordá Cerdá, 1976) and in the summer of 1959 undertook archeological digs in its main entrance, detecting eight levels with materials from the Upper Pleistocene as well as two shell middens (Fig. 3). In 1969, Clark took a coal sample from the shell midden from which he obtained the $14 \mathrm{C}$ first date of the site, which placed it at the end of the Upper Pleistocene (Clark, 1983). The materials from these first digs, now located in the Archaeological Museum of Asturias (Oviedo), have been subsequently studied by several authors, besides FJC himself (Jordá Cerdá, 1960, 1963, 1969, 1977; Utrilla Miranda, 1976, 1981; Bernaldo de Quirós Guidotti, 1982, Straus, 1983). Recently, the archaeological materials from certain levels have been revised, which has allowed the determination of the archaeological sequence with a higher precision (Álvarez-Alonso and de Andrés-Herrero, 2012; Álvarez-Fernández et al., 2014, 2016). Between 1977 and 1979, Alejandro Gómez Fuentes (from now on AGF) and FJC undertook a new archaeological intervention which allowed them to document a sequence consisting of fourteen levels designated by letters from $B$ to $N$ with a level $G^{\prime}$ and a lense $H^{\prime}$ (Fig. 6). In the 1978 campaign participated geologist Hoyos Gómez, who obtained a stratigraphic sequence for the Cierro cave composed by two shell middens and six levels from the Upper Paleolithic (Fig. 9). From 2012 the studies on the Cierro cave were resumed, with a small archaeological intervention undertaken in 2014 and with a research team set within the framework of the HAR2011-29907-C03-03/HIST project.

\section{Materials and methods}

After taking fifteen samples from the stratigraphic sequence of the Cierro cave we performed sedimentologi- 
Jordá Pardo, J.F., et al., 2018. Al oeste del Sella. Geoarqueología y cronoestratigrafía... Boletín Geológico y Minero, 129 (1/2): $207-250$

cal (textural or granulometrical, of insoluble residue, and mineralogical) and edaphological analyses (colour, $\mathrm{pH}$, total carbonates - $\mathrm{CaCO}_{3}{ }^{-}$, organic matter-OM-, organic carbon-OC-, electrical conductivity, salts, concentration of cations, and osmotic pressure). We have also obtained six new radiocarbon dates (Table 1).

\section{The cave and its deposits}

The Cierro cave is situated at the eastern end of the Asturian Massif of the Cantabrian Range, in a sector composed by Paleozoic materials from the Cantabrian Zone of the Iberian Massif. The karstic cavity develops in the La Escalada limestone formation from the Carboniferous (Moscovian) (Fig. 12) (Navarro et al., 1986). EI Cierro cave is a superficial, senile, and highly degraded cavity, which at the moment of its finding was partially colmated by detrital deposits, from which those situated in the main chamber were archaeological deposits (Fig. 13). Currently, we can observe the different stratigraphic cross sections of the site left by the digs of FJC and AGF. From the northern stratigraphic section, WE direction, we have obtained the lithostratigraphic sequence of the site which apparently rests on the limestone of the substrate, which is composed of fourteen sedimentary units (Fig. 14); the inferior ten are of siliciclastic character, whereas the superior four are organogenic (shell middes). Table 2 shows a correlation test of the levels of the WE cross section of the Cierro cave, according to the different authors, with an indication of their relationship with the currently visible sequence described in this paper.

\section{Sedimentologic and edaphic analysis}

The granulometric analyses offer results which allow the identification of two large sedimentary units: an inferior detrital and a superior one, organogenic-chemical, with detrital sediments composed of a succession of shell middens rich in vertebrate, and invertebrate. In the global granulometry of the clastic sequence (Table 3 , Fig. 20A) we can observe a tendency for slightly granular growth, with predominance of fine fraction at the base (Cierro N, Cierro M, Cierro L, and Cierro J1) and an increase of sands towards the mid section (Cierro H2, Cierro H1, and Cierro G1), which diminishes again at the top (Cierro F and Cierro E). The highest mud is the basal level (Cierro N) with $72,54 \%$ mud, whereas the lowest is shown at the level of Cierro J2 with $29 \%$ mud. At the top (Cierro F and Cierro E), the fine fraction (54\%) slightly surpasses the sandy one (44\%).

The mineralogy of the sediments from the fine fraction (silts and clays) is qualitatively homogeneous in the whole sequence, even though we can observe two stretches clearly differentiated from the quantitative point of view (Table 4, Fig. 25). The predominant minerals are quartz and calcite, and according to their higher or lower presence we can establish two stretches: the lower (from Cierro N to Cierro E) mainly constituted by quartz with presence of calcite except in three of the levels, and the upper (from Cierro D to Cierro A) with a predominance of calcite and the presence of quartz from low to mid proportions.

The tendency experienced by the organic matter along the sequence is parallel to those of organic carbon, with clear coincidences between the maximums and minimums of both components. A correspondence between the tendencies of the organic matter and the organic carbon with that of the calcium carbonate also exists, even though the latter is slightly present at the inferior detrital stretch of the sequence (Table 7, Fig. 27), a fact which coincides with its siliciclastic character.

\section{Chronostratigraphy of the sequence}

We have seven radiocarbon datings. One of them was obtained by Clark in 1969 from the shell midden, Gak$254810.712 \pm 515$ BP (Clark, 1983), whereas the rest are the ones we obtained in the ORAU (Tables 1 and 9) (Álvarez-Fernández et al., 2016) which cover the levels of the upper section of the stratigraphic sequence of the Cierro cave (Cierro G1, Cierro G, Cierro F, Cierro D, Cierro C, and Cierro B sup).

Chronostratigraphically, the sedimentological characteristics and those of an archaeological nature, as well as conventional and calibrated radiocarbon datings (Table 9) clearly place the upper part of the stratigraphic sequence of the Cierro cave during the last moments of the Last Pleniglacial, at the end of the final Upper Pleistocene (Fig. 30), which corresponds with OIS 2 (Shackleton and Opdyke 1973). More specifically, the upper part of the sequence of El Cierro corresponds to the Last Glacial Maximum or GS 2 (Greenland Stadial 2), the Tardiglacial Interstadial or GI 1 (Greenland Interstadial 1) and the Younger Dryas or GS 1 (Greenland Stadial 1) (Björck et al. 1998).

\section{Conclusions}

From the lithostratigraphic point of view, the levels of the sequence of the Cierro cave can be grouped into two informal units:

The lower unit, siliclastic, whose origin is related with plastic flows turning into low energy laminar flows, 
Jordá Pardo, J.F., et al., 2018. Al oeste del Sella. Geoarqueología y cronoestratigrafía... Boletín Geológico y Minero, 129 (1/2): $207-250$

with depositions of small clasts through gelifraction and gravitational falls of major blocks. During the sedimentation of this unit there were moments with human presence in the cave which left evidence of occupations with an increasing intensity towards the top.

The upper unit, organogenic, whose origin is linked to the anthropic depositions which conform two superimposed shell middens cemented by carbonates.

Chronostratigraphically, the lower and mid stretches of the lower unit can be situated at the final moments of the OIS $3 c$ and OIS 2, to the GS 2c, with human occupations perhaps from the Late Middle Paleolithic, from the Aurignacian, possibly the Gravettian, and the Solutrean. For the upper stretch of the inferior unit, with occupations from the Lower Magdalenian, we count on radiocarbon dates which place it in the temperate episode GS $2 b$ of the cold stadial GS 2. As for the superior unit, the inferior shell midden, with human occupation probably from the Late Upper Palaeolithic/Azilian, the available radiocarbon dates clearly place it at the end of the Tardiglacial or GI 1, and it could expand throughout the GS 1 (Younger Dryas) in the final moments of the Upper Pleistocene. The superior shell midden, with a Mesolithic occupation, is placed in the Boreal chronozone before the 8.2 event, already within the Holocene.

\section{Introducción}

La cueva de El Cierro está situada en la localidad de Fresno, concejo de Ribadesella (Asturias, España), en la margen oeste del río Sella, a $83 \mathrm{~m}$ s.n.m. y a $3,1 \mathrm{~km}$ en línea recta de la línea de su desembocadura y a 2,1 $\mathrm{km}$ de la costa actual. Contiene un importante yacimiento arqueológico del Pleistoceno superior final y comienzos del Holoceno conocido desde mediados del siglo $X X$, que ha proporcionado materiales del Paleolítico superior. En sus proximidades se encuentran otros importantes yacimientos arqueológicos, como la cercana cueva de Les Pedroses y las cuevas de Tito Bustillo (originalmente conocida como Pozu'l Ramu), La Lloseta o cueva del Río, La Cuevona de Ardines y Cova Rosa, situadas a escasos kilómetros (Fig. 1), todos ellos en la margen oeste del Sella.

Durante el año 2014 y dentro del marco del proyecto de investigación “La explotación de los recursos marinos en la Europa Atlántica durante el Pleistoceno tardío y el Holoceno" (HAR2011-29907C03-03/HIST), acometimos la realización del estudio geoarqueológico del yacimiento de la cueva de EI Cierro con los siguientes objetivos:

- Revisión de las secuencias estratigráficas del yacimiento de la cueva de El Cierro descritas por diferentes investigadores.

- Estudio de la secuencia sedimentaria del yacimiento arqueológico a partir de las secciones estratigráficas visibles.

- Identificación de los procesos sedimentarios y diagenéticos o postdeposicionales que dieron lugar a la actual configuración del registro arqueológico del yacimiento, diferenciación, en la medida de lo posible, de los procesos naturales ( $N$ transforms) y culturales de origen antrópico (C transforms) (Schiffer, 1987) y establecimiento de un modelo geoarqueológico para el yacimiento.
- Ubicación de la secuencia arqueológica de EI Cierro en la escala cronoestratigráfica global del Pleistoceno superior final manejada actualmente y basada en los Greenland Events detectados en los sondeos de Groenlandia (Björck et al., 1998) mediante la obtención de edades numéricas.

\section{Antecedentes sobre las investigaciones geoarqueológicas en la zona}

Los yacimientos arqueológicos en contextos kársticos están bien representados en el territorio de Asturias. Así, existen numerosas cavidades con restos paleontológicos y arqueológicos cuya cronología comprende el final del Pleistoceno medio y predominantemente el Pleistoceno superior y comienzos del Holoceno.

Los trabajos de investigación en los yacimientos kársticos asturianos y, más concretamente, en los de la zona de la desembocadura del Sella, comenzaron con los estudios pioneros del geólogo Eduardo Hernández-Pacheco (1872-1965) y de los prehistoriadores y paleontólogos Ricardo Duque de Estrada y Martínez de Moratín (1870-1941), más conocido como Conde de la Vega del Sella, Hugo Obermaier (18771946) y Paul Wernert (1889-1972), quienes Ilevaron a cabo en los primeros años del siglo $\mathrm{XX}$ intervenciones arqueológicas en cuevas y abrigos rocosos desde el oeste al este de Asturias, tales como La Paloma (Soto de Las Regueras, Las Regueras), El Conde (Tuñón, Santo Adriano), cueva del Río o de Ardines (Ardines, Ribadesella), La Cuevona (Ardines, Ribadesella), Cueto de la Mina (Posada de Llanes, Llanes), La Riera (Posada de Llanes, Llanes), Balmori (Barro, Llanes), Penicial (Nueva de Llanes, Llanes) y Mazaculos o La Franca (La Franca, Rivadedeva) (Hernández-Pacheco, 1959; Obermaier, 1925; Rasilla 


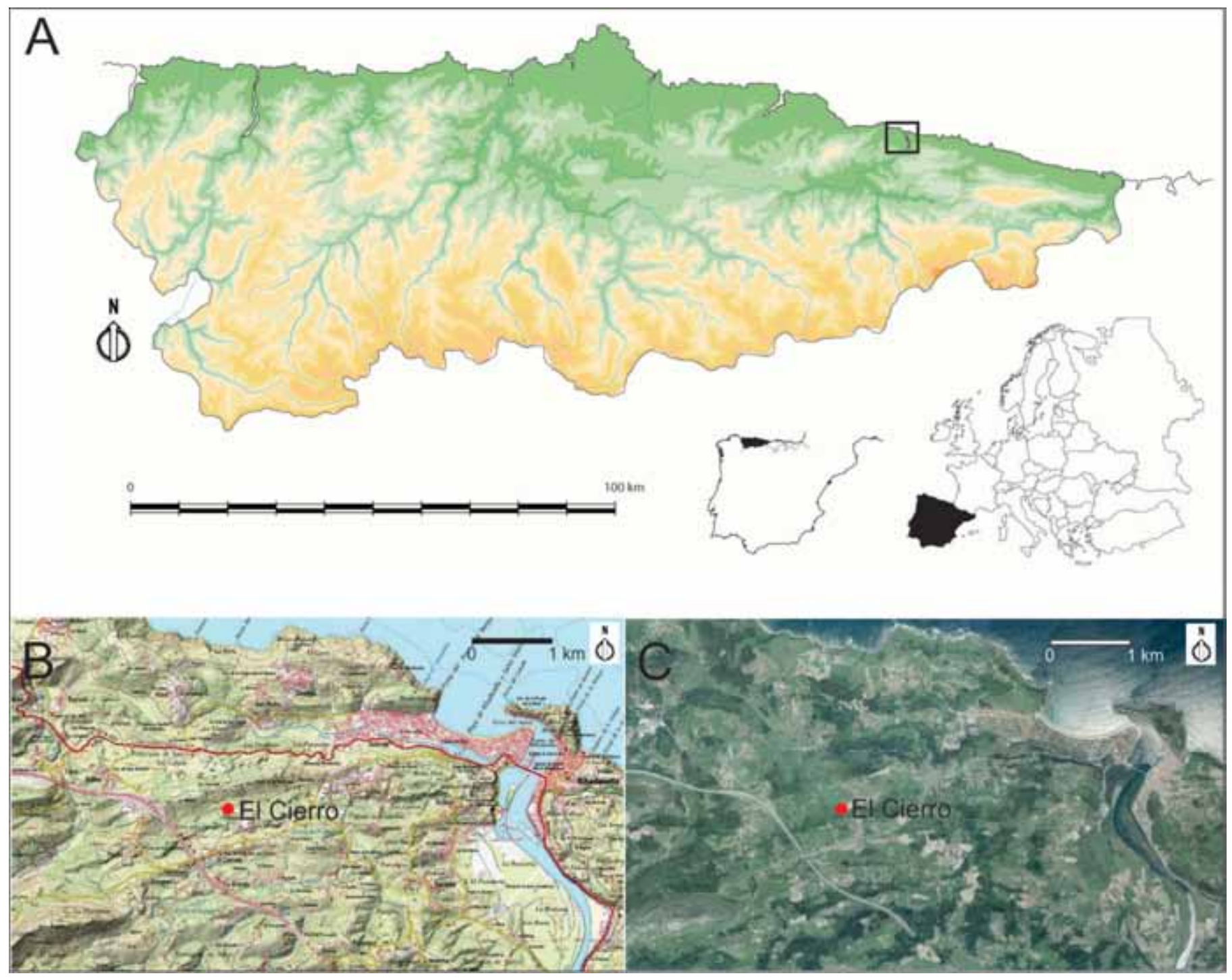

Figura 1. A: Situación geográfica de la cueva de El Cierro en el contexto europeo, peninsular y asturiano (ilustración de LuisTeira Mayolini). B y C: Situación de la cueva de El Cierro en la zona de Ribadesella, sobre mapa topográfico y ortofoto (elaborado a partir de SIGPAC en línea).

Figure 1. A: Geographical location of the Cierro cave in the European, Iberian and Asturian context (Figure from Luis Teira Mayolini). B and C: Location of the Cierro Cave on topographic map and ortophotography (from SIGPAC on line).

Vives, 1991; Díaz García and Polledo González, 2014). En estos trabajos los citados investigadores aplicaron el método estratigráfico y fruto de ellos fueron la interpretación geológica de los yacimientos, los primeros intentos de interpretación paleoclimática a partir de la naturaleza y contenido de sus depósitos e incluso la realización de generalizaciones paleoclimáticas y paleogeográficas para la región cantábrica (Hernández-Pacheco et al., 1957). Especial mención, por la cercanía al yacimiento que nos ocupa, merecen los trabajos inéditos realizados por $\mathrm{E}$. HernándezPacheco en la cueva del Río o de Ardines, a orillas del
Sella, cavidad que posteriormente fue estudiada por el prehistoriador Francisco Jordá Cerdá (1914-2004) (en adelante FJC) y publicada con la denominación de La Lloseta (Jordá Cerdá, 1958), para ser, años más tarde, identificada de nuevo y publicados los materiales de las excavaciones del insigne geólogo junto con una interpretación geológica de su relleno (Mallo et al., 1979-1980).

Después de un largo periodo de inactividad, los estudios geológicos sobre los yacimientos pleistocenos asturianos se retomaron en la década de 1950 mediante la colaboración entre FJC y el geólogo y 
profesor de la Universidad de Oviedo Noel Llopis Lladó (1911-1968). Un buen ejemplo de la colaboración entre estos dos investigadores es el Mapa del Cuaternario de Asturias (Llopis Lladó and Jordá, 1957) publicado con motivo del V Congreso Internacional del INQUA de 1957. Fruto de esta cooperación es la interpretación que ambos hacen sobre la posición estratigráfica de los concheros asturienses, a los que estos autores sitúan en momentos previos a la sedimentación de los niveles del Paleolítico superior y relacionan con el Paleolítico inferior (Jordá Cerdá, 1958, 1959; Llopis Lladó, 1953a, 1953b), hipótesis que se verá refutada por investigaciones posteriores (Clark, 1972).

Tras el prematuro fallecimiento de N. Llopis Lladó y el traslado de FJC a la Universidad de Salamanca, los trabajos de investigación arqueológica y geológica en los yacimientos pleistocenos de la zona del Sella se interrumpieron hasta que, en el comienzo de la década de los setenta del siglo pasado, el joven geólogo Manuel Hoyos Gómez (1944-1999) (en adelante $\mathrm{MHG}$ ) comenzó sus estudios sobre los aspectos geomorfológicos, sedimentológicos y paleoclimáticos de los yacimientos kársticos de Asturias durante el Pleistoceno y el Holoceno que dieron lugar a su tesis doctoral (Hoyos Gómez, 1979). MHG estableció una secuencia crono-climática articulada en seis fases de sedimentación con distinto significado climático, (Würm III-IV, Würm IV Asturias II, Würm IV Asturias III, Würm IV Asturias IV y Würm IV Asturias V) en función de las variaciones de temperatura y humedad detectadas a partir del estudio de los procesos sedimentarios y postsedimentarios identificados en los depósitos de cinco yacimientos kársticos del centro y este de Asturias, La Paloma y Sofoxó (Las Regueras), Las Caldas (Oviedo), Cova Rosa y La Lloseta o Cueva del Río, secuencia que posteriormente ampliaría con la inclusión de otros yacimientos de Asturias, Cantabria y País Vasco (Hoyos Gómez 1972-1973, 1979, 1980, 1981a, 1981b, 1987, 1989; Hoyos Gómez and Herrero Organero, 1989). Entre las cavidades estudiadas de la cuenca del Sella se encontraban la ya citada Cueva del Río o de la Lloseta y Cova Rosa, donde FJC realizó trabajos de prospección y cribado de tierras entre 1957 y 1959 para después excavarla en 1964 y, posteriormente, entre 1975 y 1979 en codirección con Alejandro Gómez Fuentes (en adelante AGF). Como veremos más adelante, MHG participó como geólogo en las excavaciones de FJC y AGF en la cueva de El Cierro que se llevaron a cabo simultáneamente a las de Cova Rosa en los años setenta. Lamentablemente, el también prematuro fallecimiento de MHG en 1999 (Rasilla Vives and Sánchez-Moral, 2003) impidió a

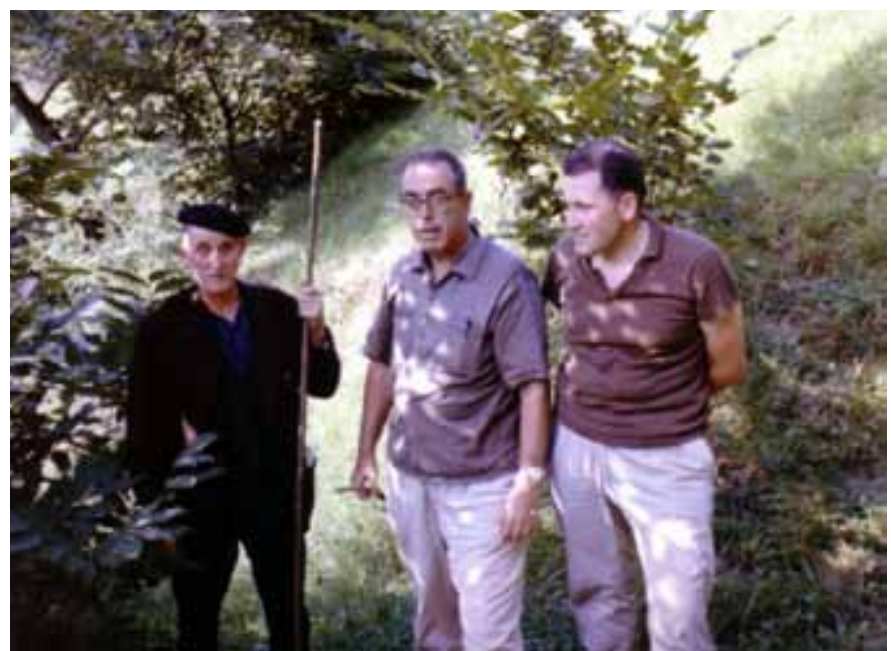

Figura 2. De izquierda a derecha, Antonio Álvarez Alonso "Antón", Francisco Jordá Cerdá y Manuel Mallo Viesca, durante la campaña de campo en la zona de Ribadesella en el verano de 1956 (fotografía de Manuel Mallo Viesca).

Figure 2. From left to right, Antonio Alvarez Alonso "Anton", Francisco Jordá Cerdá, and Manuel Mallo Viesca, during the field campaign in the Ribadesella area in the summer of 1956 (photo by Manuel Mallo Viesca).

este investigador completar sus estudios sobre este yacimiento.

\section{Historia de las investigaciones en la cueva de EI Cierro}

En 1958, FJC, a la sazón director del Servicio de Investigaciones Arqueológicas y del Museo Arqueológico Provincial de Oviedo -ambos dependientes de la Diputación Provincial de Asturias-, descubrió, en compañía del capataz del citado servicio, Antonio Álvarez Alonso "Antón" (Fig. 2), la cueva de El Cierro, tras varias campañas de investigación en el macizo kárstico de Ardines (Jordá Cerdá, 1976) que dieron lugar al reconocimiento de yacimientos ya conocidos y al descubrimiento de otros nuevos (Díaz García and Polledo González, 2014; Jordá Cerdá and Mallo Viesca, 2014). Entre junio y julio de 1959, a lo largo de quince días, trabajaron en su entrada principal, en una zona de derrumbe del techo, donde llevaron a cabo un sondeo de $2 \times 3 \mathrm{~m}$. A partir de los diarios de excavación de FJC (Archivo FJC D-1.5) se sabe que la excavación se realizó en la sala que tiene una abertura cenital y gracias a ellos se ha podido establecer de techo a muro la secuencia de capas documentadas en aquella excavación:

- capa $1^{a}$, "piedras y tierra negra", "capa superficial" (Fig. $3 \mathrm{~A}$ y B). 

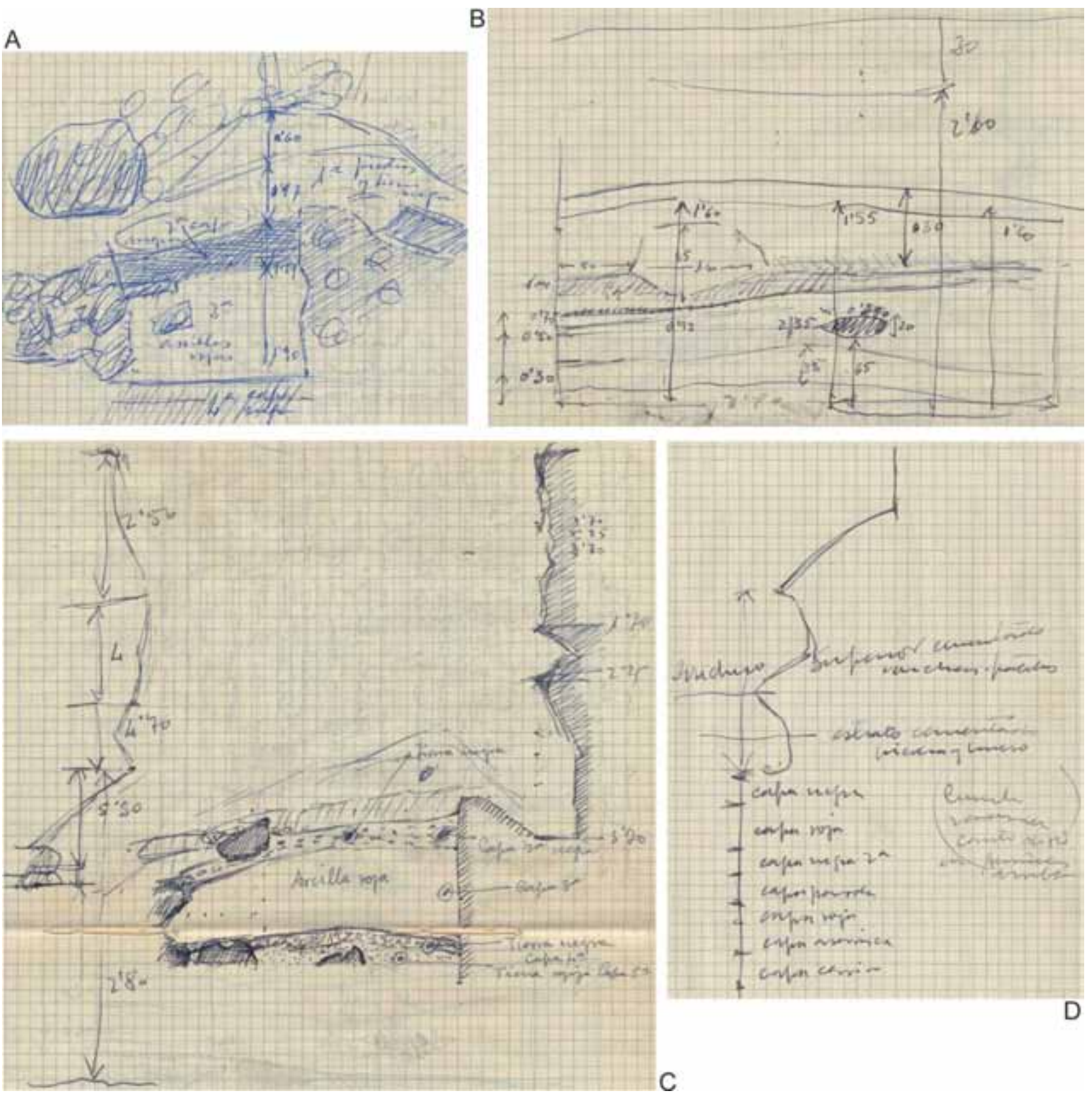

Figura 3. El Cierro. Dibujos esquemáticos de los diferentes cortes estratigráficos de la cueva realizados por FJC que aparecen en el diario de la campaña de excavaciones de junio-julio de 1958: A y C) Esquemas del corte SN de dos momentos en el avance de la excavación; B) Corte OE; D) Perfil NS del conchero y techo de la cavidad y descripción estratigráfica sucinta de la sección estratigráfica infrayacente al conchero (Archivo FJC D-1.5).

Figure 3. The Cierro cave. Schematic drawings of the different stratigraphic sections of the cave made by FJC taken from the field diary of the excavations of June-July 1958: A and C) Schemes of the SN section from two moments during the dig progress; B) WE section; D) NS profile of shell midden and roof of the cavity and succinct stratigraphic description of the deposits below the shell midden (FJC D-1.5 Archive).

- capa $2^{\mathrm{a}}$, “capa negra $\left(2^{\mathrm{a}}\right)$ que es de suponer que sea Magdaleniense superior" (Fig. 3 A y B).

- capa $3^{\mathrm{a}}$, "tierras arcillosas rojas", "¿es como un Magdaleniense medio?" (Fig. 3 A y B).
- capa 4a " "negra", "contiene materiales del Magdaleniense III" (Fig. 3 A y B).

- capa $5^{a}$, "de contacto con la negra anterior con poco hueso y buenos materiales aunque esca- 
sos". "Se observa en la base de la capa parduzca $5^{\mathrm{a}}$ una línea negra de hogares más intensa, es decir, que se comienza con un Solutrense final y se termina con un Magdaleniense inferior". No obstante, en un esquema estratigráfico califica esta capa $5^{a}$ como "tierra rojiza" (Fig. 3 C).

- capa 6a, "formada por tierra rojiza de ceniza arcillosa", "sale poco material" (Fig. 3 D).

- capa $7^{a}$, "ceniza, en ella hay rastro de hogares, la composición es semejante a anterior, quizá predomina más la arcilla. Aparecen pocas piezas típicas" (Fig. 3 D).

- capa $8^{a}$, que, aunque no la describe como tal en el texto del diario, si la indica en un esquema estratigráfico descriptivo (Fig. $3 \mathrm{D}$ ).

En uno de los croquis (Fig. $3 \mathrm{D}$ ) del diario señala la presencia de un conchero situado a techo de la anterior secuencia que se encuentra estructurado en dos cuerpos separados por una entalladura: "superior cementado conchas - patelas" y "estrato cementado piedras y hueso".

Con posterioridad, en 1969, Geoffrey A. Clark realizó una nueva intervención en uno de los testigos dejados por FJC, que le permitió documentar un conchero, correlacionable con los niveles 1 y 2 del citado investigador. De este conchero, Clark recuperó 1.280 restos arqueológicos, entre los que un gran número eran conchas de gasterópodos marinos (Patella vulgata y Littorina littorea), acompañadas por conchas de gasterópodos terrestres (Helix sp.) y de equínidos (Paracentrotus lividus), y por restos óseos de peces, micromamíferos y ungulados (Cervus elaphus, Capreolus capreolus) (Clark, 1983). Este investigador obtuvo una muestra de carbón del conchero a partir de la cual se realizó la primera fecha radiocarbónica del yacimiento, que lo situó en los momentos finales del Pleistoceno superior, en pleno Dryas reciente (Clark, 1983).

Los materiales provenientes de estas primeras excavaciones, actualmente custodiados en el Museo Arqueológico de Asturias (Oviedo), han sido estudiados posteriormente por diversos autores, además del propio FJC (Jordá Cerdá, 1960, 1963, 1969, 1977). Estos investigadores han precisado el carácter de las ocupaciones y el periodo al que se adscriben. Así, sus materiales formaron parte de la elaboración de diferentes tesis doctorales. Pilar Utrilla Miranda (1976, 1981) estudió las ocupaciones del Magdaleniense, Federico Bernaldo de Quirós Guidotti (1982) las del Auriñaciense y Lawrence G. Straus (1983) las del Solutrense. Otras tesis doctorales incluyeron determinados materiales de la cueva, como el arte mueble (Corchón Rodríguez, 1986), la industria ósea (Adán

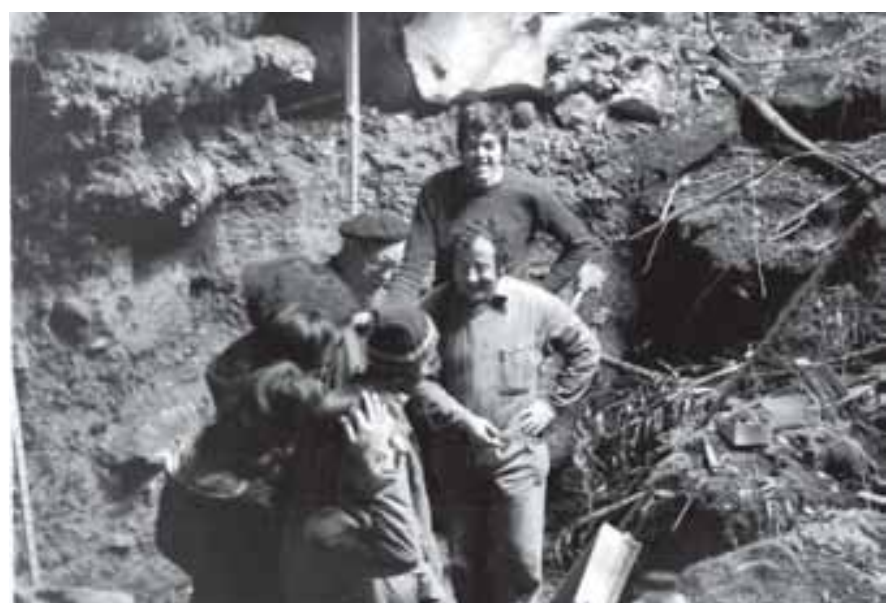

Figura 4. Un momento de una de las campañas de excavación en la cueva de El Cierro de los años setenta del siglo pasado. En el centro con boina aparece Francisco Jordá Cerdá e inmediatamente a su derecha está Alejandro Gómez Fuentes (carecemos de datos para la identificación del resto de personas) (foto JBP).

Figure 4. A moment from one of the excavation campaigns at the Cierro cave during the seventies in the twentieth century. At the centre Francisco Jordá Cerdá appears and immediately to his right is Alejandro Gomez Fuentes (we have no data for identifying the other participants) (photo by JBP).

Álvarez, 1997) y los objetos de adorno-colgante (Álvarez-Fernández, 2006). Recientemente se han realizado trabajos específicos sobre los materiales arqueológicos de determinados niveles que han permitido determinar con una mayor precisión la secuencia arqueológica (Álvarez-Alonso and de Andrés-Herrero, 2012; Álvarez-Fernández et al., 2014, 2016 en prensa).

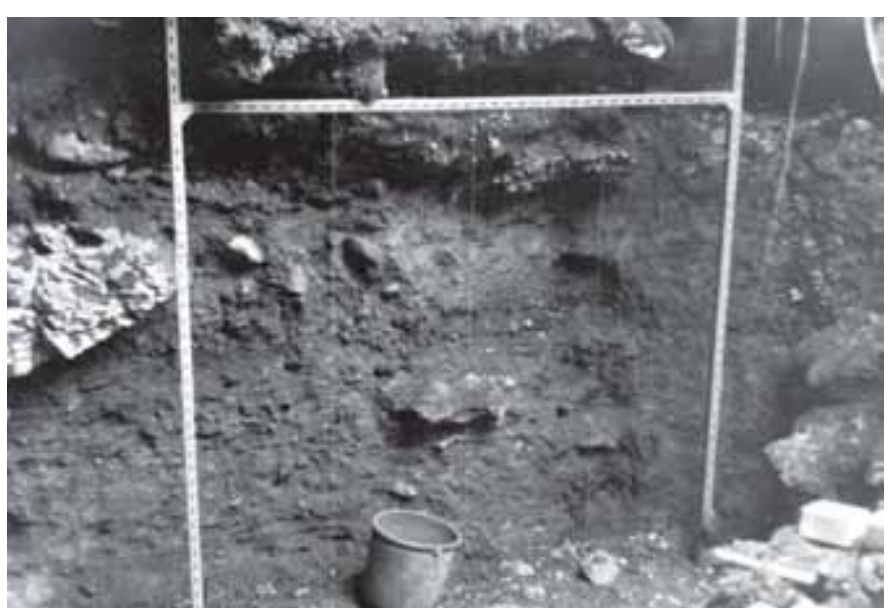

Figura 5. El Cierro. Fotografía del corte estratigráfico OE tras la instalación del sistema de referencia espacial y la realización de su limpieza superficial (foto JBP).

Figure 5. The Cierro cave. Photograph of the stratigraphic WE section after installing the spatial reference system and the realization of its surface cleaning (photo by JBP). 


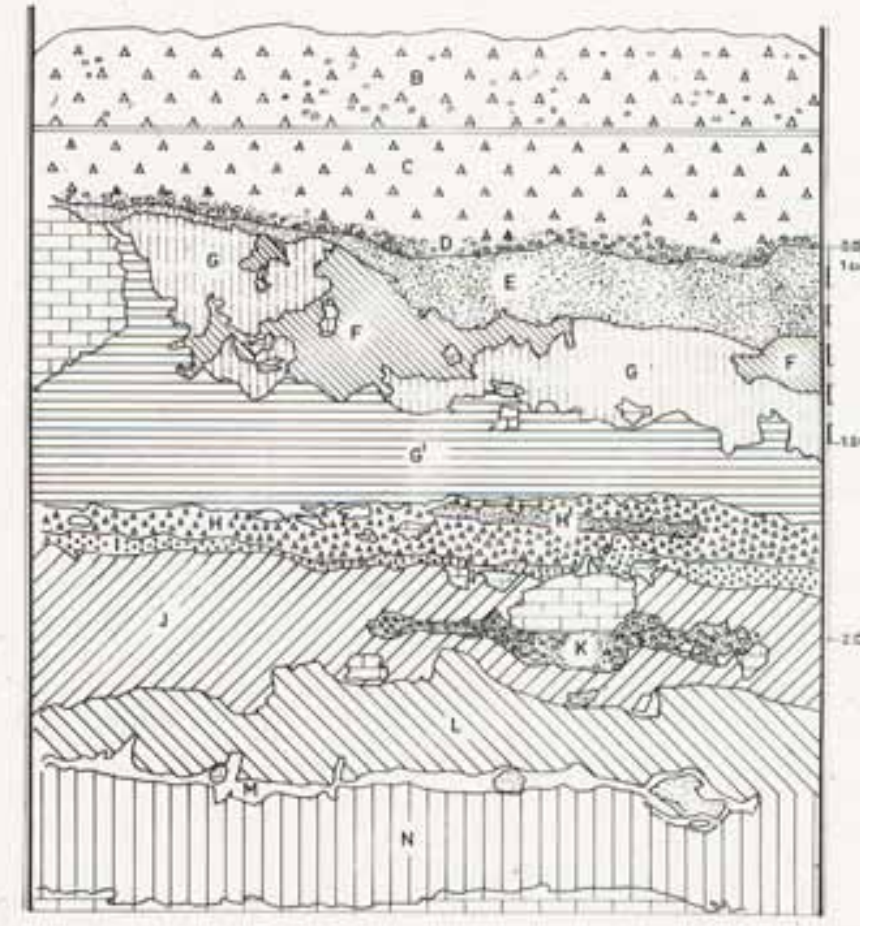

SORTE ESTRATIGRAFICO DE LA CUEVA DE EL CIERRO (EL CARMEN, RIBADESELL segun : Jor dd Cerdd - Gómez Fuentes.

Figura 6. El Cierro. Dibujo del corte estratigráfico OE realizado por FJC y AGF tras la limpieza del mismo (fuente AGF).

Figure 6. The Cierro cave. Drawing of WE stratigraphic section by FJC and AGF after cleaning (source AGF).

Años más tarde, AGF, con el apoyo de FJC, llevó a cabo tres campañas de excavación (1977, 1978 y 1979) (Fig. 4). Los trabajos iniciales consistieron en la limpieza, muestreo y dibujo de la estratigrafía del corte de uno de los testigos dejados en las excavaciones de 1959 coronado por un conchero. Posteriormente, se acometió la excavación vertical del corte por debajo del conchero para obtener una secuencia arqueológica larga, mediante la instalación de una cuadrícula métrica en posición vertical y nivelada horizontalmente con objeto de poder registrar las coordenadas de los restos arqueológicos recuperados (Fig. 5). Los sedimentos extraídos fueron cribados con tamices de 5 y $2 \mathrm{~mm}$, recogiéndose los materiales que quedaban en los tamices para su posterior selección y clasificación. La secuencia estratigráfica que obtuvieron estaba integrada por catorce niveles designados con letras de la $\mathrm{B}$ a la $\mathrm{N}$ con un nivel $\mathrm{G}^{\prime}$ y un lentejón $\mathrm{H}^{\prime}$ (Fig. 6). Esta excavación vertical se desarrolló sobre una superficie horizontal de un metro de fondo con una anchura de dos metros, pero se interrumpió antes de llegar a la base de la secuencia, quedando de esta forma el corte escalonado en el techo del nivel $\mathrm{H}$. Pese a establecer sobre dibujo esta secuencia estratigráfica alfabética, en 1979 AGF y Julián Bécares Pérez (en adelante JBP) publican una secuencia articulada en seis niveles que correlacionan con los FJC (Gómez Fuentes and Bécares Pérez, 1979; ÁlvarezAlonso and de Andrés-Herrero, 2012):

- Nivel I u horizonte superior.

- Nivel II, equivalente a la capa $3^{a}$ (rojiza grisácea), Magdaleniense intermedio.

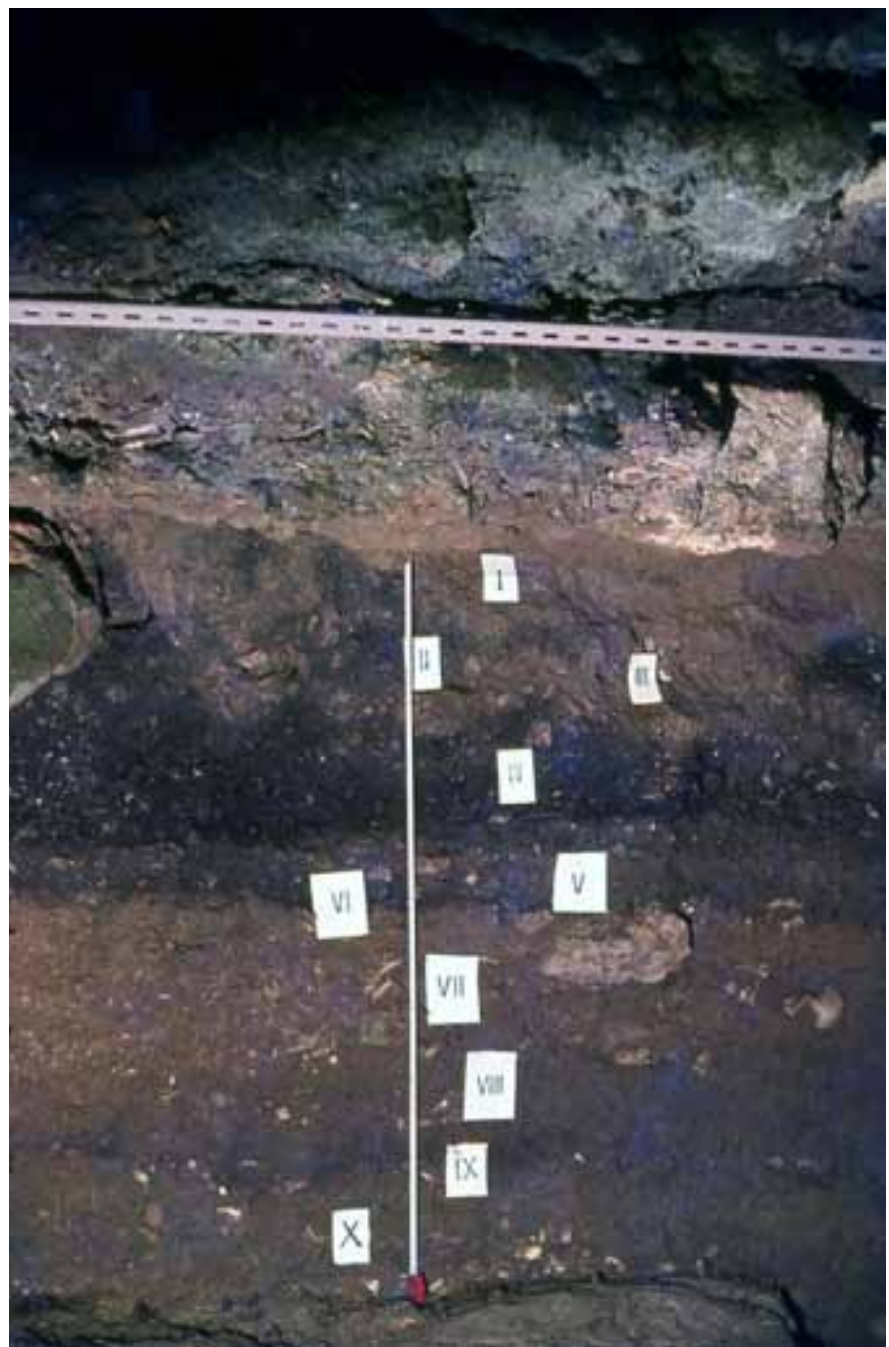

Figura 7. El Cierro. Fotografía del corte estratigráfico OE con la denominación en números romanos de los niveles inferiores al conchero publicada por AGF y JBP en 1979 (Gómez Fuentes and Bécares Pérez, 1979) (fuente AGF).

Figure 7. The Cierro cave. Photo of the WE stratigraphic section with the roman numerical designation of the lower levels below the shell midden published by AGF and JBP in 1979 (Gómez Fuentes and Bécares Pérez, 1979) (source AGF). 
- Nivel III, equivalente a la capa $4^{\text {a }}$ (color negro), Magdaleniense inferior.

- Nivel IV, equivalente a la capa $5^{\text {a }}$ (parduzca).

- Nivel V, equivalente a la capa $6^{a}$ (arcilla estéril)

- Nivel VI, equivalente a las capas $7^{a}$ y $8^{a}$, Auriñaciense.

Además, una vez limpiado el corte y comenzada la excavación, AGF y JBP obtuvieron una fotografía en la que señalaron los niveles con etiquetas en numerales romanos (Fig. 7), que se pueden correlacionar con la secuencia alfabética de la siguiente forma: $\mathrm{N}=$ $X, M=I X, L=V I I I, J=V I I, I=V I, H=V, G^{\prime}=I V, G=I I I$, $F=I I$ y $E=I$. Los niveles superiores que corresponden a los concheros, no recibieron numeración en esta secuencia.

Durante esta excavación se recuperó un omóplato con grabados estriados adscrito al Magdaleniense inferior (Gómez Fuentes and Bécares Pérez, 1979). En esa publicación se indica que, en ese momento, la estratigrafía documentada en los trabajos de 1977 a 1979 estaba en curso de estudio e interpretación por MHG. En 1979 se tomaron una serie de muestras que fueron enviadas al Instituto Lucas Mallada del CSIC (Madrid) con objeto de que fueran sometidas a análisis sedimentológicos por MHG. También se tomaron muestras para análisis palinológicos que debería realizar Anaïs Boyer-Klein en el Musée de I'Homme de París. Desconocemos si ambos análisis fueron realizados pues carecemos de más información sobre ellos.

P. Utrilla Miranda (PUM), en el transcurso de la realización de su tesis doctoral (Utrilla Miranda 1976) visitó las excavaciones de El Cierro y realizó un esquema del corte estratigráfico en el que se observan siete capas que por las descripciones del pie de figura se identifican con las capas documentadas por FJC (Fig. 8) (Utrilla Miranda, 1981: 44). En el esquema dibuja un gran bloque de caliza que se apoya y defor-
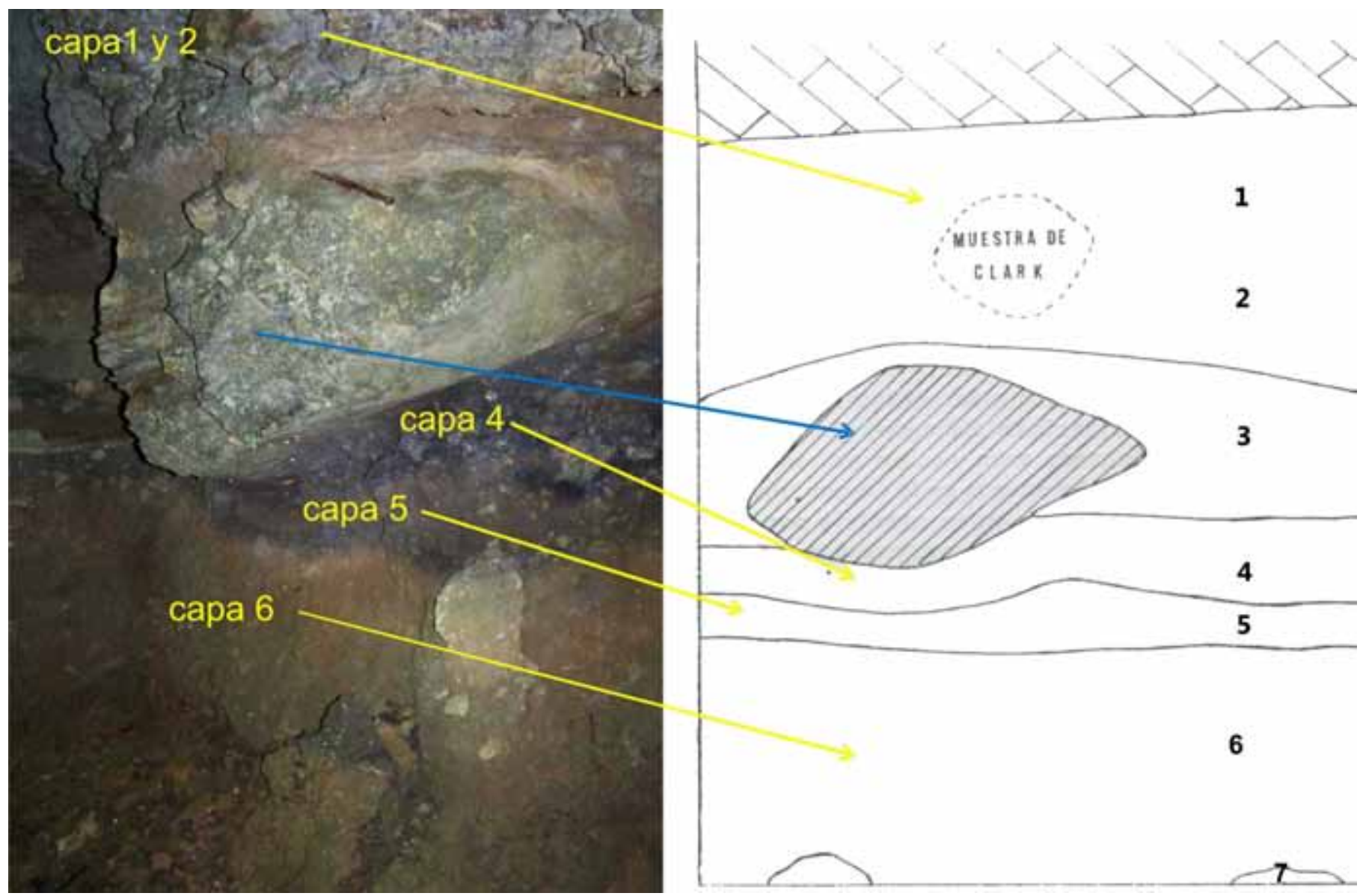

Figura 8. El Cierro. Correlación entre el esquema estratigráfico de Utrilla Miranda (1981) y una fotografía reciente, realizada y publicada por Álvarez-Alonso and de Andrés-Herrero (2012).

Figure 8. The Cierro cave. Stratigraphic correlation between Utrilla Miranda (1981) scheme and a recent photograph, taken and published by Alvarez-Alonso and Andres-Herrero (2012). 
ma la capa $4^{\text {a }}$ (Magdaleniense inferior) de FJC. Además, PUM, a partir de la estratigrafía de FJC, de las observaciones de L. G. Straus y las etiquetas de los materiales depositados en el Museo Arqueológico de Asturias, realizó una reagrupación de la secuencia en seis niveles arqueológicos (Utrilla Miranda, 1981: 45): nivel I (superficial), nivel II (Magdaleniense indeterminado, conchero de brecha capa $3^{\mathrm{a}}$ rojiza y arciIlosa), nivel III (capa 4a, Magdaleniense inferior, negra), nivel IV (capa $5^{a}$, Solutrense superior-final, parduzca), nivel $\mathrm{V}$ (capa $6^{\mathrm{a}}$, posiblemente de arcilla estéril) y nivel VI (capas $7^{\mathrm{a}}$ y $8^{\mathrm{a}}$, Auriñaciense, cenicientas). Recientemente se ha presentado una correlación de la secuencia de niveles de PUM con la de capas de FJC mediante una fotografía actual parcial del corte estratigráfico (Fig. 8) (Álvarez-Alonso and de Andrés-Herrero, 2012).

Como ya hemos apuntado, en la campaña de 1978 participó el geólogo MHG, que por esa época se encontraba realizando su tesis doctoral sobre otros yacimientos pleistocenos kársticos de la zona (Hoyos Gómez, 1979), de cuyos cuadernos de campo hemos podido extraer la información relativa a El Cierro, que se limita a dos páginas. La primera de ellas, sin fecha, contiene un esquema estratigráfico y una sucinta descripción de los niveles (Fig. 9), mientras que la segunda, fechada el 20 de abril de 1978, es una descripción de los niveles sin notación numérica o alfabética, pero con indicaciones de posición, color, textura y contenido arqueológico, ilustrada con un pequeño dibujo (Fig. 10). A partir de los datos de ambas páginas hemos reconstruido la estratigrafía observada y descrita por MHG, que se compone de los siguientes niveles de techo a muro(1):

- "Conchero Ast?" (conchero asturiense). De características similares al anterior.

- "Conchero Mag?" (conchero magdaleniense). Se trata de un paquete horizontal rayado oblicuamente sin indicación de espesor y con límites bien marcados.

- M-1, $40 \mathrm{~cm}$, "arcillas marrones" que en el dibujo aparecen representadas por rayas continuas y discontinuas paralelas. Lo atribuye de manera confusa al Magdaleniense III: "En el nivel

(1) Para ello utilizaremos las descripciones escritas de MHG que aparecen en su libreta de campo y nuestras propias apreciaciones a partir de sus dibujos.

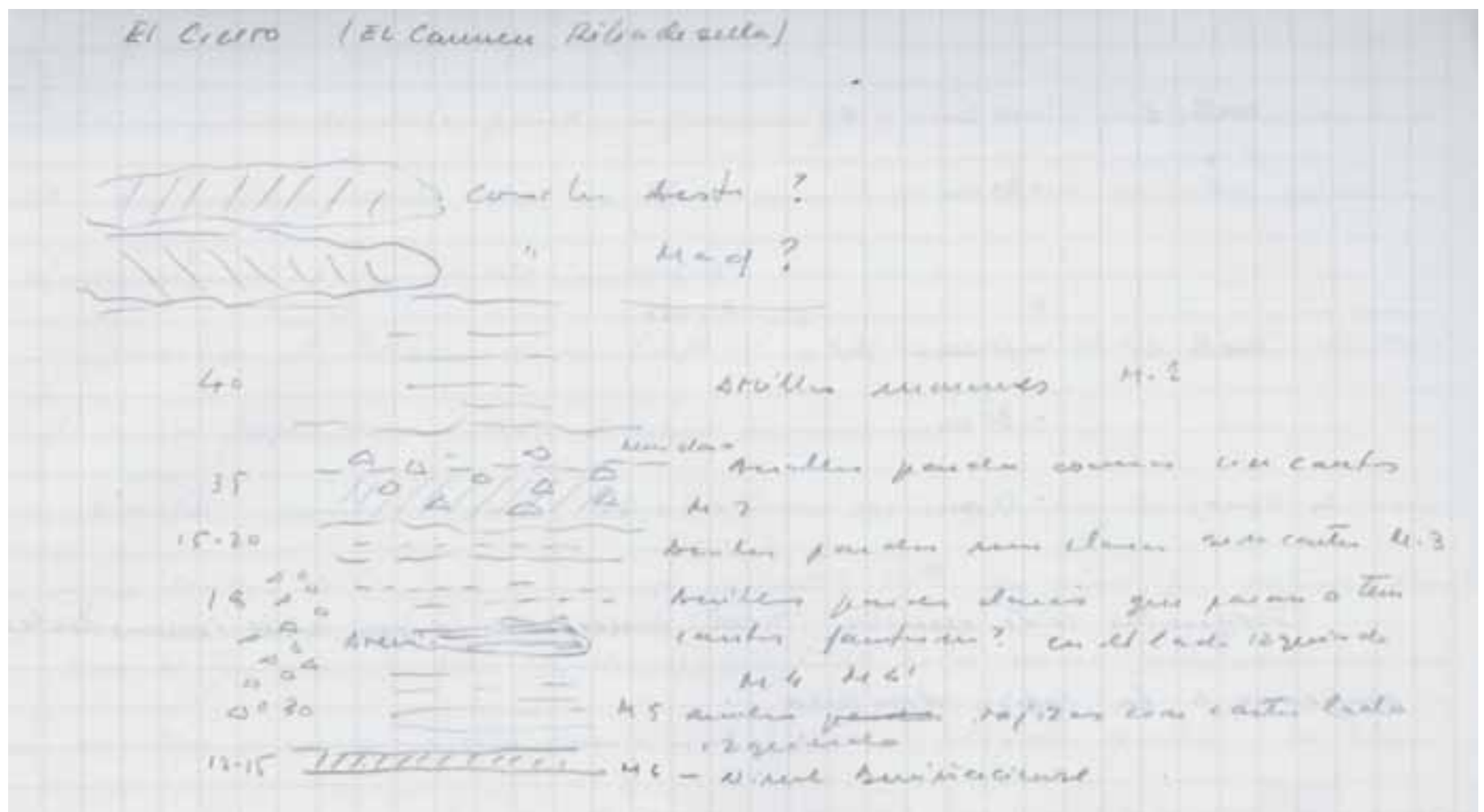

Figura 9. El Cierro. Esquema de la estratigrafía realizado por MHG, tomado de su diario de campo de la campaña de 1978 (fuente: Archivo Manuel Hoyos Gómez por cortesía de Pilar Vidal y Marco de la Rasilla Vives).

Figure 9. The Cierro cave. Scheme of the stratigraphy by MHG, taken from his field diary, campaign 1978 (source: Manuel Hoyos Gomez Archivo, courtesy of Pilar Vidal and Rasilla Vives). 


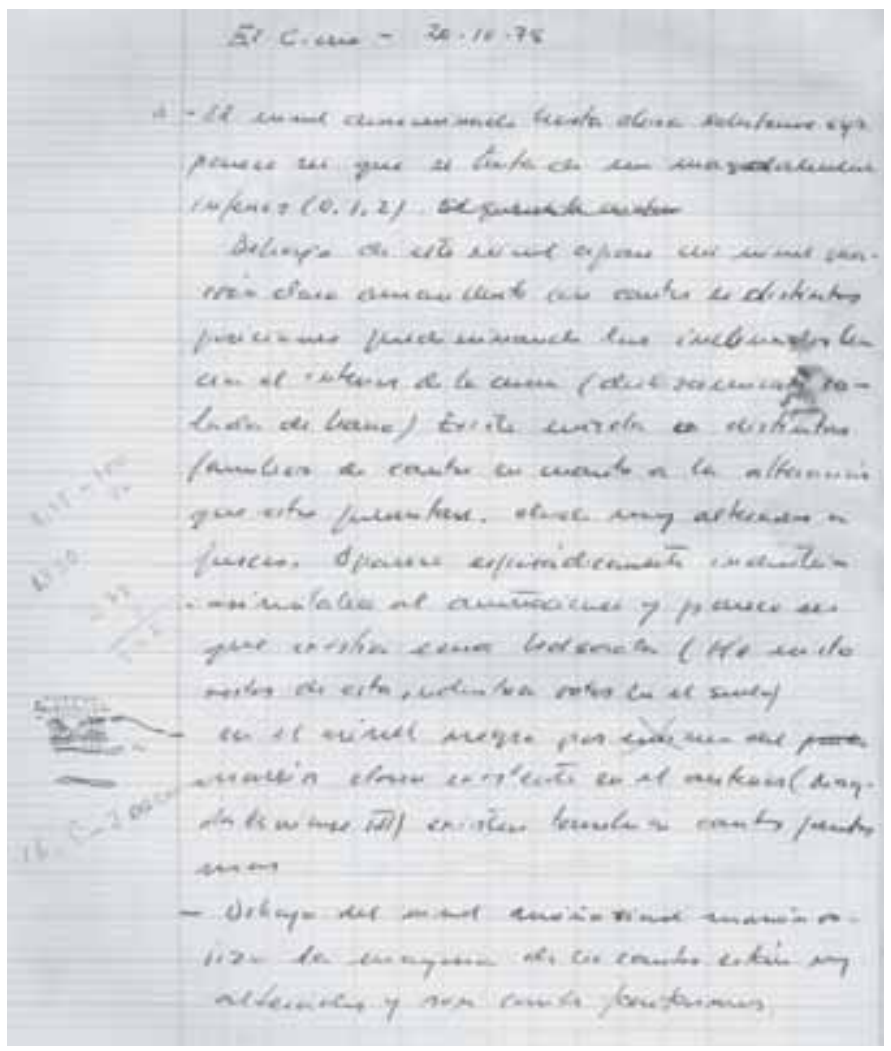

Figura 10. El Cierro. Descripción de la estratigrafía realizada por MHG, tomada de su diario de campo de la campaña de 1978 (fuente: Archivo Manuel Hoyos Gómez por cortesía de Pilar Vidal y Marco de la Rasilla Vives).

Figure 10. The Cierro cave. Description of the stratigraphy by $M H G$, taken from his field diary; 1978 campaign (source: Manuel Hoyos Gomez Archivo, courtesy of Pilar Vidal and Rasilla Vives).

negro por encima del marrón claro existente en el nivel anterior (Magdaleniense III) existen también cantos fantasmas".

- M-2, $35 \mathrm{~cm}$, "arcillas pardo oscuro con cantos". En el esquema los límites del nivel son claros y en su parte superior dibuja un contacto discontinuo que separa un nivel inferior con rayas oblicuas continuas con cantos triangulares dispersos de otro superior sin trama con tres cantos triangulares, del que indica que su color es "Más claro". En cuanto a su contenido arqueológico hace el siguiente comentario: "El nivel denominado hasta ahora solutrense sup. (sic) parece ser que se trata de un magdaleniense (sic) inferior $(0,1,2)$ ".

- M-3, 15-20 cm, "arcillas pardas muy claras sin cantos". Este nivel presenta los contactos claramente marcados por una línea de trazos discontinuos en el dibujo de MHG.

- M-4 y M-4', $18 \mathrm{~cm}$, “arcillas pardas claras que pasan a tener cantos fantasmas? en el lado izquierdo". En el dibujo se observa en su parte derecha una lentícula basal descrita como "arenas", denotada con rayas continuas, que tiene por encima dos líneas de rayas discontinuas, mientras que a la izquierda aparecen cantos de forma triangular y algunos de forma redondeada. La descripción de este nivel se completa con las siguientes indicaciones: "Debajo de este nivel" -se refiere al anterior- "aparece un nivel marrón claro amarillento con cantos en distintas posiciones predominando las inclinadas hacia el interior de la cueva (deslizamiento colada de barro). Existe mezcla o distintas familias de cantos en cuanto a la alteración que éstas presentan, desde muy alteradas a frescas. Aparece esporádicamente industria auriñaciense y parece ser que existía una bolsada ( $\mathrm{He}$ visto restos de esta industria rotos en el suelo)". - M-5, $30 \mathrm{~cm}$, "arcillas rojizas con cantos lado izquierdo". En el esquema se observan cantos angulosos en la zona izquierda, mientras que la derecha está ocupada por rayas horizontales y paralelas discontinuas. De la descripción del nivel anterior se deduce que este nivel también contiene industria auriñaciense.

- M-6, 12-15 cm, "Auriñaciense". En el esquema, dibuja a este nivel entre dos límites claros bien delineados, que rellena con rayas oblicuas. “Debajo del nivel auriñaciense de color rojizo la mayoría de los cantos están muy alterados y son cantos fantasmas".

A la vista de las descripciones de los diferentes autores, parece claro que existe un conjunto estratigráfico inferior constituido por dos o tres niveles con materiales del Auriñaciense, un nivel con evidencias del Solutrense, dos niveles con materiales del Magdaleniense inferior y dos nivel de conchero, uno situado por MHG con dudas en el Magdaleniense y por FJC en el Aziliense y otro, adscrito con dudas por MHG al Asturiense. La muestra de conchero obtenida por G. Clark en 1969, parece que fue tomada "en la conjunción de los dos concheros, formando parte de ambos" (Utrilla Miranda, 1981: 45).

A partir del 2012 se comenzaron a estudiar los materiales arqueológicos de las intervenciones llevadas a cabo entre 1977 y 1979 en la cueva de El Cierro, que en la actualidad se encuentran depositados en el Departamento de Prehistoria, Historia Antigua y Arqueología de la Universidad de Salamanca. En el 2014, AGF solicitó permiso a la Consejería de Cultura del Principado de Asturias para realizar una nueva intervención en el yacimiento. En febrero de 2014 se realizó una pequeña intervención en el corte estrati- 
gráfico oeste-este dejado por FJC y AGF en 1979, que se encuentra situado tras una reja protectora (Fig. 11). Durante esta intervención, la Consejería de Cultura del Principado de Asturias, a la vista del riesgo de desprendimiento que presentaban los concheros culminantes, procedió a su estabilización mediante un entibado de tablas y puntales, con objeto de garantizar la seguridad de los investigadores. Durante esa campaña se realizaron la topografía de la cueva y la fotogrametría de la zona excavada por FJC y AGF. Además, con objeto de precisar las características de la secuencia y su cronología, se tomaron muestras para análisis sedimentológicos y radiocarbónicos, cuyos resultados presentamos aquí, así como para estudios de micromorfología, palinología y antracología, en curso de realización. Para llevar a cabo estos análisis y acometer el estudio del material arqueológico de las campañas de 1977/1979 y del 2014, se formó un grupo de investigación interdisciplinar compuesto por una veintena de investigadores nacionales y extranjeros en el marco del proyecto "La explotación de los recursos marinos en la Europa Atlántica durante el Pleistoceno tardío y el Holoceno" (HAR2011-29907-C03-03/HIST) liderado por uno de nosotros (EAF).

A día de hoy, la secuencia documentada en El Cierro abarca, al menos, si no todo, buena parte del Paleolítico superior (Álvarez-Fernández et al., 2014, 2016 en prensa). Particularmente destaca la presencia de tres niveles de conchero con materiales de finales del Paleolítico superior (los dos inferiores) y del

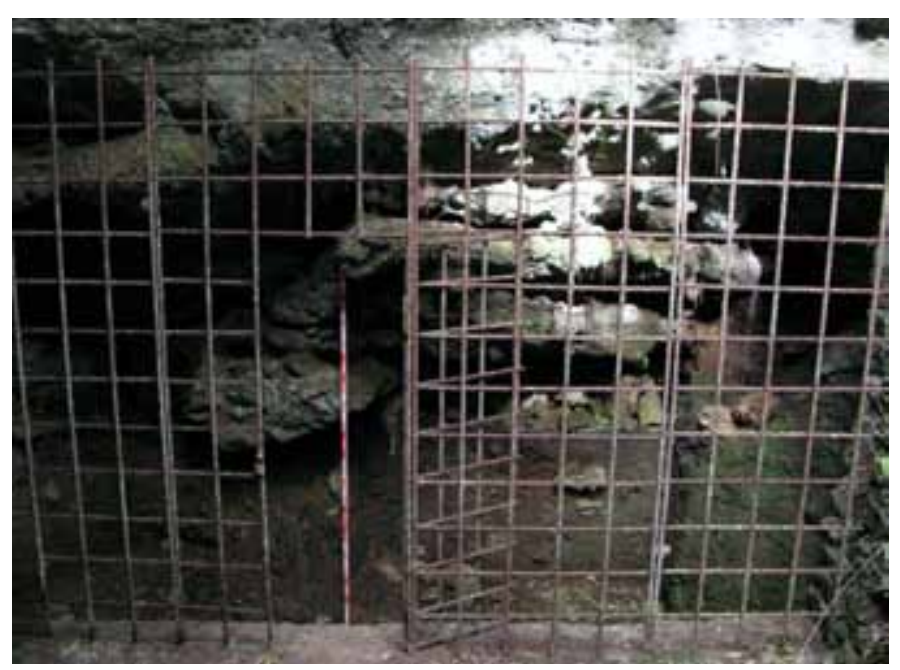

Figura 11. El Cierro. Vista del corte estratigráfico OE antes de la intervención del año 2014 (foto JFJP). En la parte superior se observan los concheros de las unidades Cierro D a Cierro B.

Figure 11. The Cierro cave. View of the WE stratigraphic section prior to the 2014 intervention (photo by JFJP). Shell middens observed on the top of the Cierro $D$ to Cierro $B$ sequence.
Mesolítico (el superior), que contienen abundantes restos de huesos de mamíferos e invertebrados marinos (conchas de moluscos, crustáceos, equinodermos, etc.) y terrestres (gasterópodos continentales). También se han documentado dos niveles del Magdaleniense inferior en los que se han recuperado abundantes restos arqueológicos, como huesos de mamíferos (fundamentalmente de ciervo), conchas de moluscos marinos (Patella vulgata y Littorina littorea), industria lítica (realizada fundamentalmente en cuarcita y en sílex, tanto de procedencia local como foránea), e industria ósea (azagayas, agujas, objetos de adorno, etc.), así como los objetos de arte mueble, todo ello actualmente en estudio. Los materiales de los niveles inferiores están también en estudio, pero en una primera aproximación parece que contienen restos atribuibles al final del Paleolítico medio y al Auriñaciense, Gravetiense y Solutrense. Por tanto, en una primera aproximación, la secuencia cubre el final del Pleistoceno superior y termina en el comienzo del Holoceno.

\section{Materiales y métodos}

\section{Muestreo y métodos analíticos}

Para la realización de la investigación geoarqueológica en la cueva de El Cierro hemos seguido los pasos habituales en este tipo de estudios (Goldberg and Macphail, 2006), partiendo del trabajo de campo seguido de diferentes análisis de laboratorio y gabinete.

El trabajo de campo consistió en el análisis del yacimiento y del medio físico del entorno, destacando la obtención de datos geológicos del entorno, el levantamiento topográfico de la cavidad y la realización de descripciones litoestratigráficas y muestreos para análisis posteriores. El plano topográfico de detalle de la cavidad con curvas de nivel cada $20 \mathrm{~cm}$ se realizó utilizando una estación total Leica TCRM1205. Todos los elementos estructurales de la cavidad, las unidades estratigráficas, así como los materiales arqueológicos recuperados y las muestras obtenidas, fueron georreferenciados mediante la citada estación total en un sistema de coordenadas local establecido a favor del corte estratigráfico antiguo. Posteriormente todos estos elementos han sido reorientados $y$, de nuevo, georreferenciados en el sistema de coordenadas oficial de España (ETRS89).

El estudio de la estratigrafía del yacimiento y la toma de muestras se llevó a cabo en el corte estratigráfico dejado por FJC y AGF tras sus intervenciones de los años 1977/1979, una vez refrescado y limpio el 


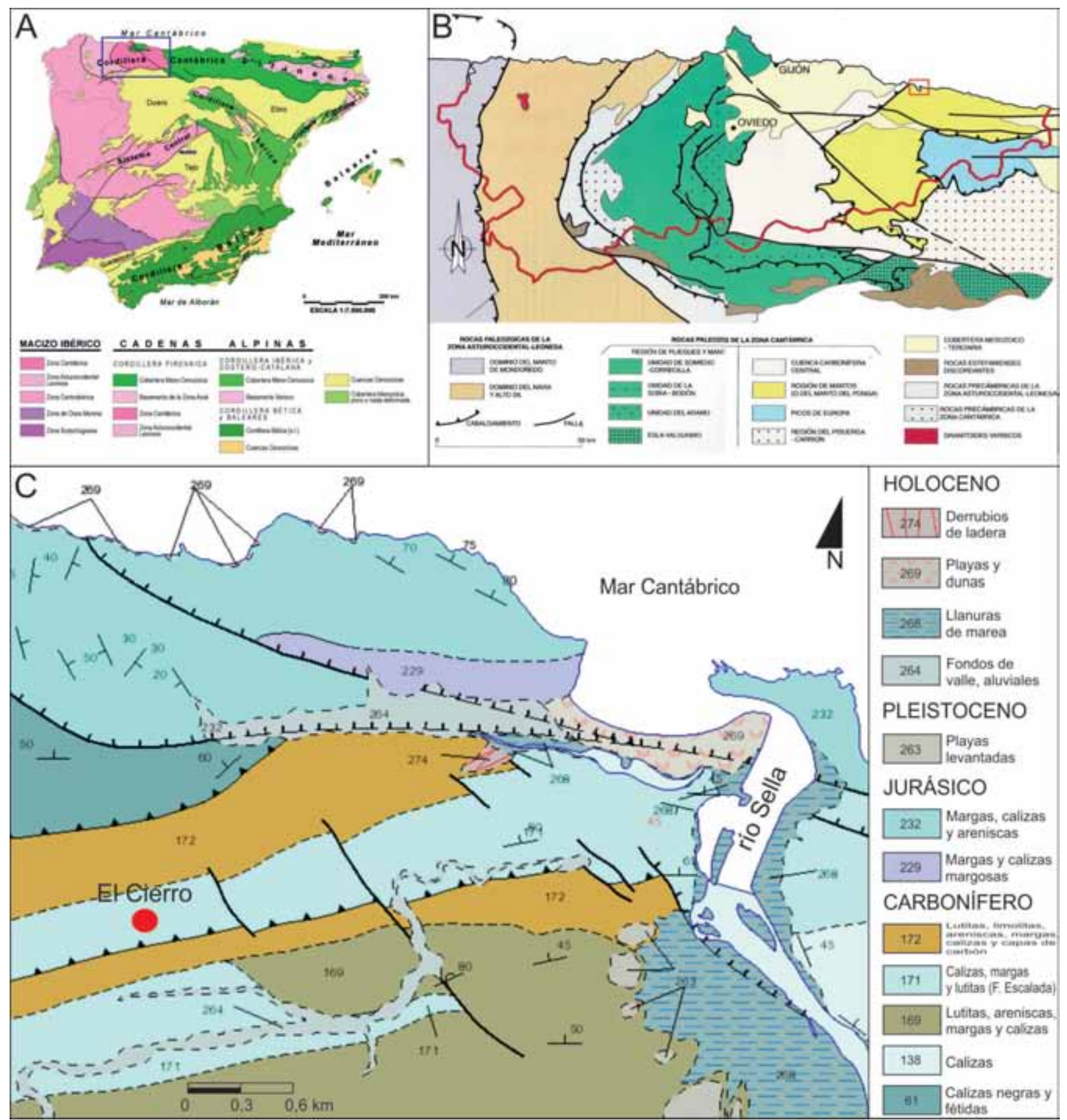

Figura 12. Situación geológica de la cueva de El Cierro. A) Contexto geológico peninsular (Vera, 2004). B) Contexto geológico de Asturias (Bastida and Aller, 1995). C) Contexto geológico local (GEODE en línea).

Figure 12. Geological location of the Cierro cave. A) Peninsular geological context (Vera, 2004). B) Asturian geological context (Bastida and Aller, 1995). C) Local geological context (GEODE on line).

perfil y aseguradas con puntales las capas superiores constituidas por los concheros que amenazaban desprenderse debido a que se encontraban descalzadas por efecto de la intervención arqueológica citada. De este corte se tomaron quince muestras para análisis sedimentológicos y edafológicos así como otros tan- 
tos juegos de muestras para estudios micromorfológicos, palinológicos y antracológicos, que se encuentran en curso de realización, por lo que sus resultados no se pueden incorporar a este trabajo.

El trabajo de laboratorio consistió en la obtención de diferentes datos analíticos tanto sedimentológicos como edafológicos. Los análisis sedimentológicos (texturales o granulométricos, de residuo insoluble y mineralógicos), se realizaron en los laboratorios del Departamento de Geología del Museo Nacional de Ciencias Naturales de Madrid. Los análisis edafológicos (color, $\mathrm{pH}$, carbonatos totales $-\mathrm{CaCO}_{3^{-}}$, materia orgánica -MO-, carbono orgánico - $\mathrm{CO}$-, conductividad eléctrica, sales, concentración de cationes y presión osmótica) se realizaron en el Laboratorio de Edafología del Departamento de Geología y Geoquímica de la Universidad Autónoma de Madrid.

Los análisis texturales o granulométricos se han realizado mediante torre de tamices CISA con intervalos cada 0,5 y balanza de sedimentación Sartorius modelo 4610. El objetivo de estos análisis es la clasificación granulométrica de los sedimentos que componen las muestras. Para ello, se separan los sedimentos en diferentes clases cuyos límites varían según los diferentes autores. En este trabajo hemos tratado los datos mediante el programa GRADISTAT 5.0 (Blott and Pye, 2001), siguiendo la clasificación granulométrica adoptada por el programa que procede de la modificación de las escalas de Udden (1914) y Wentworth (1922): cantos (clastos con diámetros superiores a $64 \mathrm{~mm}$ ), gravas (clastos con diámetros comprendidos entre $64 \mathrm{~mm}$ y $2 \mathrm{~mm}$ ), arenas (granos entre $2 \mathrm{~mm}$ y 62 micras), limos (granos entre 62 y 2 micras) y arcillas (partículas inferiores a 2 micras). Este programa realiza el tratamiento informático de los resultados de los análisis granulométricos y permite obtener los parámetros estadísticos según los diferentes autores y realizar diagramas triangulares y curvas granulométricas con el diámetro de grano expresado tanto en $\mathrm{mm}$ como en unidades, tanto del conjunto de la muestra como solo de la matriz.

La evaluación del contenido en minerales insolubles de la fracción inferior a 0,063 mm de cada una de las muestras se realizó mediante la descalcificación de $1 \mathrm{gr}$ de muestra por ataque con ácido clorhídrico (ClH) al $50 \%$ en caliente, filtrando tras un cuarto de hora de ataque el residuo insoluble resultante, el cual, una vez pesado, sirve para calcular la proporción de sustancias solubles, mayoritariamente carbonatos.

Los componentes mineralógicos de las muestras han sido determinados por difracción de rayos $X$ (DRX) a partir de la matriz de las muestras, sometida previamente a molienda para unificación del tamaño de grano. Todas las muestras se han analizado por el método de polvo para la identificación y cuantificación de las fases minerales predominantes y el análisis se ha efectuado mediante un difractómetro Philips-PW 1830 con cátodo de $\mathrm{Cu}$ y longitud de onda $\mathrm{Ka}=1.54051$ con un barrido entre $3^{\circ}$ y $65^{\circ}$ de ángulo 29, con salida sobre registro digital Philips PW 1710. El control y tratamiento de los difractogramas se ha efectuado con el software XPowder12 (Martín, 2008) para el análisis cualitativo y cuantitativo de las muestras (Martín, 2006).

Para la determinación precisa del color -en secohemos utilizando como referencia las Munsell Soil Color Charts (Munsell, 1981) con objeto de realizar una descripción objetiva y una denominación normalizada. Para la descripción del color estas tablas utilizan tres parámetros básicos que se expresan en el siguiente orden: Matiz (HUE) + Brillo (VALUE) + Croma (CHROMA).

El pH lo hemos medido siguiendo los criterios de la Soil Science Society of America (Thomas, 1996), a partir de una relación suelo: agua $=1: 2,5$, obteniendo la acidez actual ya que el suelo, dada su dinámica, es muy sensible a las modificaciones que se producen en su evolución. Uno de los factores relacionado con tales modificaciones es la concentración de iones hidrógeno. El concepto de $\mathrm{pH}$ aquí utilizado es el mismo que para soluciones verdaderas a pesar de ser un sistema heterogéneo. Su medida es una técnica que, pese su sencillez, permite obtener un dato rutinario de gran utilidad.

La salinidad la hemos obtenido de forma indirecta a partir de la conductividad eléctrica, indicando la concentración total de componentes ionizados (sólidos totales disueltos) en una suspensión del suelo en agua. La medida realizada en extracto acuoso en la relación 1:5 se obtiene midiendo la resistencia eléctrica entre dos electrodos paralelos sumergidos en la suspensión. Dado que la conductividad eléctrica aumenta con la temperatura, se efectúa una corrección para referirla a $25^{\circ} \mathrm{C}$. La presión osmótica está relacionada con la concentración de moles de soluto, y por lo tanto con la conductividad eléctrica. El dato de conductividad viene expresado en $\mathrm{dS} / \mathrm{m}$, pudiéndose calcular el porcentaje en sales, concentración catiónica y presión osmótica con los siguientes factores de conversión:

- Sales $(\mathrm{mg} / \mathrm{l})=0,64 \times \mathrm{CE}(\mathrm{dS} / \mathrm{m})$

- Concentración de cationes $(\mathrm{meq} / \mathrm{l})=10 \times \mathrm{CE}$ $(\mathrm{dS} / \mathrm{m})$

- Presión osmótica (atm) =0,36 x CE (dS/m)

El carbono inorgánico del suelo se presenta en forma de carbonatos formando sales, principalmente, con metales alcalino-térreos. Los carbonatos son unos constituyentes edáficos a veces muy abundan- 
tes. Su presencia da especiales características a los suelos como son un alto estado de saturación de nutrientes, $\mathrm{pH}$ neutro básico y alto poder amortiguador de la acidez, entre otras. Para su determinación cuantitativa se recurre a la adición de una cantidad conocida de ácido que provoca la disolución de los carbonatos y a la valoración posterior del exceso de ácido añadido (ácido no consumido) con una base. La reacción primaria que tiene lugar es

$$
\mathrm{CaCO}_{3}+2 \mathrm{HCl} \rightarrow \mathrm{CaCl}_{2}+\mathrm{CO}_{2}+\mathrm{H}_{2} \mathrm{O}
$$

Bajo la denominación de carbono total se incluyen diferentes formas de presentación del $\mathrm{C}$ tales como carbonatos, formas condensadas, residuos de plantas etc. Nosotros hemos calculado aquella materia orgánica denominada fácilmente oxidable. Por ello su determinación se realizó mediante una oxidación húmeda del $\mathrm{C}$ orgánico por exceso de dicromato potásico, en medio fuertemente sulfúrico, utilizando el calor de dilución de este ácido, para facilitar la oxidación según la fórmula

$$
\begin{gathered}
3 \mathrm{C}+2 \mathrm{~K}_{2} \mathrm{Cr}_{2} \mathrm{O}_{7}+8 \mathrm{H}_{2} \mathrm{SO}_{4} \rightarrow \\
2 \mathrm{~K}_{2} \mathrm{SO}_{4}+2 \mathrm{Cr}_{2}\left(\mathrm{SO}_{4}\right)_{3}+3 \mathrm{CO}_{2}+8 \mathrm{H}_{2} \mathrm{O}
\end{gathered}
$$

El exceso de dicromato se valora con sulfato ferroso amoniacal, $\left(\mathrm{NH}_{4}\right)_{2} \mathrm{Fe}\left(\mathrm{SO}_{4}\right)_{2} 6 \mathrm{H}_{2} \mathrm{O}$, sal de Mohr, en presencia de ácido fosfórico, utilizando difenilamina como indicador.

\section{Dataciones radicarbónicas}

Como ya hemos visto anteriormente, la primera datación radiocarbónica de la cueva de El Cierro la obtuvo Clark a partir de una muestra de carbón vegetal recogida en el conchero, que fue analizada por el procedimiento convencional en el laboratorio de radio- carbono de la Universidad de Gakushuin de Tokyo (Japón) (Tabla 1) (Clark, 1983).

Actualmente disponemos de otras seis fechas radiocabónicas obtenidas por nosotros en el marco del proyecto de investigación HAR2011-29907-C0303/HIST (Tabla 1) (Álvarez-Fernández et al., 2016 en prensa). En la campaña de campo de 2014 y durante los trabajos de selección de materiales de las excavaciones de FJC y AGF realizados en el laboratorio del Departamento de Prehistoria, Historia Antigua y Arqueología de la Universidad de Salamanca, recuperamos numerosos elementos susceptibles de ser datados mediante radiocarbono. Cinco muestras de estos materiales procedentes de los niveles superiores (Cierro G1, Cierro G, Cierro F, Cierro D, Cierro C y Cierro B sup) fueron enviadas a datar al laboratorio Oxford Radiocarbon Accelerator Unit (ORAU) de la Universidad de Oxford (Reino Unido). Cuatro de las muestras eran conchas de los moluscos marinos Littorina littorea $(n=2)$, Patela vulgata $(n=1)$ y P. lineatus $(n=1)$, mientras que las otras dos eran de hueso de Cervus elaphus. Todas las muestras permitieron realizar la datación y obtener resultados numéricos (Álvarez-Fernández et al., 2016 en prensa). Todas ellas fueron tratadas siguiendo los métodos habituales de ORAU: extracción del colágeno y ultrafiltración para los huesos y disolución por ácido de los carbonatos de las conchas (Brock et al., 2010; Douka et al., 2010). Todos los parámetros analíticos $(\%$ de $\mathrm{C}$ en el colágeno, número de isótopos estables de $\mathrm{C}$ y $\mathrm{N}$ y mineralogía de las conchas) proporcionaron los valores esperados.

\section{La cavidad y su relleno}

El yacimiento arqueológico de la cueva de El Cierro se encuentra en el extremo oriental del Macizo Asturiano de la Cordillera Cantábrica, en un sector

\begin{tabular}{|l|l|l|l|l|l|l|}
\hline Nivel & Material y especie & Código de laboratorio & Fecha 14C BP & 13C & 15N & Publicación \\
\hline Cierro B sup & Concha (P. lineatus) & OxA-31705 & $8.575 \pm 40$ & 2.01 & - & Álvarez-Fernández et al., 2016 \\
\hline Conchero / Cierro C & Carbón & GaK-2548 & $10.400 \pm 500$ & n/a & n/a & Clark, 1983 \\
\hline Cierro C & Concha (P. vulgata) & OxA-27856 & $11.190 \pm 38$ & 0.04 & - & Álvarez-Fernández et al., 2016 \\
\hline Cierro D & Concha (L. littorea) & OxA-27857 & $11.403 \pm 37$ & -0.32 & - & Álvarez-Fernández et al., 2016 \\
\hline Cierro F & Hueso (C. elaphus) & OxA-27869 & $15.460 \pm 75$ & -20.60 & 3.8 & Álvarez-Fernández et al., 2016 \\
\hline Cierro G & Hueso (C. elaphus) & OxA-27870 & $15.580 \pm 75$ & -20.20 & 4.3 & Álvarez-Fernández et al., 2016 \\
\hline Cierro G1 & Concha (L. littorea) & OxA-27871 & $16.360 \pm 55$ & 0.20 & - & Álvarez-Fernández et al., 2016 \\
\hline
\end{tabular}

Tabla 1. Dataciones radiocarbónicas de El Cierro con indicación del nivel de procedencia de las muestras, el material datado, la fecha radiocarbónica BP y su código de laboratorio, parámetros analíticos $\left({ }^{13} \mathrm{C}\right.$ y $\left.{ }^{15} \mathrm{~N}\right)$ y referencia biliográfica.

Table 1. Radiocarbon dates of the Cierro cave indicating the level of origin of the samples, the dated material, the BP radiocarbon dates and their laboratory codes $B P$, the analytical parameters $\left({ }^{13} \mathrm{C}\right.$ and $\left.{ }^{15} \mathrm{~N}\right)$ and the bibliographic references. 


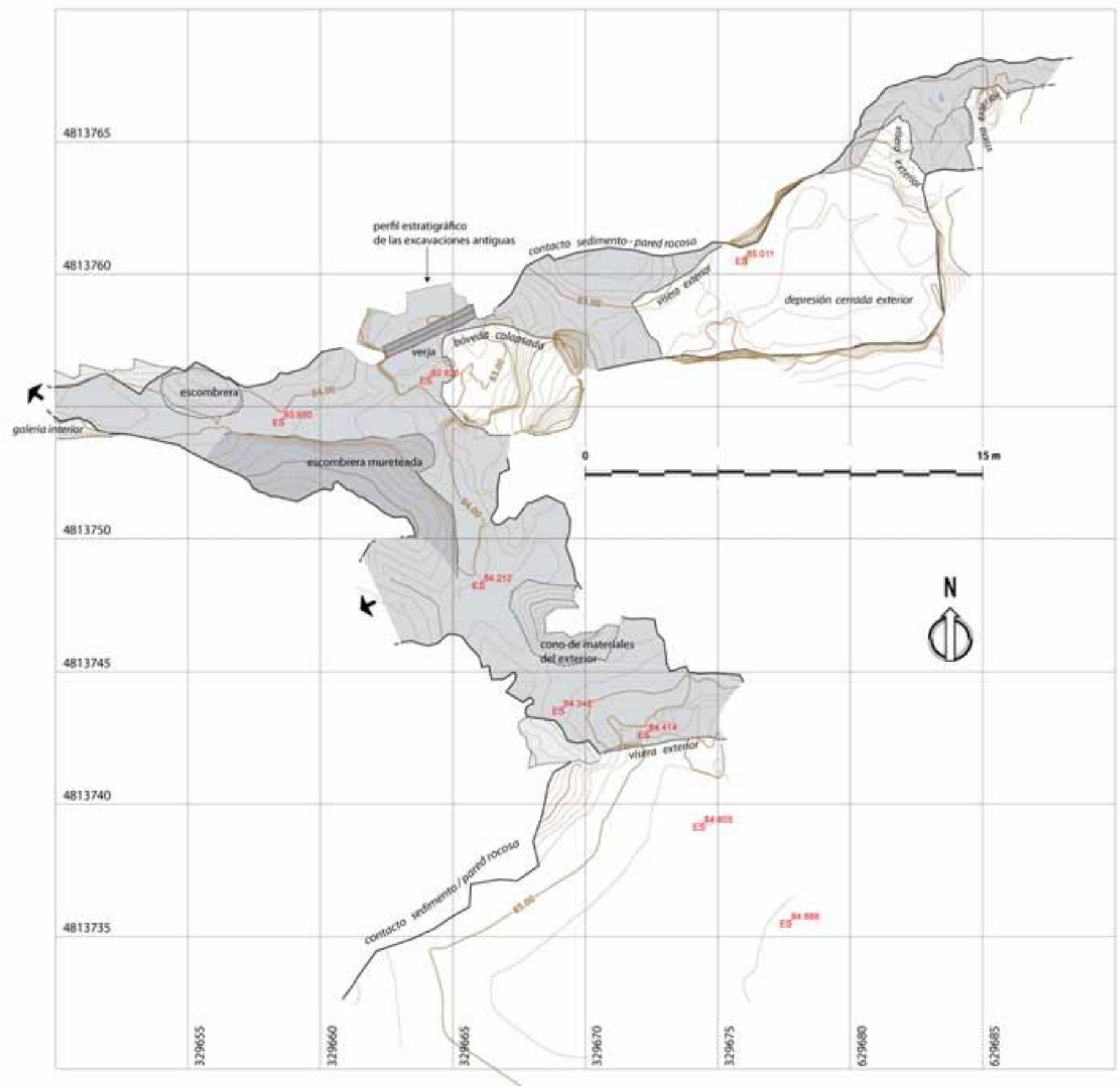

Figura 13. El Cierro. Plano topográfico de la cueva realizado durante la campaña de campo de 2014 (plano realizado por LT). Figure 13. The Cierro cave. Topographical map of the cave made during the 2014 field campaign (performed by LT).

formado por los materiales paleozoicos de la Zona Cantábrica del Macizo Ibérico. Se trata de una cavidad kárstica desarrollada en la formación Calizas de la Escalada del Carbonífero (Moscoviense) (Fig. 12) (Navarro et al., 1986). Son unas calizas micríticas y bioclásticas con intraclastos algales de tamaño canto y birdeseyes, muy recristalizadas, acompañadas por margas y lutitas. Afloran en la escama El Carmen Collera, donde pasan en la vertical y lateralmente a materiales detríticos (areniscas, limolitas, lutitas). Se encuentran afectadas por pliegues y cabalgamientos producidos durante la orogenia Varisca. En la zona de EI Carmen afloran en una estrecha franja de dirección SO-NE con un buzamiento de $75 / 80^{\circ} \mathrm{N}$. También están 
afectadas por fracturas NO-SE generadas al final de la orogenia Varisca y con funcionamiento durante la Alpina. En esta misma zona, las citadas calizas se encuentran intensamente karstificadas, con desarrollo de dolinas en superficie y cavidades subterráneas.

La cueva de El Cierro es una cavidad subsuperficial, de carácter senil y muy degradada, que, una vez desarrollada, se vio afectada por el crecimiento de las dolinas superficiales, de tal forma que está cortada al este $y$ al sur por sendas dolinas contiguas que dan lugar a arcos kársticos (Fig. 13). El techo de la sala principal, donde se localiza el yacimiento, se encuentra desplomado por lo que da lugar a una ventana cenital que permite la entrada de la luz solar. La cueva se prolonga hacia el oeste por una galería sinuosa en la que se observan al menos tres fases de encajamiento de la red hídrica hipogea que la generó. En el momento de su descubrimiento, la cueva se encontraba parcialmente colmatada en toda su extensión por depósitos detríticos, de los cuales los situados en la sala principal y en su prolongación hacia el este y sur eran depósitos arqueológicos coronados por un conchero del cual solo quedan evidencias adheridas a la paredes, tanto en la sala principal como en las aberturas este y sur. Por tanto, al yacimiento arqueológico situado en la sala principal se accede desde el este y el sur por dos galerías que se abren en sendas dolinas (Fig. 13).

En la actualidad se observan los diferentes cortes estratigráficos del yacimiento dejados por las excavaciones de FJC y AGF, que se encuentra en la zona norte de la citada sala. A partir de la sección estratigráfica norte, de dirección EO, hemos obtenido la secuencia litoestratigráfica del yacimiento, siguiendo también los esquemas estratigráficos realizados en su día por dichos investigadores. Aparentemente, la secuencia se apoya sobre las calizas del sustrato o sobre un bloque calizo de grandes dimensiones y está formada por catorce unidades sedimentarias (Fig. 14) cuya descripción realizaremos de muro a techo:

- Cierro N (50 cm) (Figs. 15 y 16): Limos y arenas arcillosos de color amarillo-grisáceo. Las arenas son de tamaño medio a fino, de cuarzo, angulosas y redondeadas. Contiene algunos cantos de caliza totalmente alterados (centil de 6 a $12 \mathrm{~cm}$ ), que se disponen de forma planar $y$ que se corresponden con los "cantos fantasmas" que MHG describe en sus notas de campo en la base de la secuencia por debajo del nivel que él adjudica al Auriñaciense. Hacia el muro, contiene fragmentos de espeleotemas planares muy alterados. La geometría del depósito es tabular con disposición horizontal.
Probablemente estemos ante un nivel de finales del Paleolítico medio si bien los escasos materiales líticos recuperados hasta el momento no son concluyentes al respecto.

Por su posición en la secuencia estratigráfica, este nivel podría ser la capa cenicienta ( ${ }^{a}$ ) situada en la base del esquema estratigráfico de FJC (Fig. 3 D, Tabla 2).

- Cierro M (0 a $10 \mathrm{~cm}$ ) (Figs. 15 y 16): Limos y arenas arcillosos, de color marrón claro. Las arenas son de tamaño medio y grueso, de cuarzo, bien redondeadas, acompañadas por pequeños granos de caliza y arenas gruesas de caliza. Contiene cantos de caliza de centil $5 \mathrm{~cm}$, algunos de ellos alterados. En la sección se observa un canto rodado de $11 \mathrm{~cm}$ de arenisca naranja, muy bien redondeado y otro canto o núcleo de cuarcita de 5 a $6 \mathrm{~cm}$. A techo hay un bloque de caliza autóctona de $40 \mathrm{~cm}$ que comprime la unidad Cierro M y se apoya sobre la Cierro N. Es un estrato muy delgado, horizontal, que se acuña hacia el $E$ hasta desaparecer.

- Cierro L (20 a $40 \mathrm{~cm}$ ) (Figs. 15 y 16): Limos y arcillas de color marrón con arenas de cuarzo y gravas de caliza, bastante homogéneas, que hacia el E contiene cantos de caliza angulosos (centil $7 \mathrm{~cm}$ ). Presenta restos de plaquetas de caliza dispuestas horizontalmente, muy alteradas por disolución. Se dispone en continuidad con la unidad anterior aunque su tonalidad es más anaranjada. Hacia el techo, en el sector oeste de la sección, pasa de forma gradada a la unidad Cierro J2, mientras que en los sectores central y oriental pasa lateralmente a un depósito con abundantes clastos. El techo de esta unidad es irregular.

El conjunto formado por Cierro $\mathrm{M}$ y Cierro $\mathrm{L}$ parece corresponder a la capa $7^{\text {a }}$ del esquema estratigráfico de FJC (Fig. 3 D, Tabla 2). Ambos niveles, contienen abundantes materiales arqueológicos (Fig. $17 \mathrm{C}$ ).

- Cierro J2 (18 a $20 \mathrm{~cm}$, aunque se llega a acuñar hasta $10 \mathrm{~cm}$ en el sector oeste) (Figs. 15 y 16): Arenas limosas con arcillas, de color marrón claro. Las arenas son de cuarzo y tamaño muy fino a medio, por un lado, y de caliza, gruesas y muy gruesas, por otro. Contiene gravas de caliza alterada y abundantes cantos de caliza autóctona (centil $15 \mathrm{~cm}$, media $6 \mathrm{~cm}$ ) con aristas angulosas, ligeramente redondeadas por alteración. Con respecto al nivel infrayacente, la presencia de cantos alterados disminuye y su tamaño es menor $(2 \mathrm{~cm})$. Los cantos tienen tendencia a la disposición planar. A techo de Cierro 


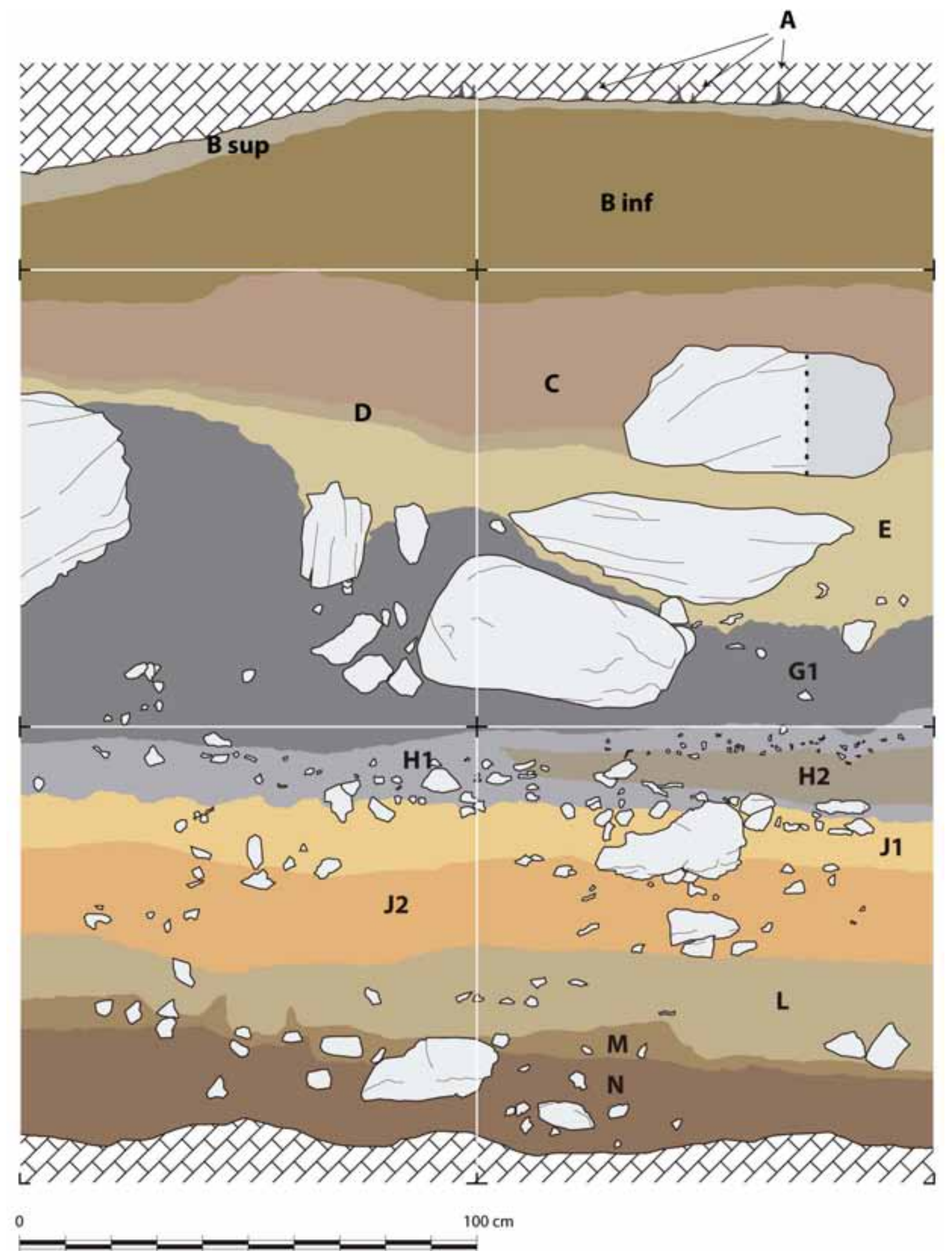

Figura 14. El Cierro. Dibujo del corte estratigráfico OE durante la campaña de campo de 2014 (plano realizado por LT).

Figure 14. The Cierro cave. Drawing of the WE stratigraphic section made during the 2014 field campaign (performed by LT). 


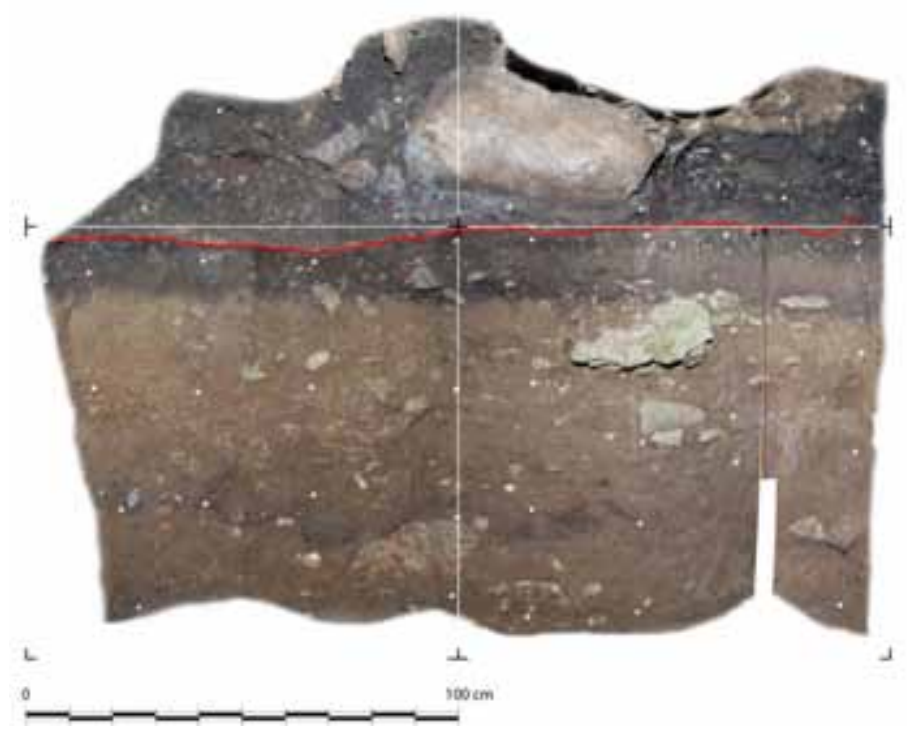

Figura 15. El Cierro. Mosaico ortofotográfico del tramo inferior al conchero del corte estratigráfico OE de la cueva de El Cierro realizado durante la campaña de campo de 2014 en el marco del proyecto de investigación actual. La línea roja indica el escalón dejado en el corte por FJC y AGF al finalizar su excavación de la parte superior de la secuencia (plano realizado por LT).

Figure 15. The Cierro cave. Ortho-photographic mosaic of the WE section of the deposit below the shell midden made during the 2014 field campaign in the current research project. The red line indicates the step left on the section by FJC and AGF when finishing their dig of the top of the sequence (performed by $L T$ ).

$\mathrm{J} 2$ hay un gran bloque de caliza de $45 \mathrm{~cm}$ de tamaño máximo visible dispuesto horizontalmente y de geometría tabular, que deforma la geometría original del depósito. Contiene fragmentos de materia orgánica carbonizada.

En la representación gráfica que FJC y AGF realizan de esta sección estratigráfica aparece, por debajo del gran bloque de caliza de nuestra unidad Cierro J2, un nivel que denominan $\mathrm{K}$, con una potencia entre 0 y $20 \mathrm{~cm}$, pero que en la actualidad no se detecta. A partir de los datos del dibujo citado parece corresponder a un depósito de clastos de caliza que configuran un lentejón de geometría irregular en el interior de su nivel J, con una extensión lateral cercana a 1 $\mathrm{m}$. En sus notas de campo, el geólogo MHG no hace ninguna indicación sobre este nivel.

- Cierro J1 (18-20 cm) (Figs. 15 y 16): Limos y arcillas, de color naranja-amarillento, muy plásticos, con escasos granos muy finos y bien redondeados de arena de cuarzo. Contiene abundantes clastos de caliza autóctona de geometría tabular y, en menor número, prismática, que se disponen de forma totalmente desorga-

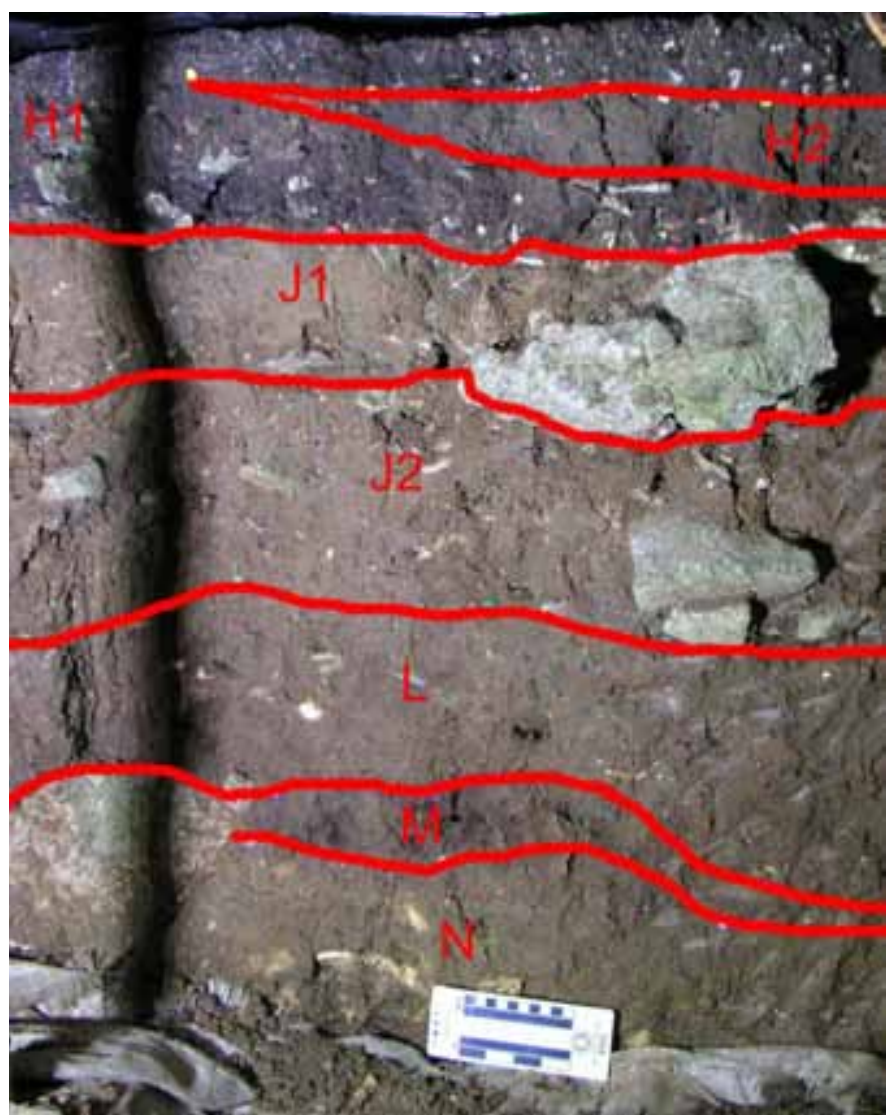

Figura 16. El Cierro. Esquema estratigráfico de la parte inferior del corte $\mathrm{OE}$ con indicaciones de los niveles desde Cierro $\mathrm{N}$ hasta Cierro H1 (foto JFJP).

Figure 16. The Cierro cave. Photo of the stratigraphic scheme of the lower part of the WE section with indication of levels from Cierro $N$ to Cierro H1 (photo by JFJP).

nizada. Su contacto superior es marcadamente neto con el $\mathrm{H} 1$. En la secuencia estratigráfica dibujada por FJC y AGF, a techo de este nivel, se observa una unidad denominada I, de escaso espesor, que en realidad es la zona de transición o contacto entre las unidades Cierro J1 y Cierro H1.

El conjunto formado por Cierro J2 y Cierro J1 parece corresponderse con la capa $6^{\mathrm{a}}$ del esquema estratigráfico de FJC (Fig. 3 D, Tabla 2). Ambos niveles contienes restos arqueológicos, tanto fragmentos óseos como restos líticos que, tanto por la tipología de algunas piezas, como por la posición estratigráfica de este conjunto sedimentario, parecen adscribirse preliminarmente a un contexto cultural gravetiense.

- Cierro H1 ( $10 \mathrm{~cm}$ en el sector este, 12 a $15 \mathrm{~cm}$ en el oeste) (Figs. 15 y 16): Arenas limosas con arcillas, de color marrón oscuro a negruzco. Las 


\begin{tabular}{|c|c|c|c|c|c|c|c|}
\hline FJC 1959 & MHG 1978 & $\begin{array}{r}A C \\
1979\end{array}$ & $\begin{array}{l}\text { JBP } \\
\text { foto } 1979\end{array}$ & $\begin{array}{c}\text { FJC-AGF } \\
1979\end{array}$ & PUM 1981 & Este trabajo & $\begin{array}{c}\text { Atribución } \\
\text { cultural }\end{array}$ \\
\hline $\begin{array}{l}\text { Conchero } \\
\text { superior }\end{array}$ & $\begin{array}{l}\text { Conchero } \\
\text { asturiense }\end{array}$ & & & B & & $\mathrm{B}$ & Mesolitico \\
\hline $\begin{array}{l}\text { Conchero } \\
\text { inferior }\end{array}$ & \begin{tabular}{|c|} 
Conchero \\
magdaleniense
\end{tabular} & & & C & & C & \multirow{2}{*}{$\begin{array}{l}\text { ¿Paleolitico } \\
\text { superior final- } \\
\text { Aziliense? }\end{array}$} \\
\hline $2^{a}$ & \multirow{3}{*}{ M1 } & I & & D & & D & \\
\hline $3^{a}$ & & II & I & $E$ & II & $E$ & Estéril \\
\hline $4^{a}$ & & III & III II $^{\text {II }}$ & $G_{G^{\prime}} F$ & III & G1 $F$ & $\begin{array}{l}\text { Magdaleniense } \\
\text { inferior }\end{array}$ \\
\hline \multirow[t]{2}{*}{$5^{a}$} & \multirow[t]{2}{*}{ M2 } & \multirow[t]{2}{*}{ IV } & V & $\mathrm{H}\langle\hat{\mathrm{H}}\rangle$ & \multirow[t]{2}{*}{ IV } & \multirow[t]{2}{*}{$\widehat{\mathrm{H} 1}$} & \multirow[t]{2}{*}{ Solutrense } \\
\hline & & & VI & I & & & \\
\hline \multirow{2}{*}{$6^{a}$} & M3 & \multirow{2}{*}{ V } & \multirow{2}{*}{ VII } & \multirow{2}{*}{$\mathrm{J}\langle\hat{\mathrm{K}}>$} & \multirow{2}{*}{ V } & J1 & \multirow{2}{*}{ ¿Gravetiense? } \\
\hline & M4 & & & & & $\mathrm{J} 2$ & \\
\hline \multirow{2}{*}{$7^{a}$} & \multirow{2}{*}{ M5 } & \multirow{3}{*}{ VI } & VIII & L & \multirow{3}{*}{ VI } & L & Auriñaciense \\
\hline & & & IX & $\mathrm{M}$ & & M & ¿Auriñaciense? \\
\hline $8^{a}$ & M6 & & $\mathrm{X}$ & $\mathrm{N}$ & & $\mathrm{N}$ & $\begin{array}{l}\text { ¿Paleolitico } \\
\text { medio final? }\end{array}$ \\
\hline
\end{tabular}

Tabla 2. Ensayo de correlación entre las diferentes denominaciones otorgadas a los niveles de la sección estratigráfica oeste-este de la cueva de El Cierro según los diferentes autores que han intervenido en ella o han estudiado sus materiales y la secuencia estratigráfica actualmente visible que se describe en este trabajo con indicación de la adscripción cultural que actualmente se atribuye a los niveles. Table 2. Correlation study between the different notations given to the levels of the west-east stratigraphic section of the cave according to the different authors who have worked in it or have studied its materials and the currently visible stratigraphic sequence described in this paper indicating the cultural attribution currently attributed to the levels.

arenas son de cuarzo, gruesas, medias y finas, bien redondeadas, por un lado, y de caliza, gruesas, apenas redondeadas. Contiene una alta proporción de arenas gruesas y muy gruesas, gravas y cantos de caliza (centil $8 \mathrm{~cm}$, media $4 \mathrm{~cm}$ ) muy irregulares, con aristas romas por alteración. Internamente los clastos presentan una disposición caótica. Es un nivel rico en materia orgánica. Este nivel se corresponde con la capa $4^{\mathrm{a}}$ del esquema estratigráfico de FJC. En su interior, hacia la parte este de la sección contiene un lentejón de arcillas que corresponde a la unidad Cierro $\mathrm{H} 2$.

- Cierro H2 (15 a $0 \mathrm{~cm}$ ) (Figs. 15 y 16): Arcillas y limos de color marrón claro que aparecen en la zona este de la sección y se acuñan hacia el centro de esta hasta desaparecer. Contienen arenas finas a muy finas, de cuarzo, bien redondeadas. Su contacto inferior es muy neto y está jalonado por las placas y plaquetas de caliza de Cierro H1. Este nivel es internamente homogéneo y de gran plasticidad y en él no se observa laminación. Es estéril arqueológicamente.

El nivel Cierro $\mathrm{H} 1$ contiene abundantes restos arqueológicos, tanto óseos como líticos, entre los que se localiza alguna pieza de factura solutrense (Fig. $17 \mathrm{~B}$ ). Estas dos unidades podrían corresponder a la capa $5^{a}$ del esquema estratigráfico de FJC (Fig. 3 D, Tabla 2) que atribuye a la transición entre el Solutrense superior y el Magdaleniense inferior.

- Cierro G1 $(30 \mathrm{~cm}$ en el sector oeste y $20 \mathrm{~cm}$ en 

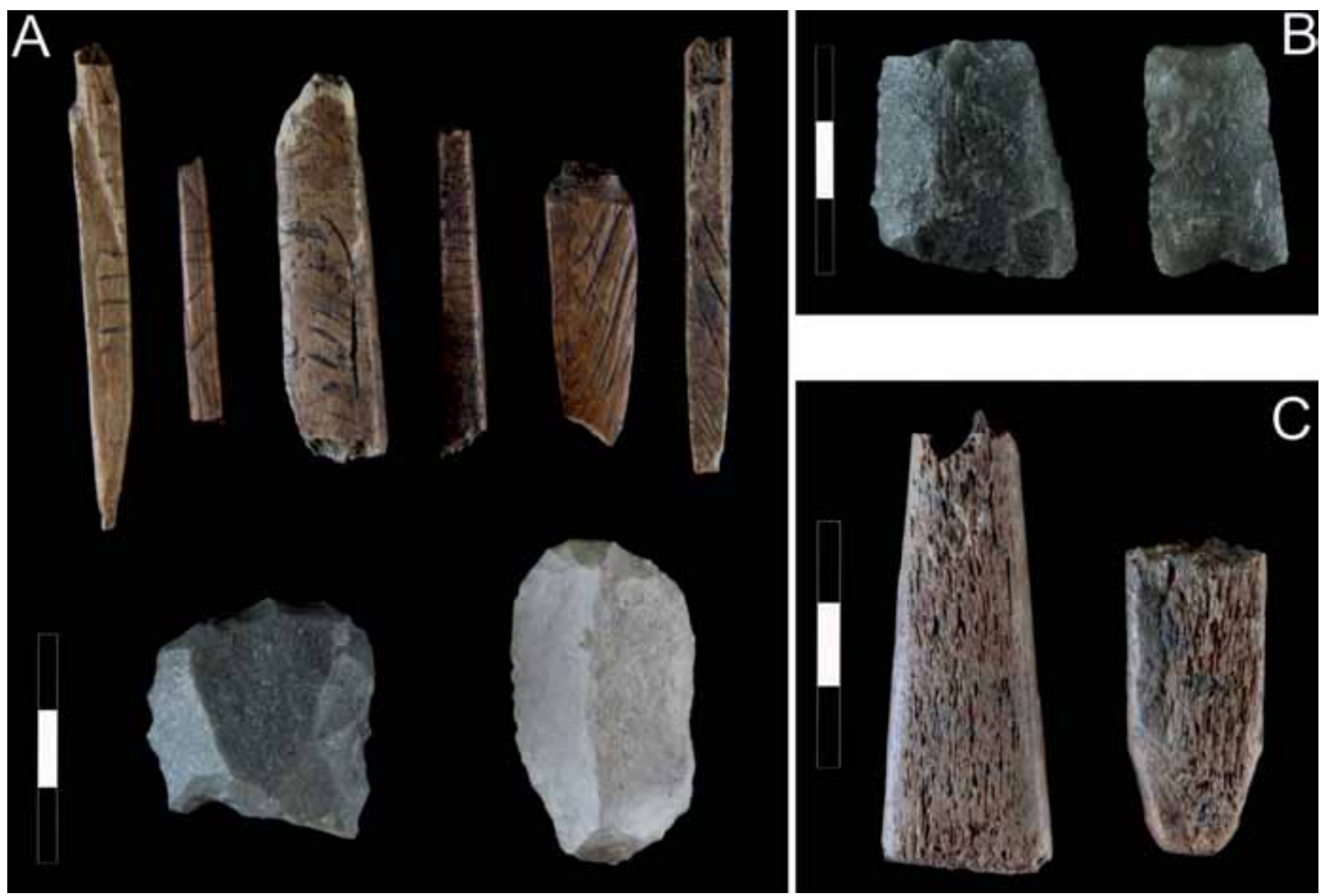

Figura 17. A) Cierro G1, industrias líticas y óseas magdalenienses. B) Cierro H1, industria lítica solutrense. C) Cierro $L$ y Cierro $M$, industrias óseas auriñacienses (tomado de Álvarez-Fernández et al., 2014).

Figura 17. A) Cierro G1, Magdalenian lithic and bone industries B) Cierro H1, Solutrean lithic industry. C) Cierro L and Cierro M, Aurignacian bone industry (from Álvarez-Fernández et al., 2014).

el este): Arenas con limos y arcillas de color negro. Las arenas son de cuarzo, finas y muy finas, redondeadas, que engloban multitud de restos arqueológicos (huesos, conchas, lítica, etc.). Contiene cantos de caliza, centil $12 \mathrm{~cm}$, prismáticos, dispuestos horizontalmente. En el centro de la sección hay un gran bloque de caliza de longitud $54 \mathrm{~cm}$ y altura $30 \mathrm{~cm}$, con las aristas muy redondeadas sobre el que se encuentra otro gran bloque tabular y anguloso (Fig. 18 A). Este gran bloque redondeado presiona el sedimento de esta unidad y lo proyecta hacia arriba de tal forma que se encuentra englobado por las arcillas negras del nivel. En el sector oeste hay un gran bloque de caliza autóctona de $125 \mathrm{~cm}$ de dimensión máxima horizontal y $60 \mathrm{~cm}$ espesor, muy anguloso, que deforma las unidades Cierro G1 y Cierro H1 (Fig. 18 B). Este es el gran bloque que dibuja
FJC en uno de los croquis de su diario (Fig. 3 B) y Utrilla Miranda (1981: 44) lo sitúa apoyado en la capa $4^{\mathrm{a}}$ de FJC y englobado por la $3^{\mathrm{a}}$ (Fig. 8). La disposición general de la unidad es horizontal en las zonas no afectadas por la deformación producida por los bloques. Contiene restos óseos longitudinales con disposición horizontal y vertical, aunque predomina la horizontal. Hay restos de Patella sp., pero sobre todo de Littorina littorea. El contenido arqueológico se adscribe al Magdaleniense inferior (Fig. $17 \mathrm{~A}$ ). Este nivel se corresponde con la capa $4^{\mathrm{a}}$ del esquema estratigráfico de FJC (Fig. $3 \mathrm{D}$, Tabla 2) y con el nivel G' del dibujo de FJC y AGF, mientras que las bolsadas denominadas $G$ por estos investigadores, que se intercalan con su nivel $F$, no se detectan en el corte actual, que se encuentra un metro retranqueado con respecto al estudiado por ellos. Del nivel Cierro G1 con- 
tamos con una fecha, OxA-27871 $16.360 \pm 55 \mathrm{BP}$, mientras que del nivel $G$ hemos obtenido la fecha OxA-27870 $15.580 \pm 75$ BP a partir de un fragmento óseo de Cervus elaphus procedente de las excavaciones de FJC y AGF (Tabla1).

- Cierro F: De esta unidad solo quedan evidencias en una bolsada situada en el perfil este situado en posición ortogonal al estudiado, que corta la unidad Cierro G1. Es una bolsada de $35 \mathrm{~cm}$ de ancho por 15 de espesor formada por limos y arcillas de color marrón claro con arenas finas y muy finas de cuarzo bien redondeadas (Fig. $18 \mathrm{C})$. Contiene clastos de caliza autóctona, angulosos de aristas romas (centil $13 \mathrm{~cm}$ y media $3 \mathrm{~cm}$ ), con disposición caótica. Contiene restos óseos muy fragmentados. A la derecha de esta bolsada hay un gran bloque de caliza de $30 \mathrm{~cm}$ que descansa sobre Cierro $\mathrm{H} 1$ y sobre el que se apoyan las unidades Cierro G1 y Cierro $\mathrm{F}$. Los materiales arqueológicos que contienen se atribuyen al Magdaleniense inferior (Fig. 17 A). De este nivel contamos con la fecha OxA$2786915.460 \pm 75$ BP obtenida a partir de un fragmento óseo de Cervus elaphus procedente de las excavaciones de FJC y AGF (Tabla1).

En la secuencia estratigráfica dibujada por FJC y AGF, este nivel configura una bolsada irregular situada entre las dos bolsadas del nivel $\mathrm{G}$ de estos investigadores. En el citado dibujo se representa sin indicaciones convencionales de sus características granulométricas.

- Cierro E (2 a $15 \mathrm{~cm}$ ): Limos arenosos con arci-
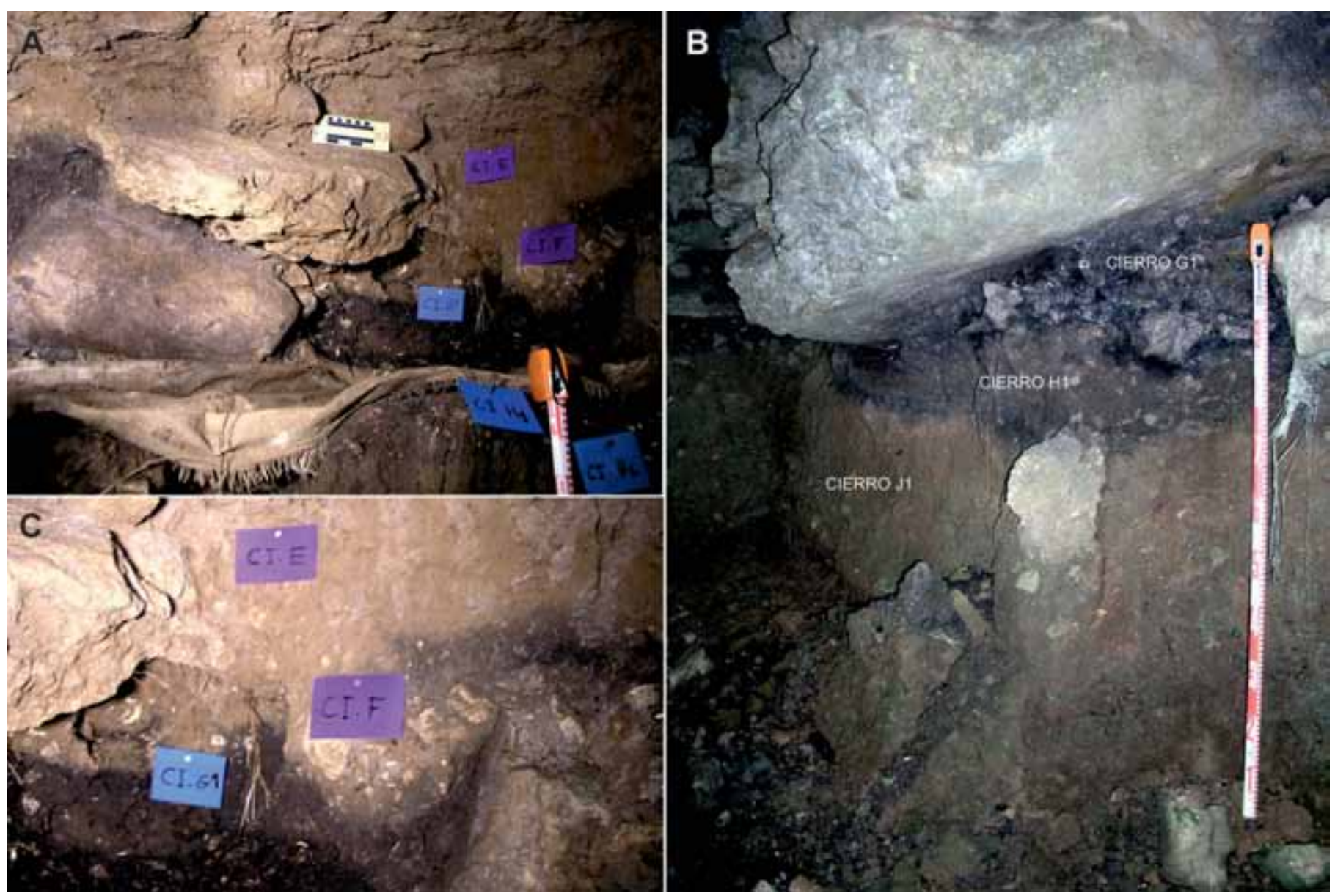

Figura 18. El Cierro. A) Detalle del gran bloque redondeado del tramo superior de la secuencia de El Cierro y de los niveles Cierro G1,

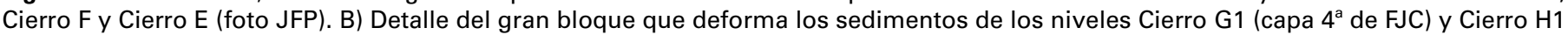
(capa $5^{a}$ de FJC), por debajo de los cuales aparece Cierro J1 (capa $6^{a}$ de FJC) (foto JFJP). C) Detalle de los niveles Cierro G1, Cierro F y Cierro $\mathrm{E}$ en el sector este de la sección (foto JFJP).

Figure 18. The Cierro cave. A) Detail of the large rounded block of the upper portion of the sequence of the Cierro cave and of levels Cierro G1, Cierro F and Cierro E (JFP photo). B) Detail of the large block which deforms sediment levels Cierro G1 (layer 4th of FJC) and Cierro H1 (layer 5th FJC), below which appears Cierro J1 (layer 6th FJC) (photo JFJP). C) Detail of the levels Cierro G1, Cierro F, and Cierro E at the eastern sector of the section (photo by JFJP). 
Ilas, de color naranja a amarillo. Su contacto inferior es muy irregular, pues en el sector este aparece encima de Cierro F y Cierro G1 mientras que el sector oeste lo hace encima de Cierro G1 (Fig. 18 C). En la parte media-oeste hay un bloque de caliza autóctona con forma tabular de tamaño $25 \mathrm{~cm}$ hincado verticalmente y justo encima del gran bloque redondeado descrito en Cierro G1 aparece otro bloque de caliza autóctona de $85 \mathrm{~cm}$ longitud máxima y espesor $20 \mathrm{~cm}$, con aristas angulosas pero romas. Entre ambos bloques hay un espacio de 5 a $6 \mathrm{~cm}$ con materiales de Cierro G1 y Cierro E. A techo, en el sector este, se observan dos facies diferenciadas: una carbonatada, de 15 $\mathrm{cm}$ de espesor y aspecto granular, que pasa lateralmente hacia el este a una facies arcillosa de $15 \mathrm{~cm}$ de espesor con clastos de caliza y restos óseos. En su sección actualmente visible, esta unidad en apariencia es estéril arqueológicamente.

Se corresponde con la capa $3^{\mathrm{a}}$ del esquema estratigráfico de FJC (Fig. $3 \mathrm{D}$, Tabla 2) que atribuye al Magdaleniense medio.

- Cierro D (5 a $10 \mathrm{~cm}$ ): Depósito carbonatado de transición entre las unidades Cierro E y Cierro C (Fig. 19 B). Lateralmente presenta materiales detríticos de color oscuro cementados con carbonatos. A techo, en el contacto entre este nivel $y$ el suprayacente (Cierro C) se observa una concreción carbonatada granular milimétrica de $1 \mathrm{~cm}$ de espesor. También se observa el desarrollo de concreciones botroidales alrededor de partículas detríticas. Contiene restos muy fragmentados de invertebrados marinos, terrestres y huesos de vertebrados. Contiene materiales arqueológicos que parecen corresponder al Paleolítico superior final/Aziliense. A
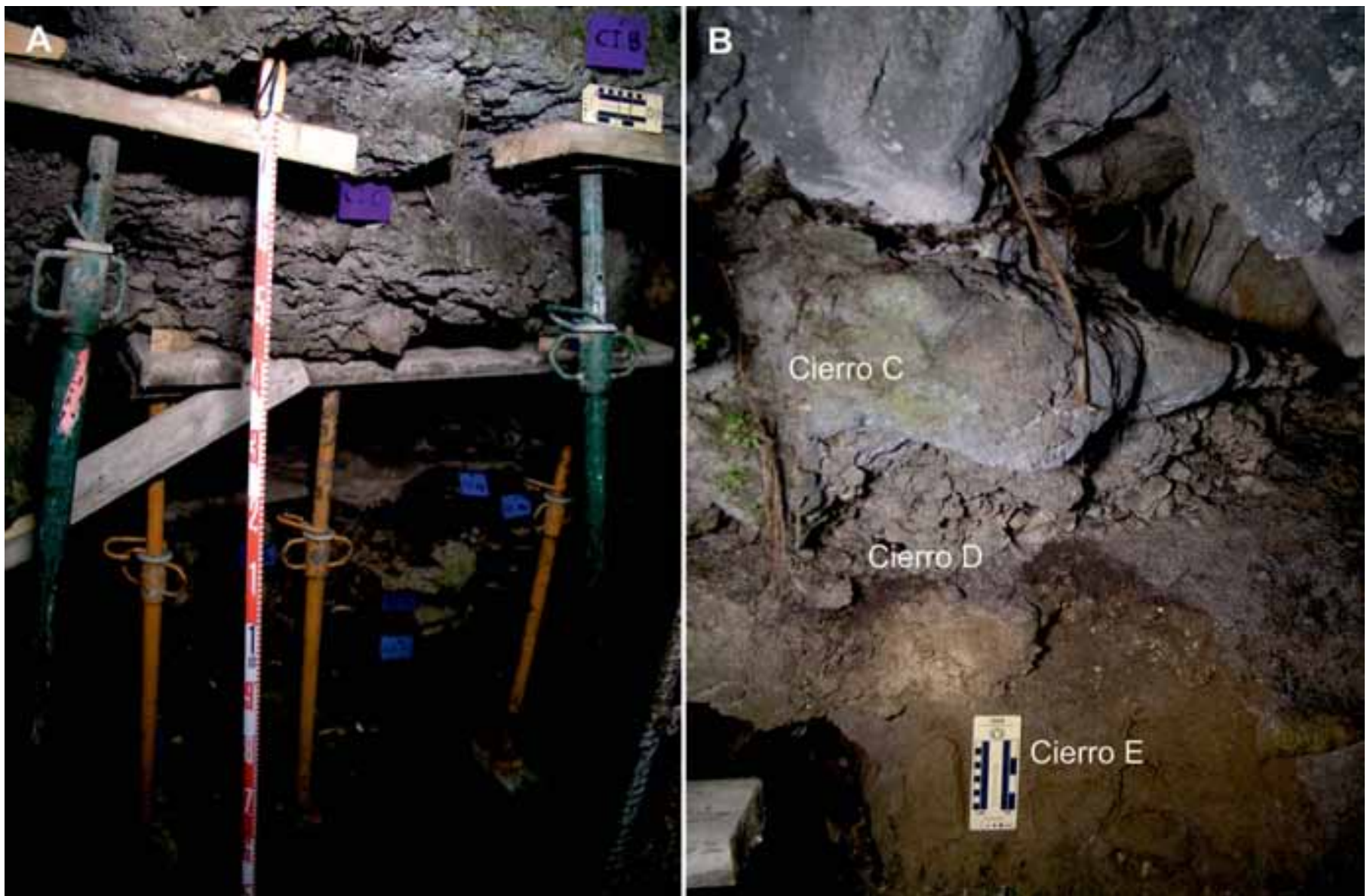

Figura 19. El Cierro. A) Aspecto general de la secuencia con los concheros a techo (foto JFJP). B) Detalle del los niveles Cierro E, Cierro D y Cierro C (foto JFJP).

Figure 19. The Cierro cave. A) Overview of the sequence with the shell midden at the top (photo by JFJP). B) Detail of levels Cierro E, Cierro $D$, and Cierro C (photo by JFJP). 
partir de una concha de Littorina littorea hemos obtenido la fecha OxA-27857 11.403 \pm 37 BP (Tabla1).

Podría corresponderse con la capa $2^{\mathrm{a}}$ de FJC que atribuye al Magdaleniense superior (Fig. 3 D, Tabla 2).

- Cierro C (35 a $40 \mathrm{~cm}$ ): Conchero de color blanquecino, muy rico en restos óseos de vertebrados con clastos de caliza autóctona (centil 15 $\mathrm{cm}$, media $2 \mathrm{~cm}$ ) y algún bloque de mayor tamaño (hasta $40 \mathrm{~cm}$ ). Los clastos son muy angulosos con las aristas vivas. Contiene restos de mamíferos con huesos largos dispuestos de manera horizontal o subhorizontal, así como abundantes conchas de invertebrados marinos y terrestres. El resultado es un conjunto de conchas y huesos unidos por carbonato cálcico con zonas donde apenas hay matriz y otras donde está es más abundante. A techo de Cierro C existe una zona menos cementada que está erosionada hacia adentro dando lugar a un socave en la zona de contacto con el conchero Cierro B (Figuras 19 A y 20 A). Al igual que le nivel anterior, contiene materiales arqueológicos que se pueden adscribir al Paleolítico superior final/Aziliense. De este nivel contamos con dos fechas (Tabla1), una la ya mencionada GaK$254810.400 \pm 500$ BP (Clark, 1983) y otra nueva, obtenida a partir de una concha de Patella vulgata, OxA-27856 $11.190 \pm 38$ BP.
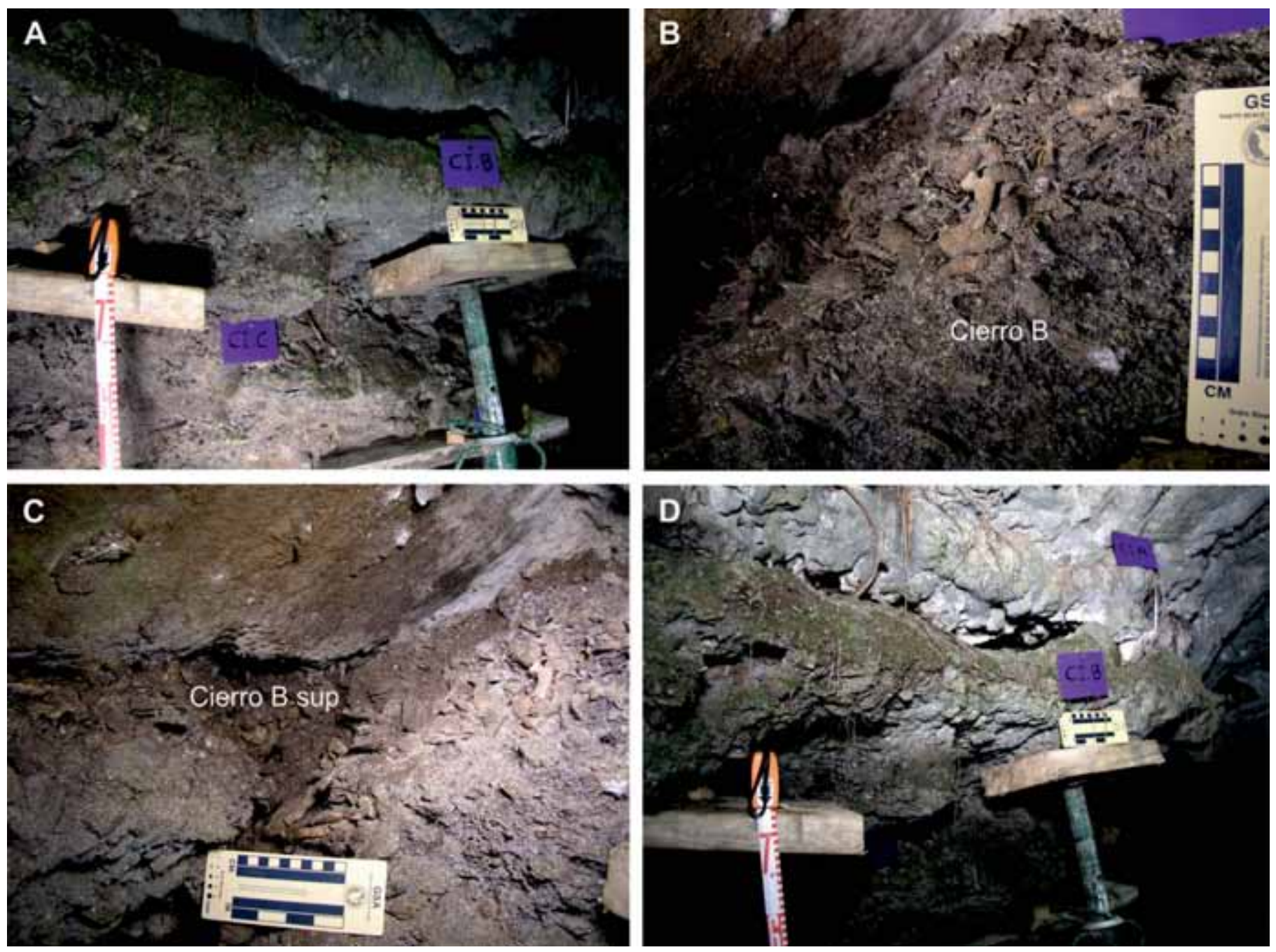

Figura 20. El Cierro. A) Detalle de los concheros Cierro C y Cierro B (foto JFJP). B) Detalle del conchero Cierro B. C) Detalle del nivel Cierro $B$ superior. D) Detalle del conchero Cierro B y del espeleotema Cierro A (foto JFJP).

Figure 20. The Cierro cave. A) Detail of shell middens Cierro C and Cierro B (photo JJP). B) Detail of shell midden Cierro B. C) Detail of Cierro $B$ sup. D) Detail of shell midden Cierro B and espeleothem Cierro A (photo by JFJP). 
Se corresponde con el conchero inferior del esquema estratigráfico de FJC (Fig. 3 D, Tabla 2).

- Cierro B (30 a $35 \mathrm{~cm}$ ): Conchero de color blanquecino, muy rico en restos de diferentes especies de Patella, fragmentos óseos alargados horizontales, así como de caparazones de equínidos y de valvas de mejillones (Fig. $20 \mathrm{~A}, \mathrm{~B}$ y D). Contiene escasos cantos de caliza, pequeños (centil $3 \mathrm{~cm}$ ) y angulosos. A techo del conchero Cierro $\mathrm{B}$ y en contacto con la roca del techo y la pared hay unos $5-10 \mathrm{~cm}$ de sedimento suelto formado por arcillas marrones-negras que denominamos Cierro B superior (Fig. 20 C). Estos depósitos se localizan en el sector oeste y hacen de plano de despegue del conchero respecto a la pared y el techo de tal forma que todo el conchero está desprendido de la roca de la cavidad, que es muy lisa y tiene pequeñas adherencias de conchero cementado. Actualmente en ella se generan estalactitas muy finas. En cuanto a su adscripción cronocultural, una datación radiocarbónica obtenida de una concha de $P$. lineatus ofrece la fecha OxA-31705 $8.575 \pm 40$ BP (Tabla1). Que sitúa a este nivel en el Mesolítico. Se corresponde con el conchero superior del esquema estratigráfico de FJC (Fig. 3 D, Tabla 2).

- Cierro A: Concreciones carbonatadas cenitales de color blanco y forma globular que enlazan con el conchero Cierro B y están en contacto con la pared y el techo rocoso de la cavidad (Fig. 20 D).

En la tabla 2 se muestra un ensayo de correlación de los niveles del corte oeste-este de la cueva de El Cierro según los diferentes autores con indicación de su correspondencia con la secuencia actualmente visible y descrita en este trabajo.

En otras zonas de la cavidad, como los accesos noreste y sur, se observan restos de los concheros adheridos a las paredes de la cueva, lo cual es indicativo de la gran extensión que llegó a tener en su día el registro sedimentario de la cavidad. Estos retazos de concheros serán objetos de futuras investigaciones.

\section{Análisis sedimentológicos y edafológicos}

\section{Granulometría}

Los análisis granulométricos de la secuencia de EI Cierro ofrecen unos resultados que a grandes rasgos permiten identificar dos grandes unidades sedimentarias: una inferior detrítica y otra superior, químicaorganogénica con sedimentos detríticos integrada por una sucesión de concheros ricos en huesos de vertebrados y en conchas y caparazones de invertebrados. En la granulometría global de la parte clástica de la secuencia (Tabla 3, Fig. 21 A) se observa una

\begin{tabular}{|l|l|l|l|l|}
\hline \multicolumn{7}{|c|}{ El Cierro. Granulometría global (\% en peso) } \\
\hline Muestras & Gravas & Arenas & Limos & Arcillas \\
\hline Cierro A & - & - & - & - \\
\hline Cierro B sup & - & - & - & - \\
\hline Cierro B & - & - & - & - \\
\hline Cierro C & - & - & - & - \\
\hline Cierro D & - & - & - & - \\
\hline Cierro E & 0.58 & 44.95 & 32.11 & 22.36 \\
\hline Cierro F & 0.76 & 44.49 & 27.05 & 27.70 \\
\hline Cierro G1 & 12.79 & 52.78 & 21.82 & 12.62 \\
\hline Cierro H1 & 12.51 & 52.68 & 18.93 & 15.88 \\
\hline Cierro H2 & 3.88 & 51.15 & 24.24 & 20.73 \\
\hline Cierro J1 & 2.28 & 31.29 & 29.58 & 36.95 \\
\hline Cierro J2 & 37.04 & 33.90 & 15.24 & 13.82 \\
\hline Cierro L & 2.84 & 31.14 & 25.38 & 40.63 \\
\hline Cierro M & 2,08 & 36.85 & 28.95 & 32.13 \\
\hline Cierro N & 1,97 & 25,49 & 39,51 & 33,03 \\
\hline
\end{tabular}

Tabla 3. El Cierro. Granulometría global de los diferentes niveles de la secuencia estratigráfica.

Table 3. The Cierro cave. Global granulometry of the different levels of the stratigraphic sequence. 


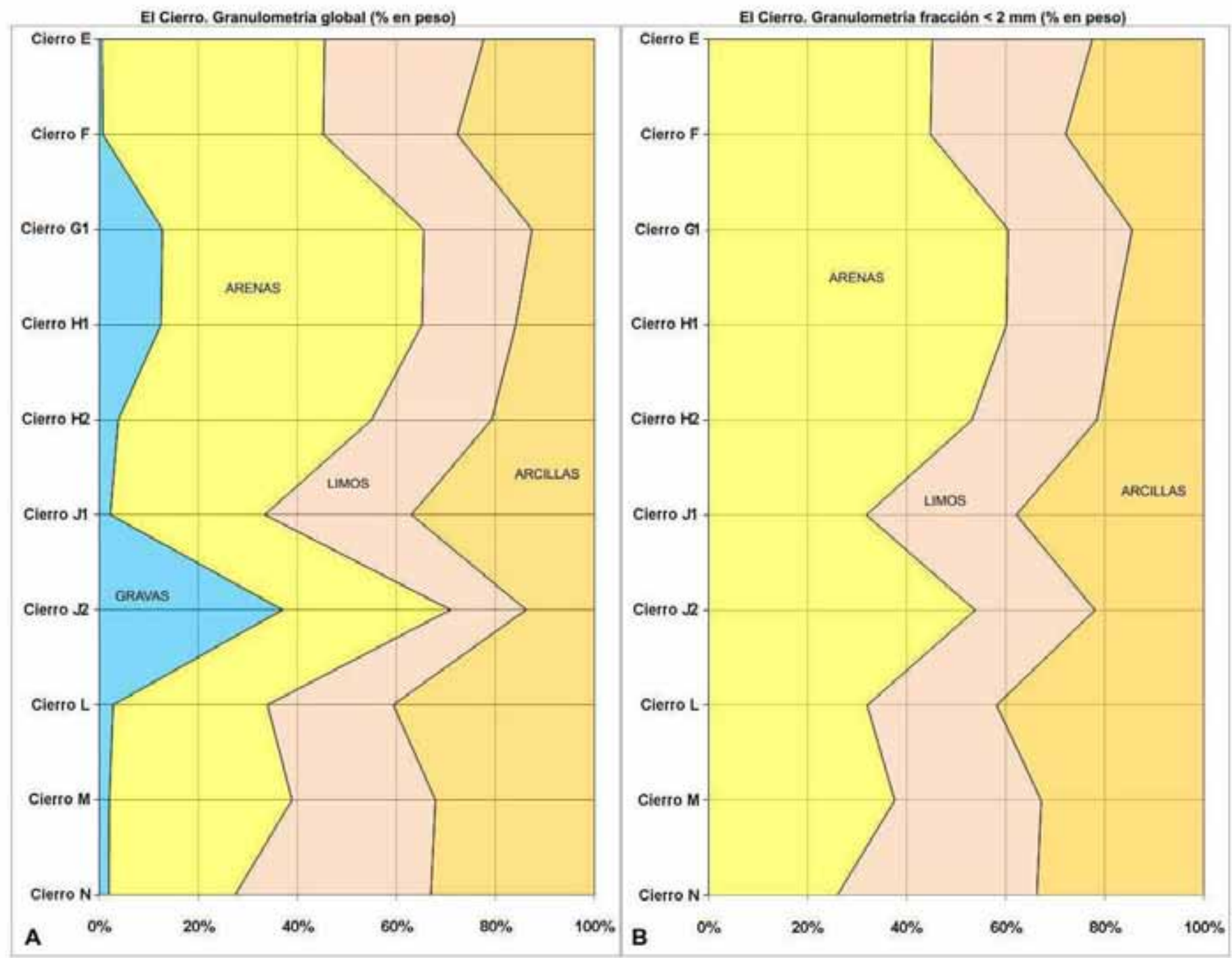

Figura 21. El Cierro. A) Diagrama acumulativo de la granulometría global. B) diagrama acumulativo de la fracción inferior a 2 mm (arenas, limos y arcillas).

Figure 21. The Cierro cave. A) Global granulometry cumulative diagram (gravel, sand, mud). B) Matrix granulometry, global diagram (sand, silt, clay).

tendencia ligeramente granocreciente, con un predominio de la fracción fina (limo y arcilla) en la base (Cierro N, Cierro M, Cierro L y Cierro J1) y una aumento de las arenas hacia la parte media (Cierro H2, Cierro $\mathrm{H} 1$ y Cierro G1), que vuelven a disminuir a techo (Cierro $\mathrm{F}$ y Cierro E). El tramo inferior lutítico está separado del más arenoso por un nivel (Cierro J2) rico en gravas (37\%) con las arenas y lutitas en proporciones similares. Exceptuando este episodio marcadamente detrítico, la secuencia experimenta un ligero aumento de las gravas de muro a techo (de Cierro $\mathrm{N}$ a Cierro $\mathrm{G} 1$ ) para caer a mínimos en los dos niveles superiores (Cierro $\mathrm{F}$ y Cierro E). El máximo arenoso lo presenta el nivel Cierro G1 con un $52,68 \%$ de arenas, mientras que el mínimo arenoso se encuentra en el nivel basal Cierro $\mathrm{N}$ con un $25,49 \%$. El máximo lutítico está en este nivel basal con un $72,54 \%$, mientras que el mínimo lo presenta el nivel Cierro J2 con un $29 \%$. A techo (Cierro F y Cierro E), la fracción fina (54\%) supera ligeramente a la arenosa (44\%). La granulometría de la fracción inferior a 2 $\mathrm{mm}$ (arena, limo y arcilla) sigue la misma tendencia y en ella se observa un aumento progresivo hacia el techo de las arenas, con un retroceso de las arenas en Cierro J1, para terminar en los dos niveles superiores (Cierro $\mathrm{F}$ y Cierro E) con un ligero predominio de limos y arcillas frente a las arenas (Fig. $21 \mathrm{~B}$ ).

Mediante el uso del programa GRADISTAT 5.0 

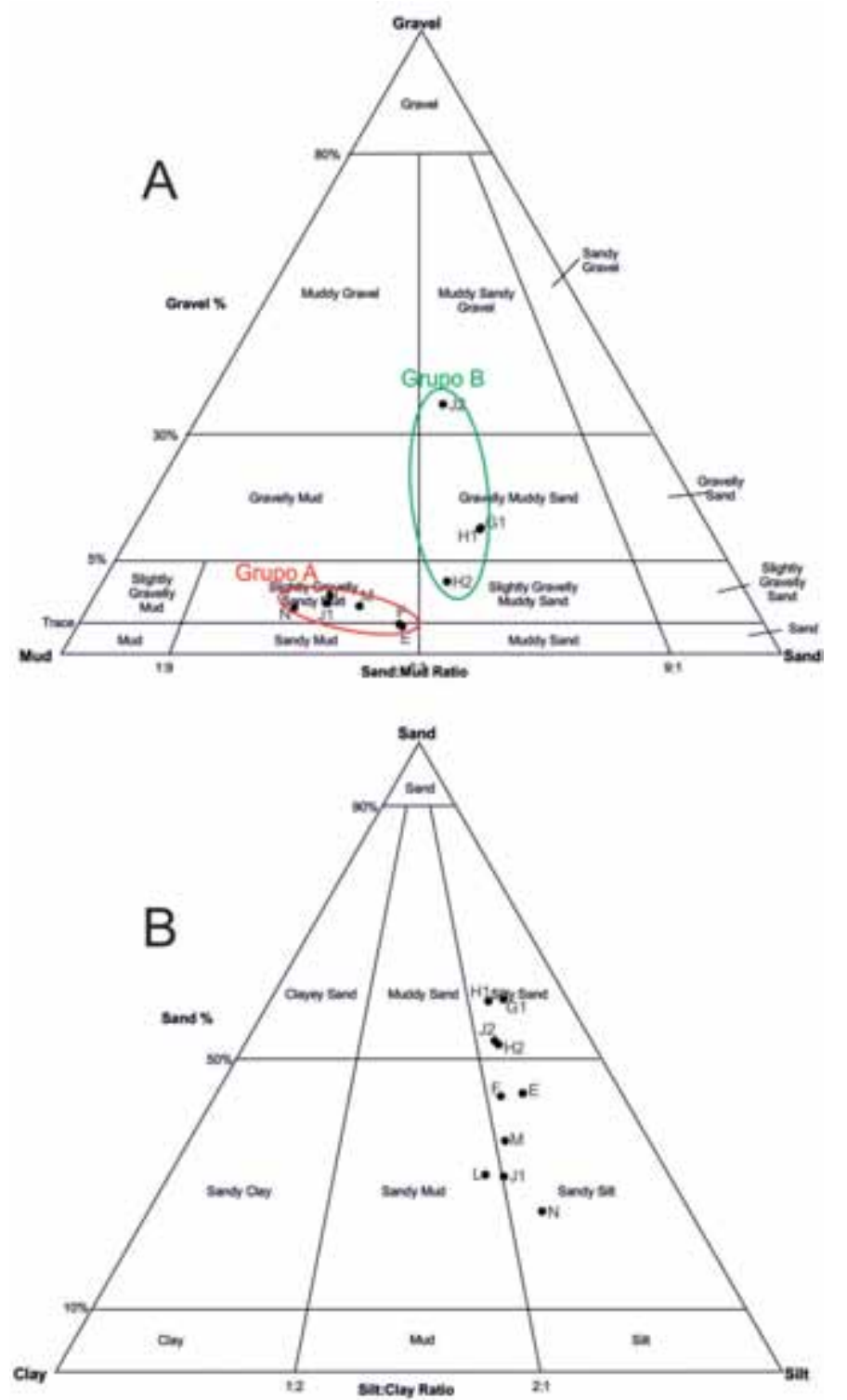

Figura 22. El Cierro. A) diagrama triangular gravas/arenas/lutitas de la granulometría global de los diferentes niveles muestreados en la secuencia litoestratigráfica, con indicación de las dos poblaciones granulométricas diferenciadas. B) diagrama triangular de la fracción inferior a $2 \mathrm{~mm}$ (arenas, limos y arcillas) de los diferentes niveles muestreados de la secuencia litoestratigráfica.

Figure 22. The Cierro cave. A) Triangular diagram (gravel, sand, mud) of the global granulometry of the samples from the different levels of the lithostratigraphic sequence, indicating two different granulometric populations. B) Triangular diagram (sand, silt, clay) of the matrix granulometry of the samples from the different levels of the lithostratigraphic sequence.

(Blott and Pye, 2001), podemos agrupar estadísticamente los sedimentos de las muestras detríticas analizadas en diferentes grupos texturales en función de la mayor o menor presencia de gravas, arenas y lutitas (limos y arcillas). Como se observa en el diagrama triangular (Fig. 22 A) que representa la granulometría global (gravas, arenas, lutitas) de las muestras, existe una gran homogeneidad en los sedimentos que componen los niveles de El Cierro, en los que, no obstante, se pueden diferenciar dos grupos de sedimentos:

- Grupo A, en el que los sedimentos se agrupan hacia el vértice de los fangos ( $m u d$ ) en el diagrama triangular $y$, más concretamente, en el grupo textural de los fangos arenosos con escasas gravas (slightly gravelly sandy mud) (Cierro J1, Cierro L, Cierro M y Cierro N) e incluso en el límite de este grupo textural con el de los fangos arenosos (sandy mud) (Cierro E y Cierro F). La presencia de arenas en este grupo está relacionada con flujos hídricos de escasa energía, mientras que la aparición de limos y arcillas lo está con procesos de decantación y/o infiltración gravitacional.

- Grupo B, en el que los sedimentos se agrupan hacia el vértice de las arenas en el diagrama triangular, con una muestra (Cierro $\mathrm{H} 2$ ) en el grupo textural de las arenas fangosas con escasas gravas (slightly gravelly muddy sand), dos muestras (Cierro G1 y Cierro H1) en el grupo de las arenas fangosas con gravas (gravelly muddy sand) y una muestra (Cierro J2) en el grupo de las gravas arenoso fangosas (muddy sandy gravel). La aparición de gravas está relacionada con la caída gravitacional de fragmentos de caliza y de espeleotema del techo de la cavidad. Al igual que en el grupo anterior, la presencia de arenas, limos y arcillas está en relación con flujos hídricos y procesos de decantación y/o infiltración.

Si prescindimos de la fracción grava y nos centramos en los tamaños de grano inferiores a $2 \mathrm{~mm}$ (arenas, limos y arcillas), la homogeneidad del sedimento de los distintos niveles aumenta, pues cinco muestras (Cierro E, Cierro F, Cierro J1, Cierro L, Cierro $\mathrm{M}$ y Cierro $\mathrm{N}$ ) se sitúan en los grupos de los limos arenosos (sandy silty), otras cuatro (Cierro G1, Cierro H1, Cierro $\mathrm{H} 2$ y Cierro J2) en el de las arenas limosas (silty sand) y una (Cierro $L$ ) en el de los fangos arenosos (sandy mud) (Fig. $22 \mathrm{~B}$ ).

Las curvas granulométricas de la fracción global son también bastante homogéneas, con una forma de tendencia sigmoidal que indica una sedimentación poligénica con arenas, limos y arcillas en diferentes proporciones, con escasa presencia de tamaños gruesos (> $2 \mathrm{~mm}$ ) salvo en Cierro J2 (Fig. 23). Las curvas de la fracción fina $(<2 \mathrm{~mm}$ ) son también muy homogéneas, aunque en ellas se puede diferenciar dos grupos (Fig. 24) que también se intuyen en las curvas de la fracción global (Fig. 23): 
- Uno formado por las muestras Cierro G1, Cierro $\mathrm{H} 1$, Cierro H2 y Cierro J2, con una presencia de arenas superior al $50 \%$, que responden a una sedimentación de arroyada difusa con flujos laminares de baja a moderada energía, acompañada por procesos posteriores de decantación, si bien los datos de campo apuntan a que los niveles Cierro J2, Cierro H1 y Cierro H2 fueron depositados por flujos densos.

- Otro integrado por las restantes muestras, en el que los limos y arcillas superan a las arenas, relacionado con flujos laminares de baja energía y coladas de barro de tipo mud flow.

En cuanto a los parámetros estadísticos (Folk and Ward, 1957) el tamaño medio de los sedimentos se sitúa entre los limos gruesos para los niveles inferiores (Cierro N, Cierro M, Cierro L, Cierro J2 y Cierro J1) y los limos muy gruesos y las arenas finas y muy finas de los niveles superiores (Cierro H2, Cierro H1, Cierro G1, Cierro F y Cierro E). La clasificación en general es mala y la secuencia analizada presenta sedimentos trimodales en los niveles inferiores (Cierro N, Cierro M, Cierro L y Cierro J1) y polimodades en el resto. Respecto a la asimetría, en la mayoría de los niveles (Cierro N, Cierro M, Cierro L, Cierro J1, Cierro H2, Cierro F y Cierro E) está ligeramente desplazada hacía los tamaños finos, mientras que en Cierro J2 se desplaza hacia tamaños más gruesos o incluso es simétrica en Cierro H1 y Cierro G1. Con relación a la curtosis, que describe la forma de la distribución de los sedimentos, los niveles centrales (Cierro H2, Cierro H1 y Cierro G1) presentan curvas marcadamente leptocúrticas indicativas de una elevada concentración de los sedimentos muy cerca de las medias de sus respectivas distribuciones, mientras que los niveles inferiores (Cierro N, Cierro M, Cierro J2 y Cierro J1) y superiores (Cierro $\mathrm{F}$ y Cierro E) las presentan platicúrticas y mesocúrticas, indicativas de una concentración de los sedimentos baja y media alrededor de los valores centrales de sus distribuciones.

\section{Mineralogía}

En cuanto a la composición mineralógica de la fracción fina de los diferentes niveles, en una primera aproximación se observan dos tramos bien diferenciados: uno inferior desde Cierro $\mathrm{N}$ hasta Cierro $\mathrm{E}$, en el que predominan los minerales insolubles en porcentajes comprendidos entre el 74 y el $90 \%$, y otro superior desde Cierro $D$ a Cierro A, donde los minerales solubles son mayoritarios en porcentajes comprendidos entre el 60 y el $98 \%$, exceptuando Cierro B sup donde estos descienden al $37 \%$ (Fig. 25).

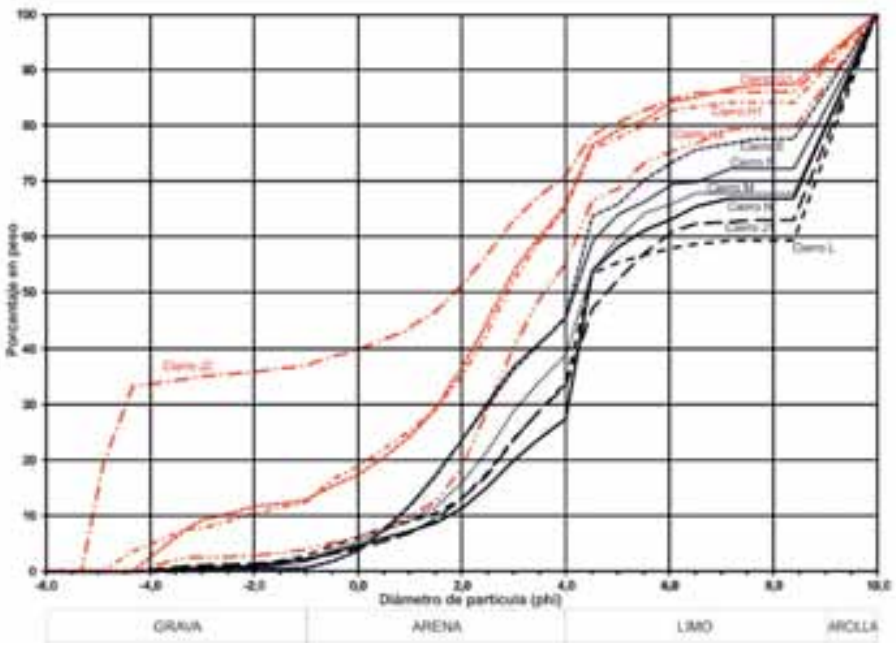

Figura 23. El Cierro. Curvas granulométricas de la fracción global de los diferentes niveles muestreados de la secuencia litoestratigráfica.

Figure 23. The Cierro cave. Granulometric curves of the global fraction of the samples from the different levels of the lithostratigraphic sequence.

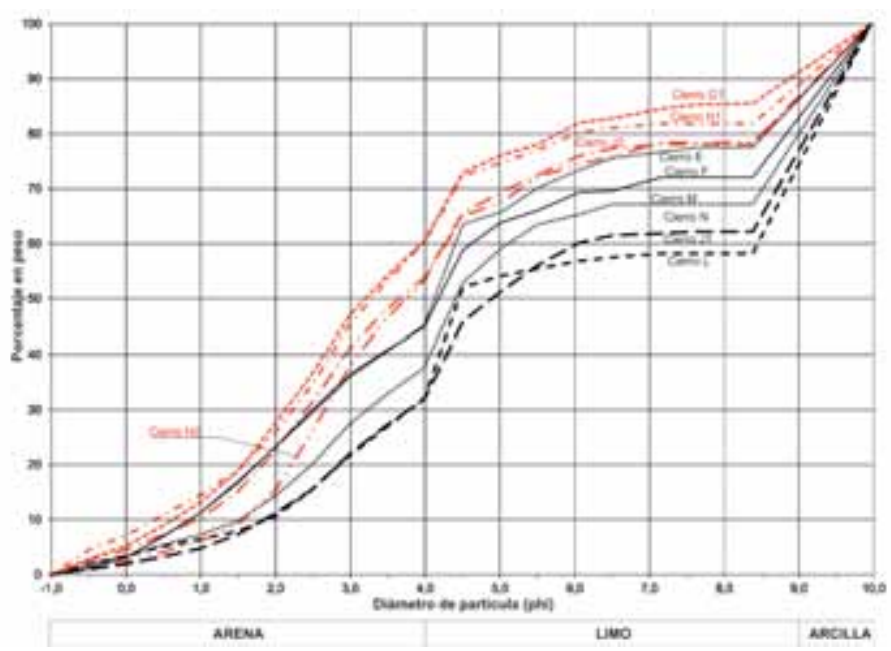

Figura 24. El Cierro. Curvas granulométricas de la matriz de los diferentes niveles muestreados de la secuencia litoestratigráfica. Figure 24. The Cierro cave. Granulometric curves of the matrix of the samples from the different levels of the lithostratigraphic sequence.

La mineralogía de los sedimentos de la fracción fina (limos y arcillas) es bastante homogénea cualitativamente en toda la secuencia, si bien se observan dos tramos claramente diferenciados desde el punto de vista cuantitativo (Tabla 4, Fig. 26). Los minerales predominantes son el cuarzo y la calcita y en función 
El Cierro. Residuo insoluble (\% en peso)

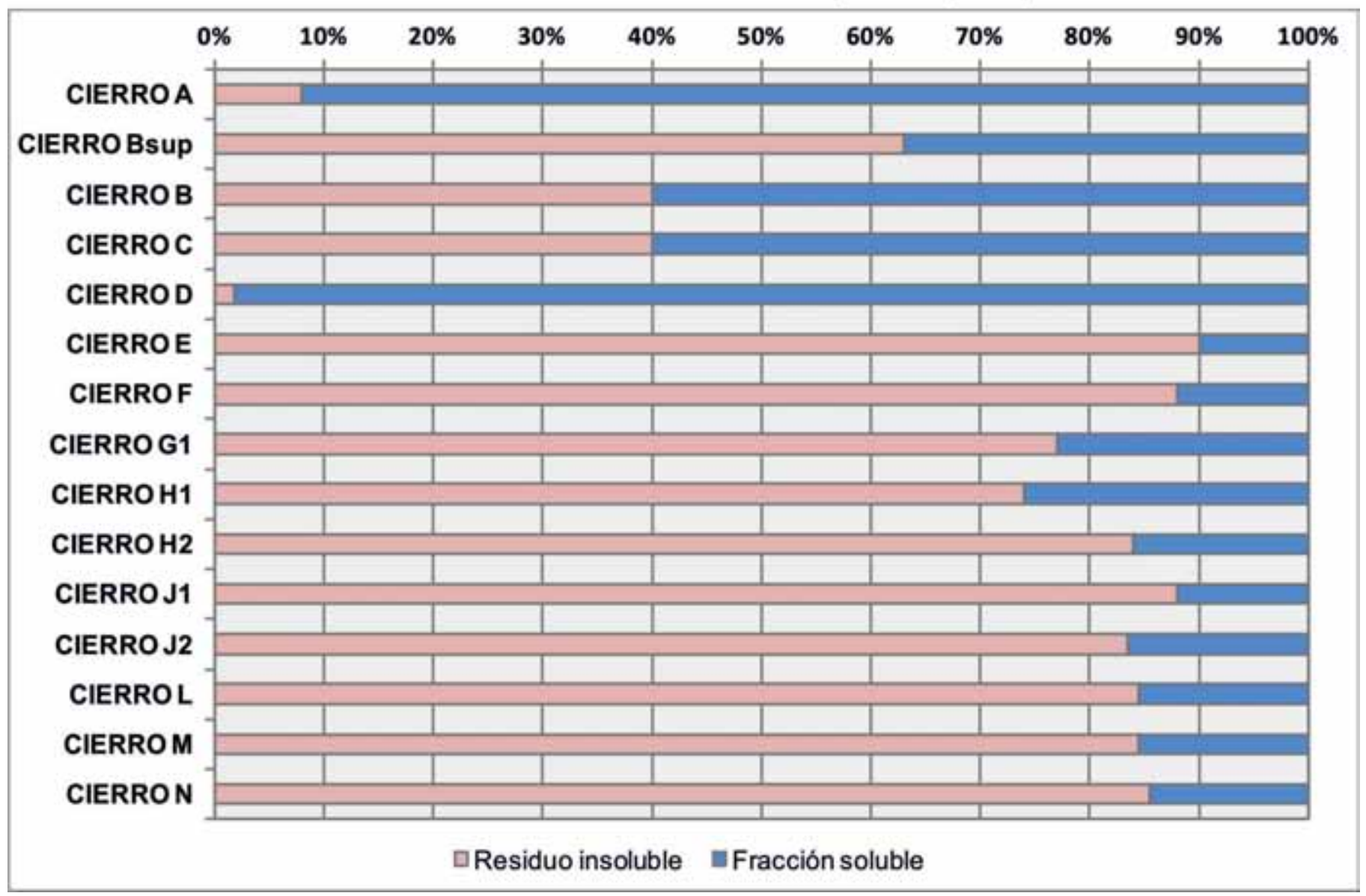

Figura 25. El Cierro. Relación entre minerales insolubles y solubles de la fracción inferior a 2 mm de los diferentes niveles muestreados de la secuencia litoestratigráfica.

Figure 25. The Cierro cave. Relationship between soluble and insoluble minerals of the matrix of the samples from the different levels of the lithostratigraphic sequence.

de su mayor o menor presencia se pueden establecer dos tramos: uno inferior (desde Cierro $\mathrm{N}$ a Cierro $\mathrm{E}$ ) constituido mayoritariamente por cuarzo con presencia de calcita excepto en tres niveles, y otro superior (desde Cierro $\mathrm{D}$ a Cierro A) con predominio de calcita y presencia de cuarzo desde proporciones bajas a medias. En el tramo inferior el cuarzo se encuentra en porcentajes superiores al $80 \%$ con máximos del 95, 89 y $93 \%$ en los niveles Cierro N, Cierro E y Cierro F, mientras que en el tramo superior oscila entre el mínimo de 1,60\% en Cierro $D$ y el máximo de $50 \%$ en Cierro B sup. El recorrido de la calcita es inverso, con ausencia en los tres niveles ricos en cuarzo del tramo inferior (Cierro N, Cierro F y Cierro E) y presencia inferior al $14 \%$ en el resto de niveles de este tramo, mientras que en el tramo superior predomina en Cierro D y Cierro A con porcentajes del $97,60 \%$ y $82,10 \%$ respectivamente, porcentajes que en los niveles centrales de este tramo oscilan entre $42,70 \%$ y $56,60 \%$. El feldespato sódico se encuentra en los niveles del tramo inferior, excepto en Cierro $\mathrm{N}$ y Cierro $M$, en porcentaje inferiores al $6 \%$, y en el nivel Cierro $\mathrm{C}$ del tramo superior. Las micas potásicas (moscovita) aparecen en todos los niveles en porcentajes inferiores al $7 \%$, excepto en Cierro G1 y Cierro $D$, donde está ausente. El residuo insoluble de Cierro D está formado mayoritariamente por cuarzo $(95,9 \%)$ al que acompañan feldespato sódico, yeso y amorfos. La caolinita únicamente aparece en Cierro G1 con un $2,60 \%$ mientras que el cloritoide lo hace en $\mathrm{H} 2$ con un $0,60 \%$. Los minerales opacos están presentes en toda la secuencia en porcentajes inferiores al $2 \%$.

Los minerales que aparecen en los distintos niveles (calcita, cuarzo, feldespatos potásico, caolinita y cloritoide) son frecuentes en depósitos detríticos de cavidades kársticas (Hill and Forti 1997). La presencia 


\begin{tabular}{|l|l|l|l|l|l|l|l|}
\hline \multicolumn{7}{|c|}{ EI Cierro. Mineralogía (DRX) } \\
\hline & CALCITA & CUARZO & FELDES Na & MICA K & CAOLINITA & CLORITOIDE & AMORFOS \\
\hline Cierro A & 82,10 & 16,90 & 0,00 & 0,00 & 0,00 & 0,00 & 1,00 \\
\hline Cierro B sup & 42,70 & 50,40 & 0,00 & 6,10 & 0,00 & 0,00 & 0,80 \\
\hline Cierro B & 55,60 & 36,80 & 0,00 & 6,30 & 0,00 & 0,00 & 1,30 \\
\hline Cierro C & 56,60 & 36,20 & 1,40 & 4,60 & 0,00 & 0,00 & 1,20 \\
\hline Cierro D & 97,60 & 1,60 & 0,00 & 0,00 & 0,00 & 0,00 & 0,80 \\
\hline Cierro E & 0,00 & 93,70 & 4,40 & 1,40 & 0,00 & 0,00 & 0,50 \\
\hline Cierro F & 0,00 & 89,00 & 5,70 & 4,40 & 0,00 & 0,00 & 0,90 \\
\hline Cierro G1 & 5,40 & 88,20 & 2,60 & 0,00 & 2,60 & 0,00 & 1,20 \\
\hline Cierro H1 & 9,90 & 81,70 & 5,80 & 1,70 & 0,00 & 0,00 & 0,90 \\
\hline Cierro H2 & 13,20 & 84,20 & 0,50 & 0,60 & 0,00 & 0,60 & 0,90 \\
\hline Cierro J1 & 3,10 & 92,50 & 3,50 & 0,30 & 0,00 & 0,00 & 0,60 \\
\hline Cierro J2 & 10,90 & 86,10 & 1,80 & 0,50 & 0,00 & 0,00 & 0,70 \\
\hline Cierro L & 4,30 & 90,10 & 3,00 & 1,80 & 0,00 & 0,00 & 0,80 \\
\hline Cierro M & 0,00 & 95,30 & 0,00 & 3,80 & 0,00 & 0,00 & 0,90 \\
\hline Cierro N & 4,50 & 89,80 & 0,00 & 4,50 & 0,00 & 0,00 & 1,20 \\
\hline
\end{tabular}

Tabla 4. El Cierro. Mineralogía (DRX) de la fracción inferior a $2 \mathrm{~mm}$ de los diferentes niveles muestreados de la secuencia.

Table 4. The Cierro cave. Mineralogy (XRD) of the fraction less than $2 \mathrm{~mm}$ of the different sampled levels of the stratigraphic sequence.

de minerales silicatados en la fracción fina de los sedimentos es compatible con la mineralogía de las rocas de las zonas del entorno de la cavidad y básicamente corresponde a tectosilicatos y filosilicatos de origen alóctono, dado que la caliza en la que se desarrolla la cavidad es muy pura y está formada exclusivamente por calcita. Los niveles del tramo inferior contienen calcita de carácter autóctono, relacionada con la presencia de clastos de caliza en esos mismos niveles, mientras que la calcita del tramo superior tiene su origen en procesos de precipitación química. Por último, la DRX detecta la presencia de compuestos amorfos en toda la secuencia con valores inferiores al $2 \%$, compuestos que pueden corresponder a minerales amorfos o bien a restos de materia orgáni$\mathrm{ca}$, constituyentes únicos del residuo insoluble de las calizas en las que se abre la cavidad.

\section{Análisis edafológicos}

A partir de la determinación del color de los sedimentos de la secuencia de El Cierro observamos una

Figura 26. El Cierro. Diagrama acumulativo de la mineralogía (DRX) de la matriz de los diferentes niveles muestreados de la secuencia litoestratigráfica.

Figure 26. The Cierro cave. Cumulative diagram showing the mineralogy $(X R D)$ of the matrix of the samples from the different levels of the lithostratigraphic sequence.

\section{El Cierro. Mineralogia (DRX)}

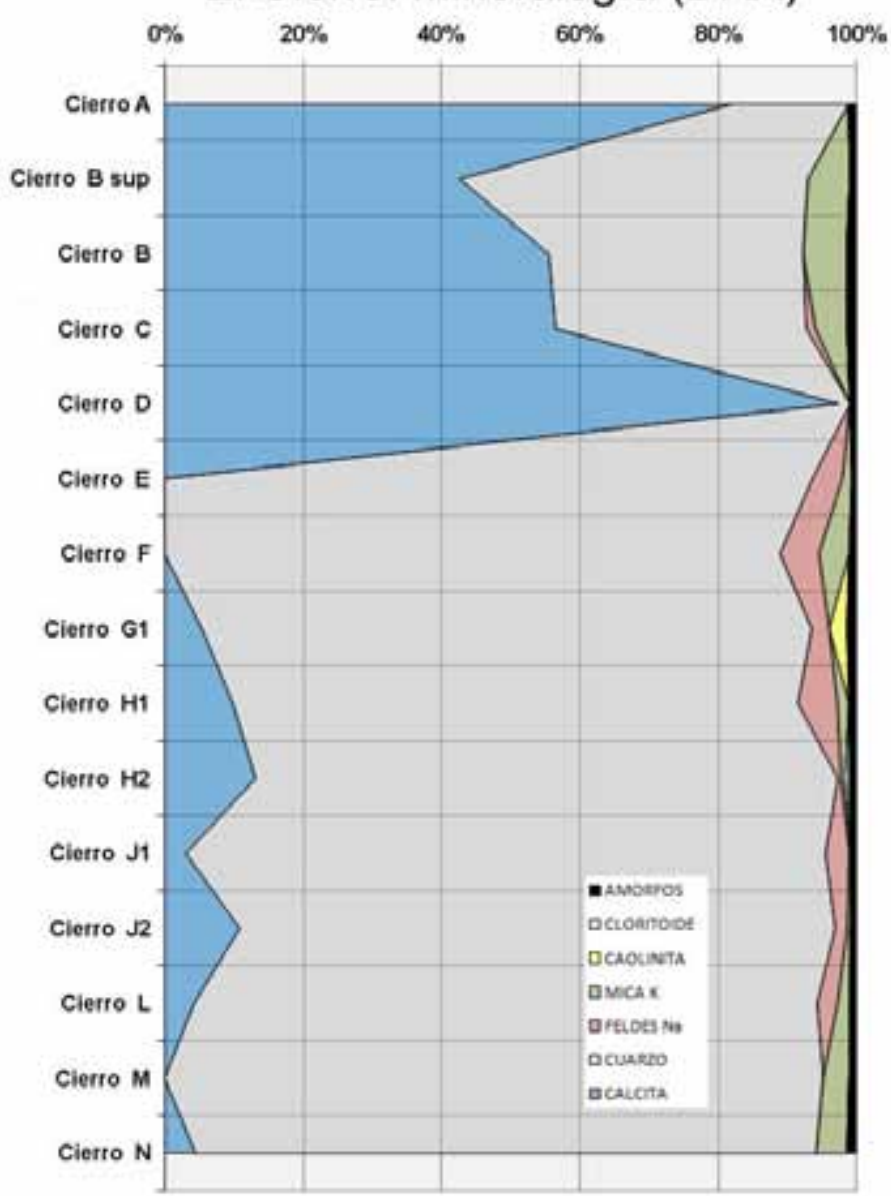


cierta diferencia entre los colores de los distintos niveles de la secuencia (Tabla 5). Desde Cierro M hasta Cierro $\mathrm{E}$, los colores son grises y marrones, más o menos intensos, con matiz 10YR, valores de brillo desde bajos a altos (entre 3 y 6) y valores bajos, medios y altos de croma (entre 2 y 6). Los niveles Cierro $\mathrm{N}$ y Cierro J2 tienen una coloración gris amariIlenta, con matiz 7,5YR y valores de brillo medios (4) y croma altos (6). El nivel Cierro D, que forma parte ya del conchero, tiene una coloración más clara, en la gama del beige, con matiz $2,5 \mathrm{YR}$ y valores altos de brillo (6) y bajos de croma (2).

La acidez de los sedimentos expresada a través del $\mathrm{pH}$ corresponde a valores ligeramente básicos situados entre 7,5 y 8,5 (Tabla 6, Fig. 27), que a lo largo de la secuencia permiten establecer tres tramos: uno inferior entre Cierro $\mathrm{N}$ y Cierro $\mathrm{H} 1$ con valores ligeramente inferiores a 8 excepto en Cierro J1 que sobrepasa 8 , otro medio, entre Cierro $\mathrm{H} 2$ y Cierro $\mathrm{D}$, con valores entre 8 y 8,5 que tienen su máximo en Cierro $E(8,21)$, y finalmente uno superior, entre Cierro $C$ y Cierro A, de nuevo por debajo de 8, excepto en Cierro $B$ sup donde se supera ligeramente 8.

La materia orgánica (Tabla 7, Fig. 28) está formada por los restos y productos de transformación de plantas y animales y aparece representada en todos los

\begin{tabular}{|c|c|}
\hline \multicolumn{2}{|c|}{ El Cierro. Color en seco } \\
\hline Muestras & color \\
\hline Cierro A & - \\
\hline Cierro B sup & - \\
\hline Cierro B & - \\
\hline Cierro C & - \\
\hline Cierro D & $2,5 Y R \quad 6 / 2$ \\
\hline Cierro E & 10YR 5/6 \\
\hline Cierro F & 10YR 5/2 \\
\hline Cierro G1 & 10YR $3 / 3$ \\
\hline Cierro H1 & 10YR $3 / 3$ \\
\hline Cierro H2 & 10YR $4 / 3$ \\
\hline Cierro J1 & 7,5YR 4/6 \\
\hline Cierro J2 & 10YR $6 / 4$ \\
\hline Cierro L & 10YR 5/6 \\
\hline Cierro M & 10YR 4/4 \\
\hline Cierro N & 7,5YR 4/6 \\
\hline
\end{tabular}

Tabla 5. El Cierro. Determinación del color de los diferentes niveles muestreados de la stratigraphic secuencia mediante el uso de las Munsell Soil Color Charts (Munsell, 1981).

Table 5. The Cierro cave. Colour determination of the different levels of the stratigraphic sequence using the Munsell Soil Color Charts (Munsell, 1981). niveles excepto en Cierro J1 donde no aparece. En el tramo detrítico inferior, entre Cierro $\mathrm{N}$ y Cierro $\mathrm{E}$, sus valores son inferiores al $5 \%$, con tres máximos en Cierro M (1,70 \%), Cierro H1 (4,04 \%) y Cierro G1 $(3,64$ $\%)$. Los niveles del conchero experimentan un aumento de materia orgánica desde Cierro $D$ hasta Cierro $B$, nivel este que alcanza el máximo absoluto de la secuencia con un 12,91\%, para volver a caer a valores mínimos en Cierro $A$.

El carbono orgánico (Tabla 7, Fig. 28) tiene una trayectoria paralela a la de la materia orgánica con valores ligeramente inferiores a los de ésta, con los tres máximos del tramo inferior en Cierro $\mathrm{M}(0,98 \%)$, Cierro H1 (4,04 \%) y Cierro G1 $(2,11 \%)$, y un aumento en la parte media del conchero que alcanza un máximo en Cierro B con 7,49 \%.

El carbonato cálcico (Tabla 7, Fig. 28) presenta una tendencia muy clara: desde el nivel Cierro $\mathrm{N}$ de la base del tramo detrítico inferior y el nivel Cierro $D$ de la base del conchero está presente de manera casi testimonial con valores en torno a 0,2 \%, mientras que en el resto de niveles del conchero experimenta un fuerte incremento en Cierro $C(47,12 \%)$ y Cierro B $(43,74 \%)$, una ligera caída en Cierro B sup $(16,50 \%)$ y un máximo en Cierro A $(78,22 \%)$.

La tendencia que experimenta la materia orgánica a lo largo de la secuencia es paralela a las del carbo-

\begin{tabular}{|l|l|}
\hline \multicolumn{2}{|c|}{ El Cierro. pH en H20 } \\
\hline Muestras & pH \\
\hline Cierro A & 7,62 \\
\hline Cierro B sup & 8,03 \\
\hline Cierro B & 7,87 \\
\hline Cierro C & 7,93 \\
\hline Cierro D & 8,14 \\
\hline Cierro E & 8,21 \\
\hline Cierro F & 8,12 \\
\hline Cierro G1 & 8,00 \\
\hline Cierro H1 & 8,01 \\
\hline Cierro H2 & 7,94 \\
\hline Cierro J1 & 7,74 \\
\hline Cierro J2 & 8,08 \\
\hline Cierro L & 7,88 \\
\hline Cierro M & 7,95 \\
\hline Cierro N & 7,86 \\
\hline
\end{tabular}

Tabla 6. El Cierro. Determinación de la acidez $(\mathrm{pH})$ de los diferentes niveles muestreados de la secuencia.

Table 6. The Cierro cave. Determination of acidity $(\mathrm{pH})$ of the different levels of the stratigraphic sequence. 


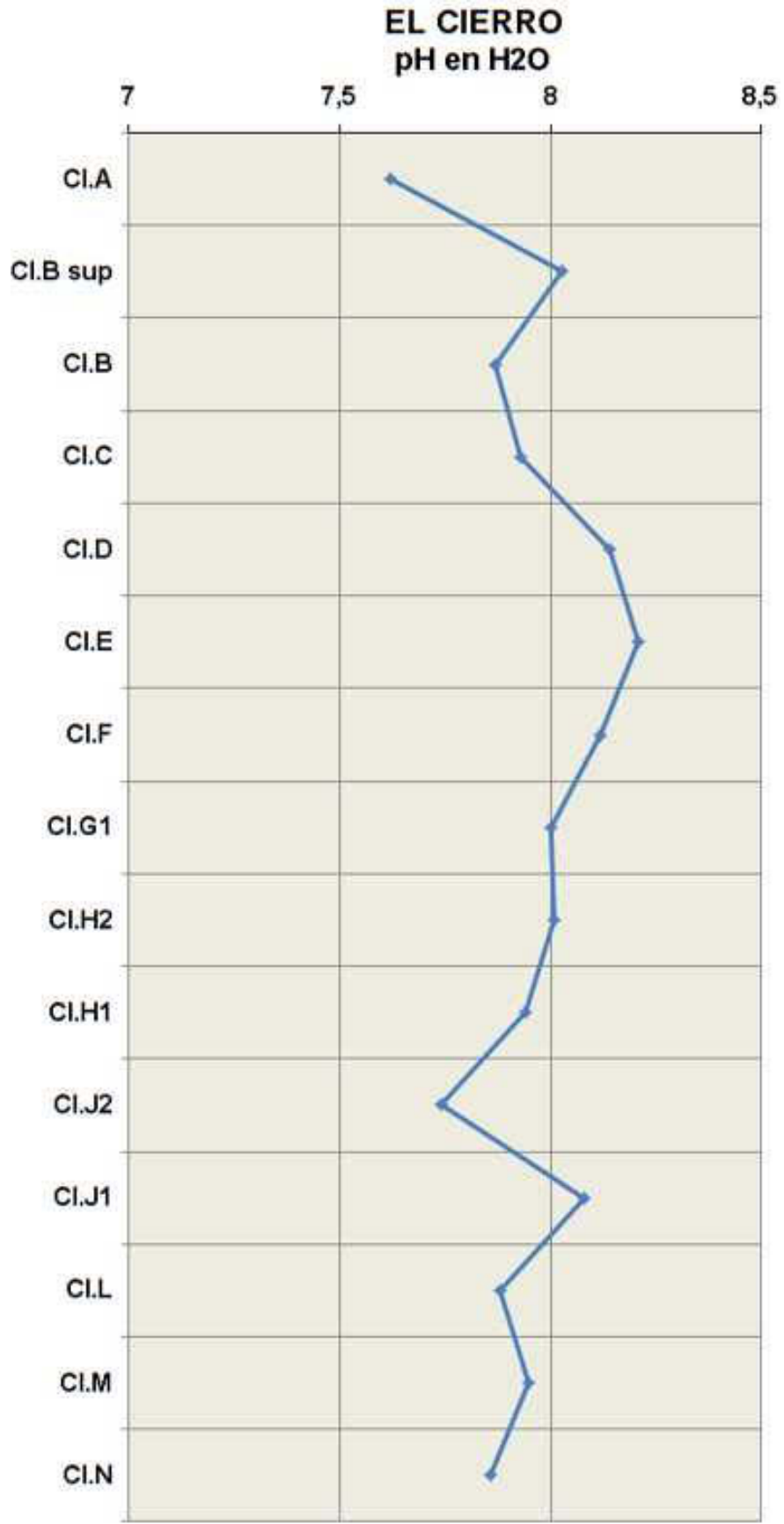

Figura 27. El Cierro. Valores de la acidez $(\mathrm{pH})$ medida en los materiales de los diferentes niveles muestreados de la secuencia litoestratigráfica.

Figure 27. The Cierro cave. Acidity $(\mathrm{pH})$ measured in the samples from the different levels of the lithostratigraphic sequence.

no orgánico, con coincidencias claras entre los máximos y los mínimos de ambos componentes analizados. También existe una buena correspondencia entre las tendencias de la materia orgánica y el carbono orgánico con la del carbonato cálcico, si bien apenas

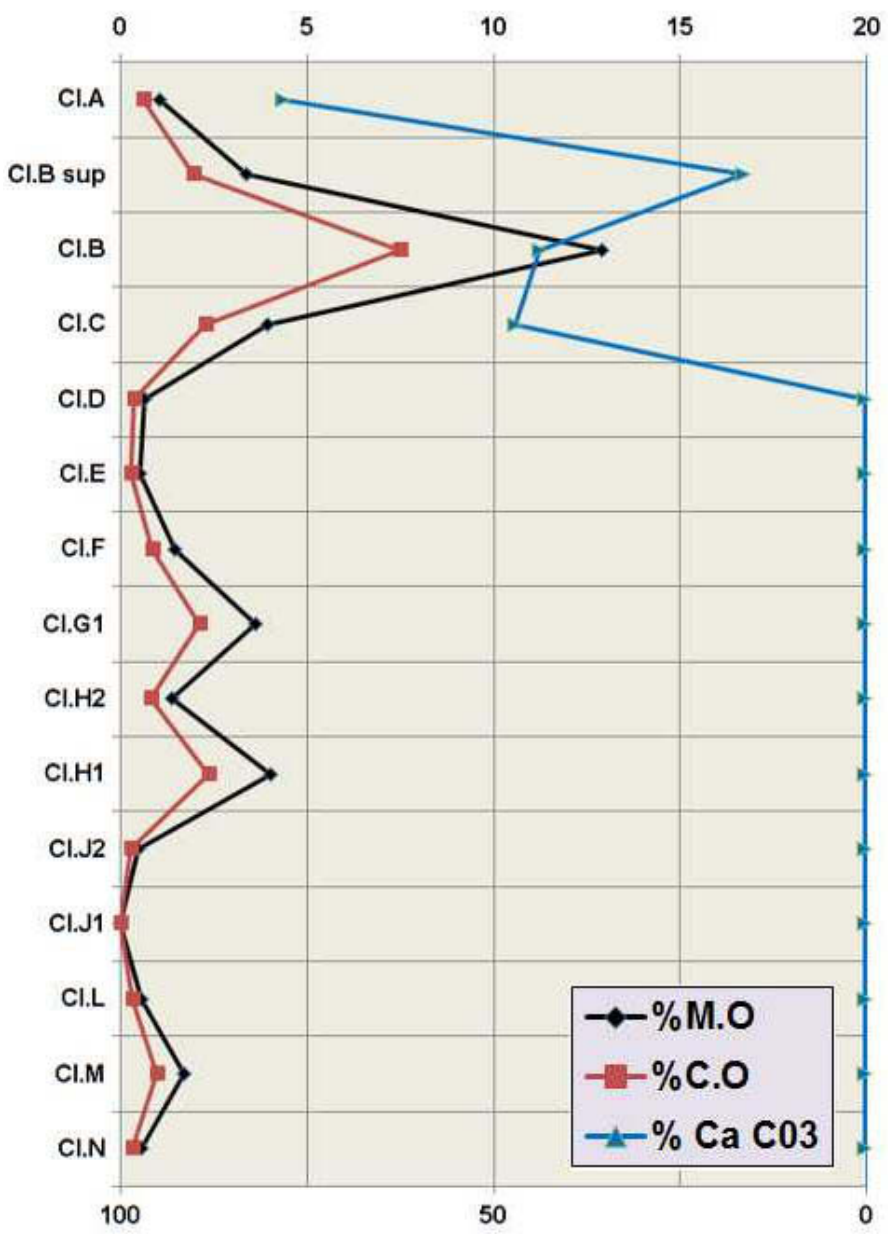

Figura 28. El Cierro. Valores (\%) del carbono orgánico, materia orgánica y carbonato cálcico medidos en los materiales de los diferentes niveles muestreados de la secuencia litoestratigráfica.

Figure 28. The Cierro cave. Values (\%) of organic carbon, organic matter, and calcium carbonate measured in the samples from the different levels of the lithostratigraphic sequence.

está presente en el tramo detrítico inferior de la secuencia (Tabla 7, Fig. 28), hecho este que concuerda con su carácter siliciclástico.

Los valores que ofrecen los análisis de conductividad eléctrica, sales, concentración de cationes y presión osmótica (Tabla 8) presentan valores constantes a lo largo de toda la secuencia con un marcado máximo en Cierro $A$ y valores ligeramente más altos en Cierro J2 y Cierro D.

\section{Cronoestratigrafía de la secuencia}

\section{Las dataciones radiocarbónicas y su calibración}

Como hemos visto, hasta el momento contamos con siete dataciones radiocarbónicas para la secuencia 
Jordá Pardo, J.F., et al., 2018. Al oeste del Sella. Geoarqueología y cronoestratigrafía... Boletín Geológico y Minero, 129 (1/2): $207-250$

\begin{tabular}{|l|l|l|l|}
\hline \multicolumn{4}{|c|}{ El Cierro. Materia orgánica, carbono orgánico y carbonato cálcico } \\
\hline Muestras & $\%$ M.O & $\%$ C.O & $\%$ Ca C03 \\
\hline Cierro A & 1,05 & 0,61 & 78,22 \\
\hline Cierro B sup & 3,38 & 1,96 & 16,50 \\
\hline Cierro B & 12,91 & 7,49 & 43,74 \\
\hline Cierro C & 3,95 & 2,29 & 47,12 \\
\hline Cierro D & 0,64 & 0,37 & 0,23 \\
\hline Cierro E & 0,51 & 0,30 & 0,26 \\
\hline Cierro $\mathbf{F}$ & 1,47 & 0,85 & 0,20 \\
\hline Cierro G1 & 3,64 & 2,11 & 0,24 \\
\hline Cierro H1 & 1,38 & 0,80 & 0,21 \\
\hline Cierro H2 & 4,04 & 2,34 & 0,20 \\
\hline Cierro J1 & 0,50 & 0,29 & 0,22 \\
\hline Cierro J2 & 0,00 & 0,21 \\
\hline Cierro $\mathbf{L}$ & 0,00 & 0,32 & 0,20 \\
\hline Cierro $\mathbf{M}$ & 0,55 & 0,98 & 0,24 \\
\hline Cierro N & 1,70 & 0,34 & 0,23 \\
\hline
\end{tabular}

Tabla 7. El Cierro. Determinación de la materia orgánica, carbono orgánico y carbonato cálcico de los diferentes niveles muestreados de la secuencia.

Table 7. The Cierro cave. Determination of organic matter, organic carbon, and calcium carbonate of different levels of the stratigraphic sequence.

arqueológica de El Cierro. Una de ellas es la obtenida por Clark del conchero, Gak-2548 $10.712 \pm 515$ BP (Clark, 1983), mientras que las otras seis son las obtenidas por nosotros en ORAU (Tablas 1 y 9) (ÁlvarezFernández et al., 2016 en prensa). Las seis dataciones de ORAU cubren los niveles de la parte superior de la secuencia estratigráfica de El Cierro (Cierro G1, Cierro G, Cierro F, Cierro D, Cierro C y Cierro B sup) y todas ellas presentan una correcta ordenación en la secuencia, sin que se observen inversiones. Respecto a los niveles inferiores (desde Cierro $\mathrm{N}$ hasta Cierro H1), recientemente hemos enviado a ORAU muestras para su datación y estamos a la espera de los resultados.

Una vez obtenidas las fechas las hemos sometido a un examen de validez (Mestres, 1995, 2000, 2003, 2008) para comprobar que cumplen los requisitos fundamentales para su posterior tratamiento e interpretación. Estos requisitos son de orden químico-físico, de orden analítico y de orden arqueológico. Los de orden químico-físicos se refieren a la capacidad de un material para proporcionar una fecha radiocarbónica válida. En el caso de las siete muestras de El Cierro, todas ellas corresponden a materiales orgánicos (conchas, fragmentos óseos y fragmento de carbón) que cumplen perfectamente estos requisitos. Los requisitos de orden analítico que deben respetar las fechas radiocarbónicas son los de exactitud (eliminación de la contaminación, tratamiento químico y medida del contenido en radiocarbono) y precisión (desviación típica) y están relacionados con la calidad de los laboratorios. En este sentido consideramos que ORAU cumple el requisito de exactitud pues sigue unos protocolos muy estrictos (Brock et al., 2010; Douka et al., 2010). Por el contrario, el laboratorio de radiocarbono de la Universidad de Gakushuin (GaK), donde Clark obtuvo la fecha del conchero (Clark, 1983), ha sido cuestionado por algunos investigadores esgrimiendo que proporciona fechas poco fiables (Rodríguez Vinceiro and Márquez Romero, 2003), en ocasiones demasiado envejecidas (Ferrer Palma and Crespo Santiago, 2005). Por tanto, esta datación la valoraremos con la debida precaución. EI requisito de precisión que deben cumplir las fechas radiocarbónicas es que su desviación típica sea lo más pequeña posible. Este requisito lo cumplen las fechas proporcionadas por ORAU, dado que todas las desviaciones típicas son menores de 100 años y de ellas, cuatro son iguales o menores de 55 años y dos son iguales a 75 años. Por el contrario, la fecha GaK presenta una desviación típica de 500 años que la hacen inadecuada para su comparación con las fechas obtenidas actualmente por AMS. Finalmente, en el orden arqueológico, las fechas radiocarbónicas deben cumplir el requisito de que sean representativas de los acontecimientos que se pretenden datar, es decir que exista una buena correspondencia entre la fecha física del material datado y la fecha arqueológica del contexto o acontecimiento que se pretende 
Jordá Pardo, J.F., et al., 2018. Al oeste del Sella. Geoarqueología y cronoestratigrafía... Boletín Geológico y Minero, 129 (1/2): $207-250$

\begin{tabular}{|l|l|l|l|l|}
\hline \multicolumn{6}{|l}{ El Cierro. Conductividad eléctrica, sales, concentración de cationes y presión osmótica } \\
\hline Muestras & CE (dS/m) & Sales $\mathbf{( m g} / \mathbf{l})$ & CC (cmol +/kg) & PO (atm) \\
\hline Cierro A & 0,55 & 0,354 & 5,53 & 0,199 \\
\hline Cierro B sup & 0,15 & 0,099 & 1,54 & 0,055 \\
\hline Cierro B & 0,16 & 0,103 & 1,62 & 0,058 \\
\hline Cierro C & 0,13 & 0,086 & 1,34 & 0,048 \\
\hline Cierro D & 0,18 & 0,117 & 1,84 & 0,066 \\
\hline Cierro E & 0,07 & 0,046 & 0,71 & 0,026 \\
\hline Cierro F & 0,08 & 0,051 & 0,80 & 0,029 \\
\hline Cierro G1 & 0,11 & 0,068 & 1,07 & 0,038 \\
\hline Cierro H1 & 0,13 & 0,084 & 1,31 & 0,047 \\
\hline Cierro H2 & 0,093 & 1,45 & 0,052 \\
\hline Cierro J1 & 0,15 & 0,115 & 1,79 & 0,064 \\
\hline Cierro J2 & 0,18 & 0,108 & 1,69 & 0,061 \\
\hline Cierro L & 0,17 & 0,092 & 1,63 & 0,059 \\
\hline Cierro M & 0,16 & 0,074 & 1,43 & 0,052 \\
\hline Cierro N & 0,14 & 1,15 & 0,041 \\
\hline
\end{tabular}

Tabla 8. El Cierro. Determinación de la conductividad eléctrica, sales, concentración de cationes y presión osmótica de los de los diferentes niveles muestreados de la secuencia.

Table 8. The Cierro cave. Determination of electrical conductivity, salts, cation concentration, and osmotic pressure of the different levels of the stratigraphic sequence.

datar. Para que una fecha sea representativa debe cumplir dos condiciones necesarias: en primer lugar, que el material mismo o su presencia en el contexto arqueológico sea producto de la actividad biológica o técnica del grupo humano que creó el contexto (asociación) y, en segundo lugar, que su formación sea contemporánea al grupo humano que creó el contexto arqueológico (sincronía). En cuanto a la asociación, no parece existir duda razonable de que la materia orgánica que constituye las seis muestras datadas no sea producto de la actividad antrópica desarrollada en los diferentes niveles del yacimiento. Respecto a la sincronía, todas las muestras datadas en ORAU corresponden a restos de organismos de vida corta (cérvidos y gasterópodos marinos), por lo que podemos considerarlas sincrónicas a la actividad antrópica que las depositó. De la fecha GaK no conocemos la identificación de la especie vegetal correspondiente a la muestra carbonosa datada pues no se indica en la publicación (Clark, 1983) y tampoco conocemos su posición exacta en el conchero, pero que por la huella dejada por la extracción de una antigua muestra podría corresponder al nivel Cierro C.

Para obtener las fechas calibradas hemos procedido al calibrado de las fechas ${ }^{14} \mathrm{C}$ convencionales mediante las curvas de calibración IntCal 13 (Reimer et al., 2013) y CalPal 2007 Hulu (Weninger and Jöris, 2008), incluidas ambas en el software CalPal (Version 2013) (Weninger and Jöris, 2004). En la tabla 9 mos- tramos los resultados de las siete fechas radiocarbónicas, indicando las fechas ${ }^{14} \mathrm{C}$ convencionales acompañadas de su incertidumbre expresada como la desviación típica de su distribución de probabilidad y los resultados de la calibración de las mismas. Se indican las fechas calibradas correspondientes a los intervalos centrados en las modas de la distribución de probabilidad de la fecha calibrada verdadera correspondientes a una probabilidad total del 95\% (calibración $2)$, expresadas como fechas cal. BP $(0=A D$ 1950).

La figura 29 muestra la curva de probabilidad acumulada global obtenida a partir de la calibración con ambas curvas (IntCal 13 y CalPal 2007) de todas las fechas radiocarbónicas de El Cierro mientras que en la figura 30 se ofrecen las curvas de probabilidad acumulada obtenidas a partir de la calibración de las fechas radiocarbónicas por niveles arqueológicos y procedimientos utilizados (convencional y AMS). En ambas figuras la calibración se ha realizado utilizando el programa CalPal (Version 2013).

\section{Situación cronoestratigráfica de los niveles datados y propuesta para el tramo inferior de la secuencia}

Para situar la secuencia estratigráfica del yacimiento de El Cierro en la escala cronoestratigráfica global del Pleistoceno superior final manejada actualmente y basada en los Greenland Events detectados en los 


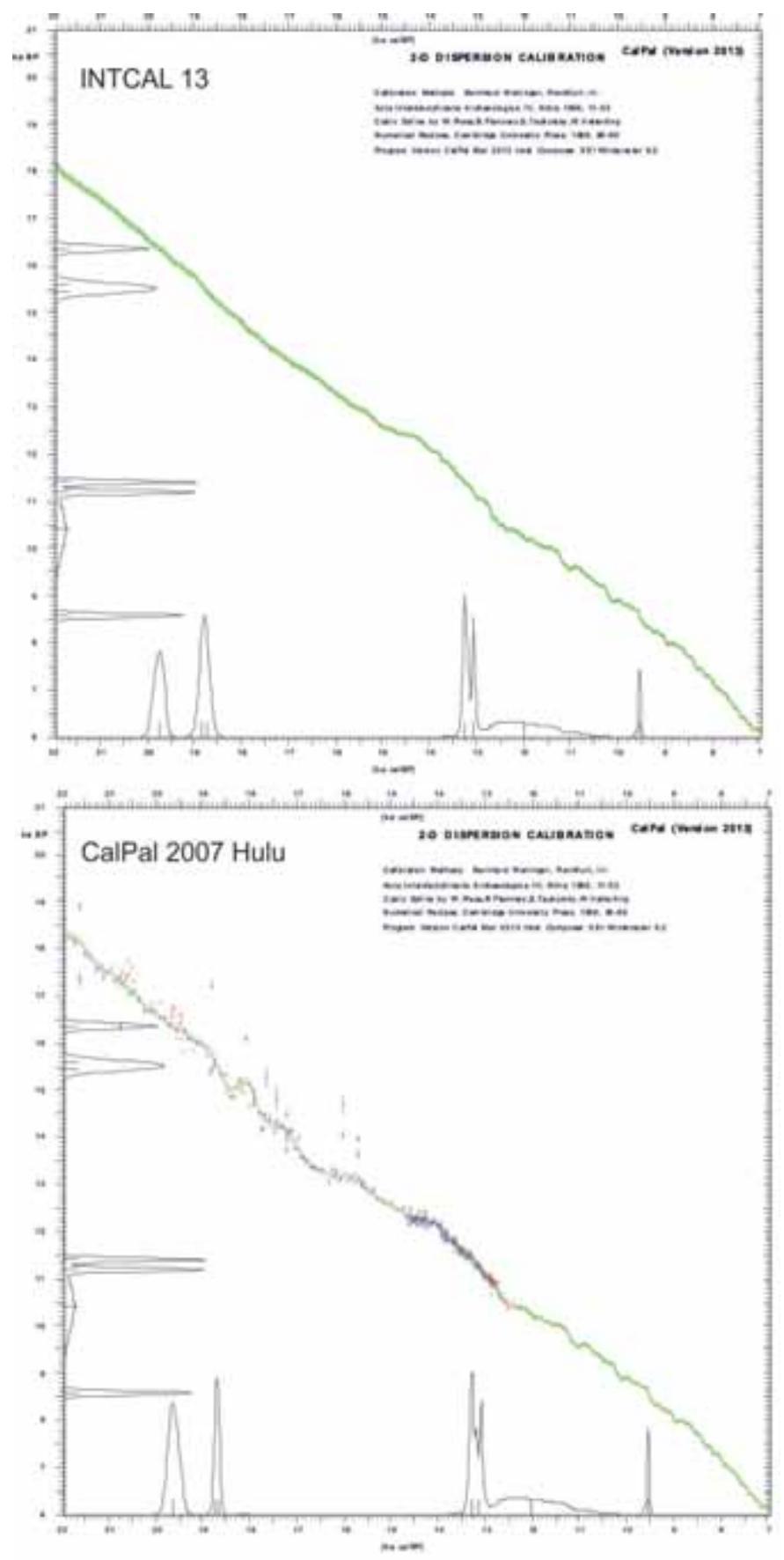

Figura 29. El Cierro. Curvas de probabilidad acumulada de las fechas radiocarbónicas obtenidas mediante su calibración con las curvas INCAL 13 y CalPal 2007 Hulu y utilizando el software CalPal (Version 2013) (Weninger and Jöris, 2004).

Figure 29. The Cierro cave. Cumulative probability curves of the radiocarbon dates obtained by INCAL 13 and CalPal 2007 Hulu calibration curves using CalPal software (2013 Version) (Weninger and Jöris, 2004).

sondeos de Groenlandia (Björck et al., 1998), hemos comparado mediante el software CalPal (versión
2013) (Weninger and Jöris 2004, 2008) la curva de probabilidad acumulada obtenida tras la calibración de todas las fechas radiocarbónicas de El Cierro con la proxi paleoclimática de alta resolución ${ }^{18} \mathrm{O}$ GISP2 Hulu Age Model (Grootes et al., 1993; Meese et al., 1994; Wang et al. 2001) (Fig. 31). Además, hemos comparado esa curva de probabilidad acumulada de El Cierro con la curva de probabilidad acumulada correspondiente a 155 fechas radiocarbónicas (65 AMS y 90 convencionales) de yacimientos asturianos del Pleistoceno superior y Holoceno (Jordá Pardo et al., 2014) extraídas de la base de datos de fechas radiocarbónicas de la Radiocarbon Palaeolithic Europe Database (v14) de la Universidad de Leuven (Bélgica) (Vermeersch en línea).

Cronoestratigráficamente, tanto las características sedimentológicas y de contenido arqueológico, como las dataciones radiocarbónicas convencionales y calibradas (tabla 9) sitúan claramente la parte superior de la secuencia estratigráfica de El Cierro en los últimos momentos del último pleniglacial, al final del Pleistoceno superior final (Fig. 30), que se corresponden con el OIS 2 (Shackleton y Opdyke 1973). Más concretamente, la parte superior de la secuencia de EI Cierro corresponde al Último Máximo Glacial o GS 2 (Greenland Stadial 2), el interestadio Tardiglacial o GI 1 (Greenland Interstadial 1) y el Dryas reciente o GS 1 (Greenland Stadial 1) (Björck et al. 1998).

Las dataciones radiocarbónicas más antiguas que disponemos hasta el momento sitúan los niveles con Magdaleniense inferior Cierro G1, Cierro G y Cierro F en el GS $2 b$ o tramo central, ligeramente más templado, del estadio frío GS 2 (Fig. 30). Las tres dataciones de estos niveles ofrecen la horquilla calendárica 19.860 - 18.580 cal BP que tiene una buena correlación con las fechas de otros niveles del Magdaleniense inferior de la región cantábrica, como el nivel 19 de La Riera (Posada de Llanes, Asturias) (Straus and Clark, 1986), el nivel Co.B.4 de Coímbre (Peñamellera Alta, Asturias) (Álvarez-Alonso et al., 2016; Álvarez-Alonso and Jordá Pardo, 2017, los niveles 2 y 4 de Altamira (Lasheras et al., 2012), los niveles 17 y 119 de El Mirón (Ramales de la Victoria, Cantabria) (Straus and Gonzalez Morales, 2010; Straus et al., 2014), el nivel VII de Ekaín (Deba, Gipuzkoa) (Altuna, 1984) y el nivel V de Erralla (Zestoa, Gipuzkoa) (Altuna, 1985).

Las dataciones más recientes corresponden a los niveles superiores de la secuencia con materiales adscritos al Paleolítco superior final/Aziliense $y$ al Mesolítico. Las dos fechas nuevas de muestras obtenidas en los niveles azilienses, Cierro D y Cierro C, ofrecen la horquilla calibrada $13.390-12.990$ cal BP que sitúan estos dos niveles en los momentos finales 
Jordá Pardo, J.F., et al., 2018. Al oeste del Sella. Geoarqueología y cronoestratigrafía... Boletín Geológico y Minero, 129 (1/2): $207-250$

\begin{tabular}{|l|l|l|l|l|l|l|}
\hline \multirow{2}{*}{ Nivel } & Material & Código de labo- & \multirow{2}{*}{ ratorio } & Fecha 14C BP & \multicolumn{2}{l|}{ Fecha cal BP } \\
\cline { 4 - 6 } & & & CalPal 2007 Hulu & IntCal 2013 & Periodo \\
\hline Cierro B sup & Concha (P. lineatus) & OxA-31705 & $8.575 \pm 40$ & $9600-9480$ & $9600-9480$ & Mesolítico \\
\hline Cierro C & Carbón & GaK-2548 & $10.400 \pm 500$ & $13350-10710$ & $13300-10700$ & Aziliense? \\
\hline Cierro C & Concha (P. vulgata) & OxA-27856 & $11.190 \pm 38$ & $13270-12990$ & $13140-12980$ & PSF/Aziliense? \\
\hline Cierro D & Concha (L. littorea) & OxA-27857 & $11.403 \pm 37$ & $13390-13190$ & $13340-13140$ & PSF/Aziliense? \\
\hline Cierro F & Hueso (C. elaphus) & OxA-27869 & $15.460 \pm 75$ & $18740-18580$ & $18900-18540$ & Mag. inferior \\
\hline Cierro G & Hueso (C. elaphus) & OxA-27870 & $15.580 \pm 75$ & $18800-18640$ & $18990-18670$ & Mag. Inferior \\
\hline Cierro G1 & Concha (L. littorea) & OxA-27871 & $16.360 \pm 55$ & $19860-19380$ & $19970-19530$ & Mag. inferior \\
\hline
\end{tabular}

Tabla 9. Fechas radiocabónicas de los niveles superiors de El Cierro calibradas mediante las curvas de calibración INTCAL 13 y CalPal 2007 Hulu, utilizando el software CalPal versión 2013 (Weninger and Jöris, 2004, 2008).

Table 9. Radiocarbon dates of the upper levels of the Cierro cave calibrated with INTCAL 13 and CalPal 2007 Hulu calibration curves using the 2013 version of the CalPal software (Weninger and Jöris, 2004, 2008).

del interestadio Tardiglacial o GI 1 (Fig. 30), al final del Pleistoceno superior. Ambas fechas presentan una buena correlación con las obtenidas para el nivel $3 e 3$ del Aziliense de la cercana cueva de Los Azules
(Cangas de Onis, Asturias) (Fernández-Tresguerres and Rodríguez Fernández, 1990) y con las de los niveles azilienses de EI Mirón (Straus and Gonzalez Morales, 2010). También son coincidentes con las

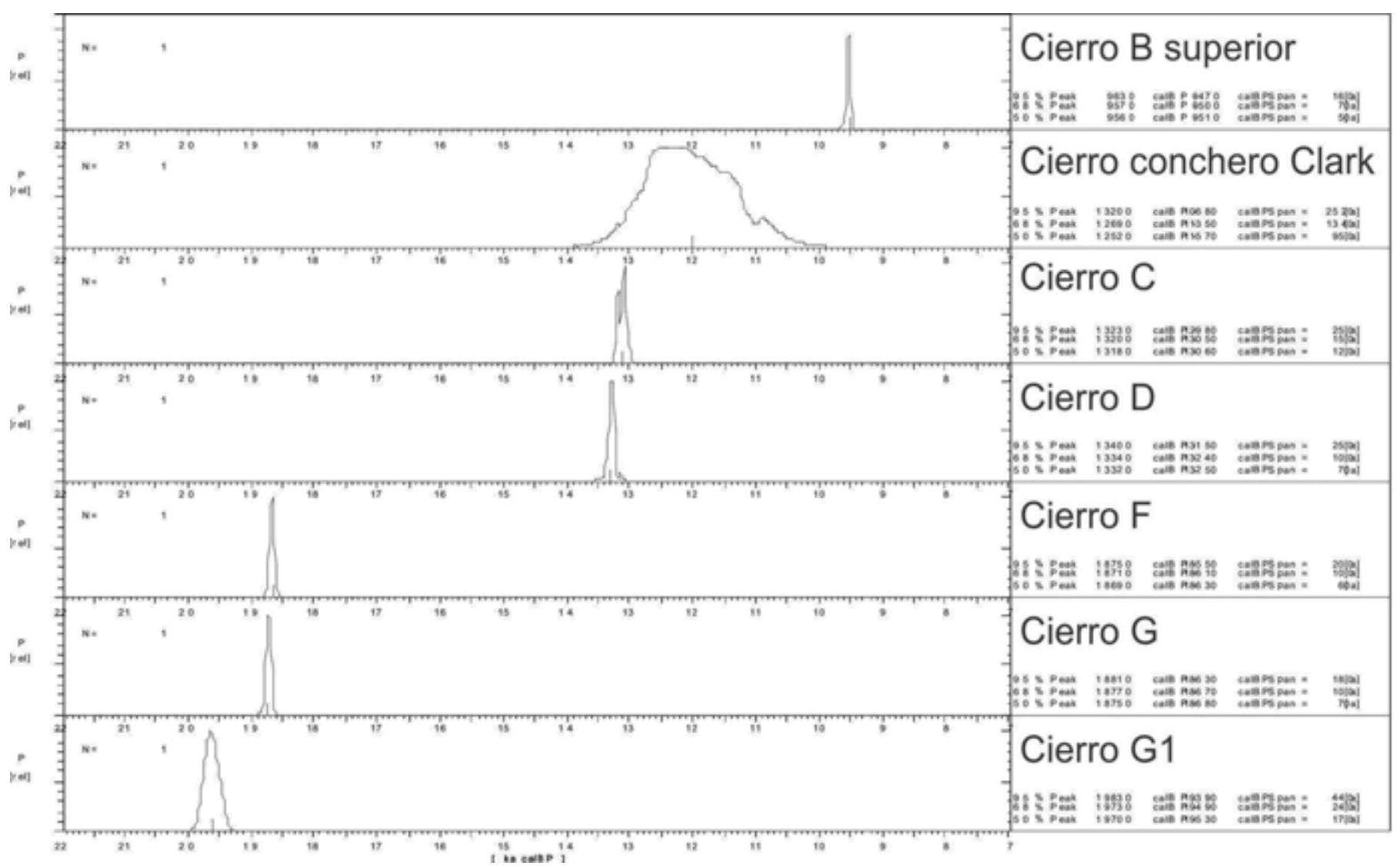

Figura 30. El Cierro. Comparación por niveles de las curvas de probabilidad acumulada de las fechas radiocarbónicas calibradas mediante la curva CalPal 2007 Hulu y utilizando el software CalPal (Version 2013) (Weninger and Jöris, 2004).

Figure 30. The Cierro cave. Comparison by levels of the cumulative probability curves of the calibrated radiocarbon dates by the curve CalPal 2007 Hulu using CalPal software (2013 Version) (Weninger and Jöris, 2004). 
fechas del nivel B de Cueto la Mina (Posada de Llanes, Asturias) obtenidas a partir de piezas de industria ósea atribuida al Magdaleniense final (Barandiarán, 1988). La fecha del Cierro C publicada con anterioridad (Clark, 1983) ofrece una amplia horquilla calendárica, 13350 - 10710 cal BP, debido a su elevada desviación típica, que situaría al nivel en un momento impreciso del GS 1 o Dryas reciente. No obstante, la citada fecha es concordante con la del nivel $3 e 1$ del Aziliense de Los Azules (Fernández-Tresguerres and Rodríguez Fernández, 1990). Finalmente, la nueva fecha obtenida del conchero mesolítico del Cierro $B$ sup ofrece una horquilla entre 9.600 y 9.480 cal $\mathrm{BP}$, que sitúa a este nivel en los comienzos del Holoceno (OIS 1), concretamente en la cronozona Boreal antes del evento 8.2 (Fig. 30), y tiene una buena correlación con las fechas del Mesolítico de La Riera (Straus et al., 1978).

Para los niveles inferiores de la secuencia, desde Cierro H1 hasta Cierro N, no contamos en este momento con dataciones radiocarbónicas que permitan un posicionamiento preciso de los mismos en la escala cronoestratigráfica del Pleistoceno superior. No obstante, su contenido arqueológico (posibles Paleolítico medio final, Auriñaciense Gravetiense y Solutrense) permite apuntar que estarían situados entre el final del OIS $3 c$ y el GS $2 c$, ya dentro del OIS 2 , siguiendo el esquema cronoestratigráfico del poblamiento paleolítico asturiano publicado recientemente (Jordá Pardo et al., 2014). En la figura 30 se hace un intento de situación cronoestratigráfica de estos niveles inferiores. El nivel Cierro N, con un posible Paleolítico medio final podría correlacionarse con el nivel 9 interior y $4 b$ exterior de la zona $D$ de la cueva de La Güelga (Narciandi, Cangas de Onis), situada unos kilómetros aguas arriba del Sella con ocupaciones atribuidas a los últimos neandertales datadas entre 60.200 y 44.420 cal BP (Menéndez et al., 2009; Jordá Pardo et al., 2013). Con respecto a los niveles auriñacienses (Cierro $M$ y Cierro $L$ ), podrían estar en relación con el nivel 5 interior de la zona $D$ de La Güelga que recientemente han sido datados entre 41.860 y 36.140 cal BP (Kehl et al., 2018 en este número). Como ya hemos indicado, en la actualidad se están llevando a cabo dataciones radiocarbónicas de esos niveles.

\section{Conclusiones}

A la vista del corte estratigráfico oeste-este estudiado en la cueva de El Cierro y de los análisis sedimentológicos y edafológicos llevados a cabo a partir de las muestras tomadas de los diferentes niveles que componen la secuencia, podemos extraer una serie de conclusiones en relación con la naturaleza de los depósitos y los procesos geológicos que los han generado para, finalmente, establecer una propuesta de unidades litoestratigráficas que situaremos en la escala cronestratigráfica del Pleistoceno superior final y Holoceno inferior.

La secuencia litoestratigráfica de la cueva de EI Cierro se caracteriza por presentar dos grupos de sedimentos con distintas características sedimentológicas y edafológicas. Por un lado se encuentran los depósitos marcadamente arenosos de naturaleza predominantemente siliciclástica (cuarzo, feldespatos, micas), que componen la parte inferior de la secuencia (desde Cierro $\mathrm{N}$ hasta Cierro D), y, por otro, los sedimentos organógenos y carbonatados del techo de la secuencia, ricos en aportes antrópicos de conchas de invertebrados y huesos de vertebrados, que componen el denominado conchero.

La parte clástica de la secuencia presenta una ligera tendencia granocreciente, con un tramo inferior lutítico de tonos grises y marrones (Cierro N, Cierro $M$, Cierro $L$ y Cierro J1), un nivel intermedio rico en gravas de color claro (Cierro J2) y un tramo superior en el que predominan las arenas de colores oscuros (Cierro H2 a Cierro E). Esta parte de la secuencia se caracteriza por una matriz con elevada presencia de cuarzo, que está acompañado por otros minerales silicatados en mínima proporción y, que en determinados niveles como Cierro J2 y Cierro H2, contiene una cierta cantidad de calcita. En esta parte de la secuencia, la presencia de materia orgánica y carbono orgánico es constante con valores máximos en Cierro M, Cierro J1 y Cierro H1, mientras que el carbonato cálcico aparece en proporciones insignificantes, inferiores al 0,3\%.

En el tramo inferior de la secuencia aparecen lechos horizontales de arenas de cuarzo, de tamaño fino a grueso, tanto bien redondeadas como angulosas, que están acompañadas por limos y arcillas, que tiene su origen en flujos hídrico de baja energía y escaso poder clasificador, que transporta materiales detríticos silicatados procedentes del exterior de la cavidad. Esto es indicativo del funcionamiento sucesivo de procesos de arroyada difusa de energía variable que transporta materiales alóctonos, heredados de otros depósitos desmantelados, los cuales estarían situados en el exterior del karst o incluso en el interior de sus galerías. En cuanto al nivel inferior de la secuencia (Cierro N), su geometría y la elevada presencia de limos y arcillas frente a las arenas, son indicativas del funcionamiento de un flujo denso de tipo mud flow en esos primeros momentos de la sedimentación. Los materiales de los niveles Cierro J1 y Cierro H1, que presentan abundantes clastos angulosos desorganizados dentro de una 


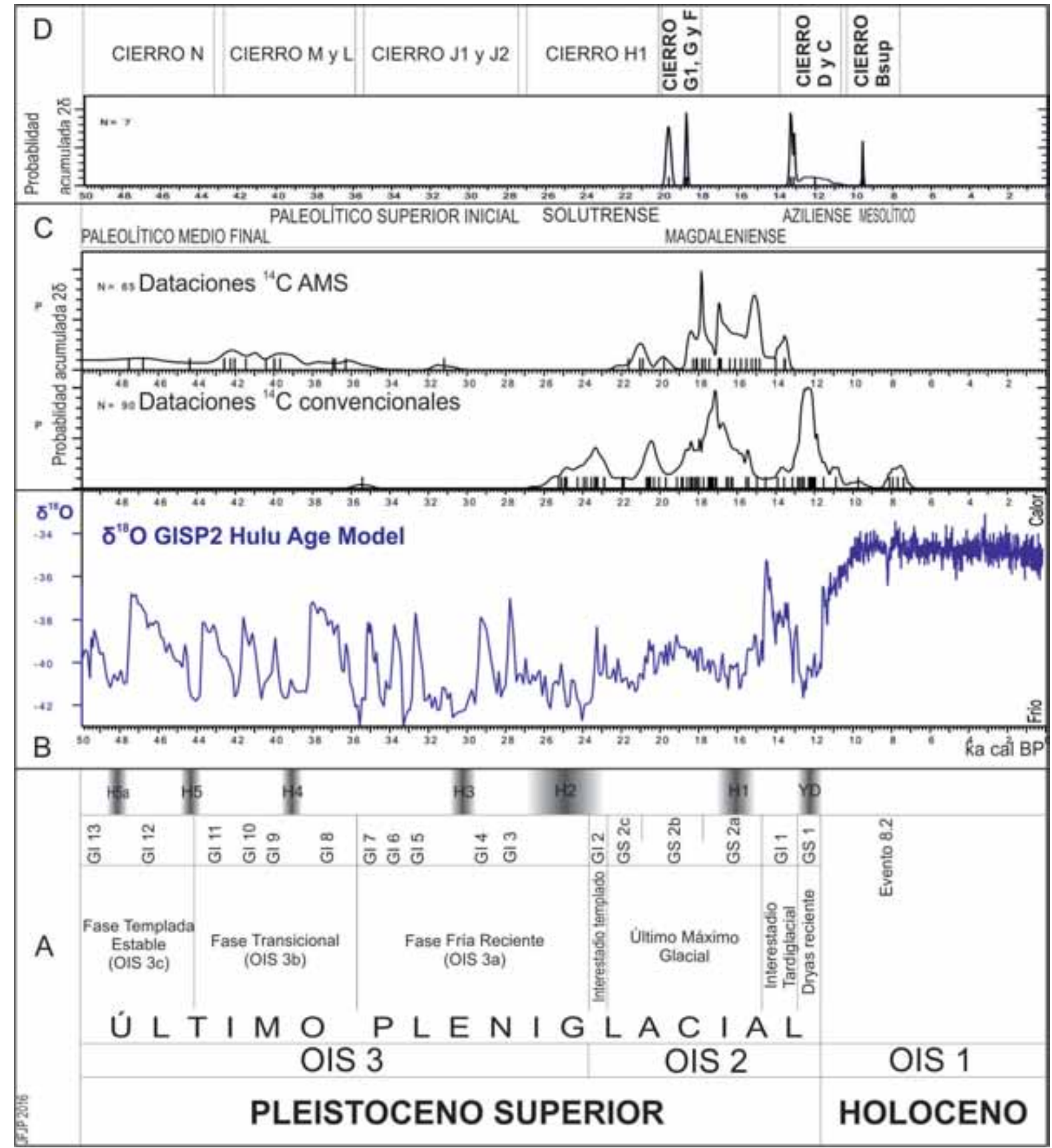

Figura 31. Cronoestratigrafía de la secuencia arqueosedimentaria de El Cierro basada en la comparación de las curvas de probabilidad acumulada de las fechas radiocarbónicas de El Cierro con las de otros yacimientos del Pleistoceno superior y Holoceno inferior de Asturias (Jordá Pardo et al., 2014), todas ellas calibradas con la curva CalPal 2007 Hulu, y con la proxy paleoclimática de alta resolución ${ }^{18} \mathrm{O}$ GISP2 Hulu Age Model (Grootes et al., 1993; Meese et al., 1994; Wang et al. 2001), utilizando el software CalPal (Version 2013) (Weninger and Jöris, 2004).

Figure 31. Chronostratigraphy of the archaeo-sedimentary sequence of the Cierro cave based on the comparison of the cumulative probability curves of the calibrated radiocarbon dates of the Cierro cave with the cumulative probability curves of other Upper Pleistocene and Holocene sites of Asturias (Jordá Pardo et al., 2014) and the high resolution proxy ${ }^{18} \mathrm{O}$ GISP2 Hulu Age Model (Grootes et al., 1993; Meese et al., 1994; Wang et al. 2001) using CalPal software (2013 Version) (Weninger and Jöris, 2004).

matriz fangosa, están relacionados con flujos de tipo debris flow. Por el contrario, el nivel Cierro H2, que constituye un lentejón horizontal de materiales finos dentro de Cierro H1, correspondería a un lóbulo fangoso (mud flow) que avanzaría hacia el E tras depositar la carga clástica 
Tras la sedimentación de Cierro G1 por procesos de arroyada difusa y con abundantes aportes antrópicos de materia orgánica, tiene lugar un episodio de caída gravitacional de la caliza del techo de la cavidad que genera el emplazamiento de un gran bloque de caliza autóctona en el sector oeste de la sección estudiada, deformando las unidades Cierro G1 y Cierro H1 (Figura 18). Este bloque, de tamaño superior a un metro, presenta las aristas muy vivas. Además, en el centro de la sección existe otro bloque de caliza de tamaño algo inferior, con las aristas muy redondeadas, que debió formar parte de la pared o del techo de la cavidad y que conserva el pulimento propio de las paredes de esta (Figura 17a). Este gran bloque presiona el sedimento de la unidad Cierro G1 y lo proyecta hacia arriba de tal forma que se encuentra englobado por las arcillas negras de esta unidad. Su emplazamiento tuvo lugar con posterioridad a la sedimentación de Cierro G1 y posiblemente de Cierro F, pero con anterioridad a la sedimentación de Cierro E. Por encima de este bloque, y ya dentro de la unidad Cierro $\mathrm{E}$, aparece otro bloque de caliza autóctona con forma angulosa pero aristas romas. La presencia entre ambos bloques de un delgado relleno con materiales de Cierro G1 y Cierro E, es indicativo de su emplazamiento durante la sedimentación de Cierro E. Este último nivel tendría su origen en un flujo plástico de tipo mud flow con cierta presencia de clastos.

A lo largo del tramo inferior de la secuencia se observa la presencia en determinados niveles (Cierro L, Cierro J1, Cierro J2, Cierro H1, Cierro F y Cierro E) con clastos de caliza autóctona de tamaño canto con morfología prismática y de plaqueta, dispuestos de forma irregular o bien horizontales paralelos a la superficie deposicional. Presentan las aristas angulosas y vivas, o bien con un ligero redondeamiento. Su origen está relacionado con la caída gravitacional de pequeños fragmentos rocosos del techo y paredes de la cavidad producida por procesos de gelifracción, como ocurre en otros yacimientos (Hoyos Gómez, 1979, 1980, 1981a, 1981b), que tuvieron lugar en los momentos más fríos del OIS 3 y del GS 2.

El tramo superior de la secuencia, de naturaleza organógena y carbonatada, se encuentra organizado en un nivel de transición (Cierro $D$ ), dos niveles de conchero (Cierro $\mathrm{C}$ y Cierro B) y un delgado espeleotema culminante (Cierro A). En contacto con la secuencia siliciclástica aparece un primer nivel de transición, intensamente carbonatado en algunos puntos, rico en conchas y huesos (Cierro D), sobre el que descansa el conchero inferior (Cierro $C$ ) que a techo presenta una mayor proporción de matriz terrígena con apenas cementación, lo que produce en el afloramiento actual un socave. Encima se encuentra el conchero superior (Cierro B), bien cementado, que también presenta a techo un tramo detrítico sin cementación que de nuevo da lugar a un ligero socave erosivo en el perfil del afloramiento. Ambos concheros están constituidos mayoritariamente por conchas y caparazones de invertebrados junto con fragmentos óseos de vertebrados, acompañados por clastos angulosos de caliza autóctona y una escasa matriz arenosa carbonatada, generada por la fracturación y disgregación de los restos de conchas. Los dos niveles se encuentran cementados por carbonatos, si bien esta cementación varía vertical y lateralmente. Ambos concheros estuvieron en su día íntimamente adheridos a la pared del fondo y al techo de la cavidad, como se observa en los restos que todavía permanecen pegados a la roca, pero que en la actualidad se encuentran desprendidos como consecuencia del asentamiento producido en los depósitos sobre los que descansan y del descalce producido por la eliminación de los sedimentos infrayacentes durante las excavaciones arqueológicas llevadas a cabo. Termina la secuencia con unas delgadas concreciones carbonatadas que enlazan el conchero Cierro B con la pared y el techo rocoso de la cavidad. Entre los componentes minerales de los sedimentos finos de la matriz de estos niveles destaca la elevada presencia de calcita, con valores en torno al $50 \%$ excepto en la muestra correspondiente a Cierro D en donde se alcanza el $97,6 \%$, que está acompañada por cuarzo, con un máximo en Cierro B sup $(50,4 \%)$. En esta parte de la secuencia, la presencia de materia orgánica y carbono orgánico experimenta un notable incremento con respecto al tramo inferior, con un máximo en Cierro $B$, mientras que el carbonato cálcico aumenta en Cierro B y Cierro hasta alcanzar valores en torno al $50 \%$ y un máximo en Cierro $A$.

El origen de estos concheros es claramente antrópico y corresponden a los aportes de conchas, caparazones y huesos generados por los habitantes de la cavidad probablemente desde una zona de habitación situada hacia el centro de la gran sala, como se ha podido comprobar en otros concheros (Arias et al., 2015). Con posterioridad se produce un proceso de cementación carbonatada que suelda los materiales entre sí y a la pared, para terminar la sedimentación con el desarrollo de unos delgados espeleotemas que enlazan el conchero Cierro B sup con la pared y el techo rocoso de la cavidad.

Por tanto, a la vista de lo anterior, desde el punto de vista de la litoestratigrafía, los niveles de la secuencia de El Cierro pueden agruparse en dos unidades informales:

- La unidad inferior (Cierro $\mathrm{N}$ a Cierro E), siliciclástica, cuyo origen está relacionado con flujos 
plásticos en la base que pasan a flujos laminares de escasa energía, con aportes de pequeños clastos por gelifracción y caídas gravitacionales de grandes bloques. Durante la sedimentación de esta unidad existieron momentos con presencia humana en la cueva que dejaron evidencias de ocupaciones con una intensidad creciente hacia el techo.

- La unidad superior (Cierro D a Cierro A), organogénica, cuyo origen está ligado a los aportes antrópicos que configuran dos concheros superpuestos cementados por carbonatos.

Cronoestratigráficamente, con los datos arqueológicos que tenemos hasta el momento, los tramos inferior y medio de la unidad inferior podemos situarlos en los momentos finales del OIS $3 c$ y OIS 2, hasta el GS 2c, con ocupaciones humanas quizá del Paleolítico medio final, del Auriñaciense, posiblemente del Gravetiense y del Solutrense. Para el tramo superior de la unidad inferior, que contiene ocupaciones del Magdaleniense inferior, contamos con dataciones radiocarbónicas que la sitúan en el episodio ligeramente más templado GS $2 b$ del estadio frío GS 2 . En cuanto a la unidad superior, el conchero inferior, correspondiente a una ocupación probablemente del Paleolítico superior final/Aziliense, las fechas radiocarbónicas disponibles lo sitúan con claridad al final del Tardiglacial o GI 1, y podría extenderse durante el GS 1 (Dryas reciente) en los momentos finales del Pleistoceno superior. El conchero superior, con una ocupación del Mesolítico, se sitúa en la cronozona Boreal antes del evento 8.2, ya dentro del Holoceno.

Con los datos con los que contamos actualmente, este modelo sedimentológico, litoestratigráfico y cronoestratigráfico permite explicar y situar en el tiempo la secuencia estratigráfica estudiada de la cueva de EI Cierro. La furura realización de una nueva excavación arqueológica en el testigo del corte estratigráfico norte, la apertura de nuevas catas en otros sectores de la cavidad y la obtención de nuevas fechas radiocarbónicas, permitirán contrastar lo hasta aquí expuesto y alcanzar un mejor conocimiento de los procesos responsables del emplazamiento de los depósitos de la cueva de El Cierro y de la cronología de los mismos y de las ocupaciones humanas correlativas.

\section{Agradecimientos}

A Angelines Fernández y Rafael Gómez del Museo Nacional de Ciencias Naturales (CSIC, Madrid) que realizaron los análisis granulométricos y mineralógicos. A Marco de la Rasilla Vives que nos proporcionó los diarios de Manuel Hoyos Gomez y a Pilar Vidal que nos autorizó a utilizarlos. Este trabajo ha sido financiado por el Plan Nacional de $I+D+l$ del Ministerio de Economía y Competitividad en el marco de los proyectos de investigación HAR2011-29907C03-03/HIST (investigador principal: Dr. Esteban Álvarez-Fernández) y HAR2011-29907-C03-00/HIST (investigador principal: Dr. Pablo Arias Cabal). Agradecemos al Ayuntamiento de Ribadesella su ayuda para desarrollar nuestros trabajos de campo, así como al Hotel El Carmen por su apoyo logístico.

\section{Referencias}

Adán Álvarez, G. E. 1997. De la caza al útil: la Industria Ósea del Tardiglaciar en Asturias. Consejería de Cultura, Principado de Asturias, Oviedo.

Altuna, J. 1984. Historia de las excavaciones. Descripción del yacimiento. Resumen estratigráfico del relleno. Utilización del espacio. Dataciones absolutas. In: Altuna, J. and Merino, M. (eds.), El yacimiento prehistórico de la cueva de Ekain (Deba, Guipúzcoa), Eusko Ikaskuntza Sociedad de Estudios Vascos, 17-45.

Altuna, J. 1985. Dataciones de carbono 14 del yacimiento de Erralla. Comparación con las dataciones de otros yacimientos próximos. In: Altuna, J., Baldeón, A. and Mariezkurrena, K. (eds.), Cazadores magdalenienses en Erralla (Cestona, País Vasco). Munibe, 37, 25-28.

Álvarez-Alonso, D. and de Andrés Herrero, M. 2012. La transición Solutrense-Magdaleniense en la Cueva de El Cierro (Ribadesella, Asturias, España). In: Ripoll López, S., Avezuela Aristu, B., Jordá Pardo, J.F. and Muñoz Ibáñez, F.J. (eds.), De punta a punta. El Solutrense en los albores del siglo XXI. Espacio, Tiempo y Forma, Serie I, Prehistoria y Arqueología, 5: 399-412.

Álvarez-Alonso, D. and Jordá Pardo, J. F. 2017. Secuencia estratigráfica, radiocarbono y cronoestratigrafía del registro del Pleistoceno superior de la cueva de Coímbre (zona B) (Asturias, España). In: Álvarez-Alonso, D. and Yravedra, J. (eds,), La cueva de Coímbre (Asturias, Spain). Ocupaciones magdalenienses en el valle del Cares. Fundación Masaveu, Oviedo, 194-217.

Álvarez-Alonso, D., Yravedra, J., Jordá Pardo, J. F. and Arrizabalaga, A. 2016. The Magdalenian sequence at Coímbre cave (Asturias, Northern Iberian Peninsula): Adaptative strategies of hunter-gatherer groups in montane environments. Quaternary International, 402: 100111.

Álvarez-Fernández, E. 2006. Los objetos de adorno-colgantes del Paleolítico Superior y del Mesolítico en la Cornisa Cantábrica y en el Valle del Ebro: una visión europea. Colección Vítor, 195. Universidad de Salamanca, Salamanca.

Álvarez-Fernández, E., Bécares, J. and Portero, R. 2014. Excavaciones arqueológicas en Cova Rosa y en El Cierro (Ribadesella, Asturias): pasado, presente y futuro. Anejos de Nailos, 2, 73-97. 
Álvarez-Fernández, E., Álvarez-Alonso, D., Bécares, J., Carral, P., Carriol, R.-P., Chauvin, A., Cubas, M., Cueto, M., Domingo, R., Douka, K., Jordá, J. F., Murelaga, X., Portero, R., Rivero, O., Tapia, J., Tarriño, A. andTeira, L. C. 2016. Nouvelles données sur le Magdalénien inférieur de la Région Cantabrique: le Niveau $\mathrm{F}$ de la grotte de $\mathrm{EI}$ Cierro (Ribadesella, Asturias, Espagne). L'Anthropologie, 120 (5): 537-567.

Arias, P., Cubas, M., Fano, M. A., Jordá Pardo, J. F., Salzmann, C., Teichner, F. and Teira, L.C. 2015. Where are the 'Asturian' dwellings? An integrated survey programme on the Mesolithic of northern Spain. Antiquity, 89 (346), 783-799.

Barandiarán, I. 1988. Datation C14 de I'art mobilier magdalénien cantabrique. Préhistoriore Ariégeoise, XLIII, 63-84.

Bastida, F. and Aller, J. 1995. Rasgos geológicos generales. In: Aramburu, A. and Bastida, F. (eds.), Geología de Asturias, Ediciones Trea, Gijón, 27-33.

Bernaldo de Quiros Guidotti, F. 1982. Los inicios del Paleolítico Superior Cantábrico. Monografías 8. Centro de Investigación y Museo de Altamira, Madrid.

Björck, S., Walker, M. J. C., Cwynar, L., Johnsen, S. J., Knudsen, K. L., Lowe, J. J., Wohlfarth, B. and INTIMATE Members 1998. An event stratigraphy for the Last Termination in the north Atlantic based on the Greenland Ice Core record: a proposal by the INTIMATE group. Journal of Quaternary Science, 13, 283-292.

Blott, S. J. and Pye, K., 2001. GRADISTAT: A grain size distribution and statistics package for the analysis of unconsolidated sediments. Earth Surface Processes and Landforms, 26, 1237-1248.

Brock, F., Higham, T. F. G., Ditchfield, P. and Bronk Ramsey, C. 2010. Current pretreatment methods for AMS radiocarbon dating at the Oxford Radiocarbon Accelerator Unit (ORAU). Radiocarbon, 52 (1), 103-112.

Clark, G. A. 1972. El Asturiense en Cantabria. Bases sustentadoras y evidencias de los cambios climáticos postpleistocenos. Trabajos de Prehistoria, 29, 17-30.

Clark, G. A. 1983. The Asturian of Cantabria. Early Holocene hunter-gatherers in Northern Spain. Anthropological papers of the University of Arizona 41, The University of Arizona press, Tucson.

Corchón Rodríguez, M. S. 1986. El arte paleolítico cantábrico: contexto y análisis interno. Ministerio de Cultura, Madrid.

Díaz García, F. y Polledo González, M. 2014. De Eduardo Hernández Pacheco a Francisco Jordá Cerdá: crisis y revitalización de las investigaciones arqueológicas $y$ prehistóricas en Ribadesella durante el siglo XX. La Plaza Nueva, 37, 36-56.

Douka, K., Hedges, R. E. M. and Higham T. F. G. 2010. Improved AMS 14C dating of Shell carbonates using high-precision X-Ray Diffraction (XRD) and a novel density separation protocol (CarDS). Radiocarbon, 52 (2), 735-751.

Fernández-Tresguerres Velasco, J. A. and Rodríguez Fernández, J. J. 1990. La cueva de Los Azules (Cangas de Onís). Excavaciones Arqueológicas en Asturias, 1983 1986. Consejería de Cultura y Turismo, Gobierno del Principado de Asturias, Oviedo, 129-133.
Ferrer Palma, J. E. and Crespo Santiago, M. J. 2005. Dataciones calibradas de $\mathrm{C} 14$ en el Paleolítico de Andalucía: una propuesta con la curva de calibración CalPal 2004 Jan para el marco cronológico del sur peninsular. In: Sanchidrián Torti, J. L., Márquez Alcántara, A.M. and Fullola Pericot, J. M. (eds.), IV Simposio de Prehistoria Cueva de Nerja. La Cuenca Mediterránea durante el Paleolítico Superior 3800010000 años. Reunión de la VIII Comisión del Paleolítico Superior U.I.S.P.P. Fundación Cueva de Nerja, 380-394.

Folk, T. L. and Ward, W. C. 1957. Brazos River bar: a study in the significance of grain size parameters. Journal of Sedimentary Petrology, 27 (1), 3-26.

GEODE - Cartografía geológica digital continua de España a escala 1/50.000 (en línea). Instituto Geológico y Minero de España. http://info.igme.es/cartografiadigital/geologica/geode.aspx [accesed 29/02/2016].

Goldberg, P. and Macphail, R. I., 2006. Practical and Theoretical Geoarchaeology. Blackwell Publishing, Malden-Oxford-Carlton.

Gómez Fuentes, A. and Bécares Pérez, J. 1979. Un hueso grabado de la cueva de El Cierro (Ribadesella, Asturias). XV Congreso Nacional de Arqueo-logía. Secretaría General de los Congresos Arqueológicos Nacionales, Zaragoza, 83-94.

Grootes, P. M., Stuiver, M, White, J. W. C., Johnsen, S. y Jouzel, J. 1993. Comparison of Oxygen Isotope Records from the GISP2 and GRIP Greenland Ice Core. Nature, $366,552-554$.

Hernández-Pacheco, E. 1959. Prehistoria del Solar Hispano. Orígenes del Arte Pictórico. Memorias, XX. Real Academia de Ciencias Exactas, Físicas y Naturales, Madrid.

Hernández-Pacheco, E., Llopis Llado, N., Jordá Cerdá, F. and Martínez, J.A. 1957. Guía de la excursión $n^{\circ}$. 2. El Cuaternario de la región cantábrica. INQUA V Congreso Internacional. Diputación Provincial de Asturias, Oviedo.

Hill, P. and Forti, P. 1997. Cave Minerals of the World. $2^{\text {nd }}$ Ed, National Speleological Society, Huntsville.

Hoyos Gómez, M. 1972-1973. Brecha y corteza estalgamítica de la Cueva de Sofoxo. Zephyrus XXXIII-XXIV: 40-42.

Hoyos Gómez, M. 1979. El karst de Asturias en el Pleistoceno superior y Holoceno. Estudio morfológico, sedimentológico y paleoclimático. Tesis doctoral inédita. Universidad Complutense de Madrid. Madrid.

Hoyos Gómez, M. 1980. Estudio geológico y sedimentológico de la Cueva de la Paloma (Soto de las Regueras, Asturias). In: Hoyos Gómez, M., Martínez Navarrete, M. I., Chapa Brunet, T., Castaños, P. and Sanchiz, F. B. (eds.), La Cueva de la Paloma (Soto de las Regueras, Asturias). Excavaciones Arqueológicas en España, 116, Ministerio de Cultura, Madrid, 23-63.

Hoyos Gómez, M. 1981a. Estudio geológico de la cueva de Las Caldas. In: Corchón, S. (ed.), Cueva de Las Caldas, San Juan de Priorio (Oviedo). Excavaciones Arqueológicas en España, 115, Ministerio de Cultura, Madrid, 11-55.

Hoyos Gómez, M. 1981b. La cronología paleoclimática del Würm reciente en Asturias. Diferencias entre los resultados sedimentológicos y palinolológicos. Programa 
Jordá Pardo, J.F., et al., 2018. Al oeste del Sella. Geoarqueología y cronoestratigrafía... Boletín Geológico y Minero, 129 (1/2): $207-250$

Internacional de Correlación Geológica. I Curso de conferencias celebrado en el mes de mayo de 1979. Real Academia de Ciencias Exactas, Físicas y Naturales, Madrid, 63-75.

Hoyos Gómez, M. 1987. Upper Pleistocene and Holocene marine levels on the Cornisa Cantábrica (Asturias, Cantabria and Basque Country) Spain. In : Zazo, C. (ed), Late Quaternary sea-level changes in Spain. Trabajos sobre Neogeno-Cuaternario, 10, Museo Nacional de Ciencias Naturales, Madrid, 251-258.

Hoyos Gómez, M. 1989. La cornisa cantábrica. Mapa del Cuaternario. Instituto Tecnológico Geominero de España, Madrid, 105-118.

Hoyos Gómez, M. and Herrero Organero, N. 1989. El karst en la Cornisa Cantábrica. In: Durán, J. J. and LópezMartínez, J. (eds.), El karst en España. Monografía, 4, Sociedad Española de Geomorfología, Madrid, 109-120.

Jordá Cerdá, F. 1958. Avance al Estudio de la Cueva de la Lloseta (Ardines, Ribadesella, Asturias). Memorias del Servicio de Investigaciones Arqueológicas, 3. Diputación Provincial de Asturias, Oviedo.

Jordá Cerdá, F. 1959. Revisión de la cronología del Asturiense. $V$ Congreso Nacional de Arqueología. Secretaría General de los Congresos Arqueológicos Nacionales, Zaragoza, 63-66.

Jordá Cerdá, F. 1960. El complejo cultural SolutrenseMagdaleniense en la región cantábrica. I Symposium de Prehistoria Peninsular. Diputación Foral de Navarra, Institución Principe de Viana, Pamplona, 1-22.

Jordá Cerdá, F. 1963. El Paleolítico Superior Cantábrico y sus industrias. Saitabi, XIII, 3-22.

Jordá Cerdá, F. 1969. Los comienzos del Paleolítico Superior en Asturias. Symposium del Cro-Magnon, Anuario de Estudios Atlánticos, 15, Madrid, 281-321.

Jordá Cerdá, F. 1976. Guía de las cuevas prehistóricas asturianas. Colección Popular Asturiana, 12. Ayalga Ediciones, Salinas.

Jordá Cerdá, F. 1977. Prehistoria. Historia de Asturias 1. Ayalga Ediciones, Vitoria-Oviedo.

Jordá Cerdá, F. and Mallo Viesca, M. 2014. La cueva de Les Pedroses (El Carmen, Ribadesella, Asturias). Nailos, 1, 131-162.

Jordá Pardo, J. F., Álvarez-Alonso, D. and Iriarte Chiapusso, M. J. 2014. Una aproximación geoarqueológica al hábitat humano pleistoceno del occidente cantábrico (Asturias, norte de España). In: Álvarez-Alonso, D. (ed.), Los grupos cazadores-recolectores paleolíticos del occidente cantábrico. Estudios en Homenaje a Francisco Jordá Cerdá en el centenario de su nacimiento. 19142014, Entemu, XVIII, 67-102.

Jordá Pardo, J.F., Menéndez Fernández, M., Carral González, P., Quesada López, J.M. and Wood, R. 2013. Geoarchaeology and Chronostratigraphy of the MiddleUpper Palaeolithic transition at the cave of La Güelga (Cangas de Onis, Asturias, Spain). In: Pastoors, A. and Auffermann, B. (eds.), Pleistocene foragers on the Iberian Peninsula: Their culture and environment. Festschrift in honour of Gerd - Christian Weniger for his sixtieth birthday. Wissenschaftliche Schriften des Neanderthal Museums, 7. Mettmann, 85-106.
Kehl, M., Álvarez-Alonso, D., Andrés-Herrero, M. de, Carral González, P., García, E., Jordá Pardo, J. F., Menéndez, M., Quesada, J. M., Rethemeyer, J., Rojo, J., Tafelmaier, Y. and Weniger, G.-C. 2018. Towards a revised stratigraphy for the Middle to Upper Palaeolithic Transition at La Güelga (Narciandi, Asturias, Spain) Micromorphological investigations and new radiocarbon data. Boletín Geológico y Minero, 129 (1-2), 183206. .

Lasheras Corruchaga, J.A., Fernández Valdés, J.M., Montes Barquín, R., Rasines, P., Blasco Laffon, E., Soutullo García, B., Heras Martín, C. and Fatás, P. 2012. La cueva de Altamira: nuevos datos sobre su yacimiento arqueológico (sedimentología y cronología). In: P. Arias Cabal, M. S. Corchón Rodríguez, M. Menéndez Fernández and J. A. Rodríguez Asensio (eds.), El Paleolítico superior cantábrico. Actas de la Primera Mesa Redonda. San Román de Candamo (Asturias), 26-28 Abril de 2007. Monografías del Instituto Internacional de Investigaciones Prehistóricas de la Universidad de Cantabria, 3. Universidad de Cantabria, Santander, 67-75.

Llopis Lladó, N. 1953a. Sección de Exploraciones. Asturias. Speleon, IV (2), 105.

Llopis Lladó, N. 1953b. Estudios hidrogeológicos y prehistóricos en Posada (Llanes). Speleon, IV (3-4), 266.

Mallo, M., Chapa, T. and Hoyos, M. 1979-1980. Identificación y estudio de la Cueva del Río (Ribadesella, Asturias). Zephyrus, 30-31, 231-246.

Martín, J. D. 2006. XPowder. Programa para análisis cualitativo y cuantitativo por difracción de rayos $\mathrm{X}$. Macla, $4 / 5,35-44$.

Martín, J. D. 2008. XPowder. A software package for powder $x$-ray diffraction analysis. www.xpowder.com

Meese, D., Alley, R., Gow, T., Grootes, P.M., Mayewski, P., Ram, M., Taylor, K., Waddington, E and Zielinski, G. 1994. Preliminary depth-age scale of the GISP2 ice core. CRREL Special Report, 94-1. Cold Regions Research and Engineering Laboratory, Hanover, New Hampshire, 66 pp.

Menéndez, M., Quesada, J.M., Jordá, J.F., Carral, P., Trancho, G.J., García, E., Álvarez-Alonso, D., Rojo, J. and Wood, R. 2009. Excavaciones arqueológicas en la Cueva de La Güelga (Cangas de Onís. Asturias). Excavaciones Arqueológicas en Asturias, 2003 2006, 6. Consejería de Cultura y Turismo, Gobierno del Principado de Asturias, Oviedo, 209-221.

Mestres, J. S. 1995. La datació per radiocarboni i el calibratge de les dates radiocabòniques. Objectius, problemes $\mathrm{i}$ aplicacions. Revista d'Arqueologia de Ponent, 5, 260-275.

Mestres, J. S. 2000. La datació per radiocarboni. Una visión actual. Tribuna d'Arqueologia, 1997-1998, 195-239.

Mestres, J. S. 2003. La química i la cronologia: la datació per radiocarboni. Revista de la Societat Catalana de Química, 4, 11-25.

Mestres, J. S. 2008. El temps a la Prehistòria i el seu establiment a través de la datación per radiocarboni. Cypsela, 17, 11-21.

Munsell, A. H. 1981. A color notation: an illustrated system defining all colors and their relations by measured scales for Hue, Value and Chroma. 14th ed. Munsell Color, Baltimore. 
Navarro, D., Leyva, F., Villa, E. and Granados, L. 1986. Mapa Geológico de España E. 1:50.000 Hoja 31 (15-4) Ribadesella. Instituto Geológico y Minero de España, Centro de Publicaciones, Ministerio de Industria y Energía, Madrid.

Obermaier, H. 1925. El Hombre Fósil. Madrid.

Rasilla Vives, M. de la. 1991. El Conde de la Vega del Sella y la Arqueología Prehistórica en Asturias (1870-1941). Museo Arqueológico de Asturias. Consejería de Educación, Cultura y Deportes, Principado de Asturias, Oviedo.

Rasilla Vives, M. de la and Sánchez-Moral, S. 2003. Presentación. Homenaje a Manuel Hoyos. Estudios Geológicos, 59 (1-4), 3-4.

Reimer, P. J., Bard, E., Bayliss, A., Beck, J. W., Blackwell, P. G., Ramsey, C. B., Buck, C. E., Cheng, H., Edwards, R. L.; Friedrich, M., Grootes, P. M., Guilderson, T. P., Haflidason, H., Hajdas, I., Hatté, C., Heaton, T. J., Hoffmann, D. L., Hogg, A. G., Hughen, K. A., Kaiser, K. F., Kromer, B., Manning, S. W., Niu, M., Reimer, R. W., Richards, D. A., Scott, E. M., Southon, J. R., Staff, R. A., Turney, C. S. M. and van der Plicht, J. 2013. IntCal13 and Marine13 Radiocarbon Age Calibration Curves 0-50,000 Years cal BP. Radiocarbon, 55 (4), 1869-1887.

Rodríguez Vinceiro, F. J. and Márquez Romero, J. E. 2003. Dataciones absolutas para la Prehistoria Reciente de la provincia de Málaga: una revisión crítica. Baetica. Estudio de Arte, Geografía e Historia, 25, 313-353.

Shackleton, N. J. and Opdyke, N. D. 1973. Oxygen isotope and paleomagnetic stratigraphy of equatorial Pacific core V28 238: oxigen isotope temperature and ice volumes on 105 year and 106 year scale. Quaternary Research, 3, 3955.

Schiffer, M. B., 1987. Formation Processes of the Archaeological Record. University of New Mexico Press, Albuquerque.

Straus, L. G. 1983. El Solutrense vasco-cantábrico. Una nueva perspectiva. Monografías 10. Centro de Investigación y Museo de Altamira, Madrid.

Straus, L. G., Clark, G. A. and González Morales, M. 1978. Cronología de las industrias del Würm tardío y del Holoceno temprano en Cantabria: contribuciones del proyecto paleoecológico de La Riera. C-14 y Prehistoria de la Península Ibérica. Fundación Juan March, Serie Universitaria 77, Madrid, 37-43.

Straus, L. G. and Clark, G. A. (eds.) 1986. La Riera cave. Stone age hunter-gatherer adaptations in northern
Spain. Anthropological Research Papers 36, Arizona State university.

Straus, L. G. and González Morales, M. R. 2010. The radiocarbon chronology of El Mirón Cave (Cantabria, Spain): new dates for the Initial Magdalenian occupations. Radiocarbon, 52 (1), 33-39.

Straus, L. G., González Morales, M. R., and Fontes, L. M. 2014. Initial Magdalenian artifact assemblages in $\mathrm{El}$ Mirón Cave (Ramales de la Victoria, Cantabria, Spain): a preliminary report. Zephyrus, LXXIII (enero-junio), 4565.

Thomas, G. W., 1996. Soil pH and soil acidity". Methods of Soil Analysis, Part 3-Chemical Methods. Soil Science Society of America, Madison, 475-490.

Udden, J. A. 1914. Mechanical composition of clastic sediments. Bulletin of the Geological Society of America, 25, 655-744.

Utrilla Miranda, P. 1976. Las industrias del Magdaleniense inferior y medio en la Costa Cantábrica. Tesis doctoral inédita, Universidad de Zaragoza, Zaragoza.

Utrilla Miranda, P. 1981. El Magdaleniense Inferior y Medio en la costa cantábrica. Monografías, 4. Centro de Investigación y Museo de Altamira, Madrid.

Vera, J.A. (ed.) 2004. Geología de España. Sociedad Geológica de España e Instituto Geológico y Minero de España, Madrid.

Vermeersch, P. M. 2015. Radiocarbon Palaeolithic Europe Database, Version 18. Available at: http://ees.kuleuven. be/geography/projects/14c-palaeolithic/index.html [accesed 29/02/2016].

Wang, Y. J., Cheng, H., Edwards, R. L., An, Z. S., Wu, J. Y., Shen, C. C. and Dorale, J. A. 2001. A High-Resolution Absolute-Dated Late Pleistocene Monsoon Record from Hulu Cave, China. Science, 294 (5550), 2345-2348.

Weninger, B. and Jöris, O. 2004. Glacial Radiocarbon Calibration. The CalPal Program. In: Higham. T., Bronk Ramsey, C. and Owen, C. (eds.), Radiocarbon and Archaeology. Fourth International Symposium. Oxford, 2002. Oxford University School of Archaeology, Monograph 62, 9-15.

Weninger, B. and Jöris, O. 2008. A 14C age calibration curve for the last $60 \mathrm{ka}$ : the Greenland-Hulu U/Th timescale and its impact on understanding the Middle to Upper Paleolithic transition in Western Eurasia. Journal of Human Evolution, 55, 772-781.

Wentworth, C. K. 1922. A scale of grade and class terms for clastic sediments. Journal of Geology, 30, 377-392.

Recibido: marzo 2016

Revisado: marzo 2016

Aceptado: abril 2016

Publicado: marzo 2018 